\title{
Synthetic Biology-Based Discovery of Diterpenoid Pyrones from the Genome of Eupenicillium shearii
}

Yohei Morishita, ${ }^{\ddagger a}$ Kento Tsukada, ${ }^{\mathfrak{a}}$ Kazuma Murakami, ${ }^{\mathrm{b}}$ Kazuhiro Irie, ${ }^{\mathrm{b}}$ Teigo Asai ${ }^{\mathrm{a} *}$

${ }^{a}$ Graduate School of Pharmaceutical Sciences, Tohoku University, 6-3 Aza-Aoba, Aramaki, Aoba-ku, Sendai 980-8578, Japan, ${ }^{b}$ Division of Food Science and Biotechnology, Graduate School of Agriculture, Kyoto University, Kyoto 606-8502, Japan.

\section{Table of contents}

SI-2: $\quad$ Figure S1. Comparison of esdp cluster and cle cluster for chevalone E. Chemical structure of chevalone $\mathrm{E}$ and its oxidized derivative.

Figure S2. HPLC chromatogram of culture extracts of AO-esdpA and AO-dpasA producing compound $\mathbf{1 0}$.

SI-3: $\quad$ Figure S3. HPLC chromatogram of extracts of A. oryzae transformants.

Table S1. esdp cluster in Eupenicillium shearii IFM 42152.

SI-4: Table S2. Nutrient/antibiotic additives for transformant culture medium.

Table S3. Primers used for cloning.

Table S4. Expression plasmid vector.

Table S5. A. oryzae transformants constructed in this study.

SI-5: $\quad$ Figure S4. 2D NMR correlations of 1-9.

Figure S5. $\Delta \delta_{\mathrm{H}(S-R)}$ values (parts per million) of the MTPA derivatives of $\mathbf{1}$.

SI-6: Isolation and structure determination of shearones A-I (1-9)

SI-10: $\quad$ Synthesis of MTPA derivatives of $\mathbf{1}$

SI-11: References

SI-12: $\quad$ NMR spectra of shearones A-I (1-9) and MTPA derivatives of $\mathbf{1}$ 
(A)
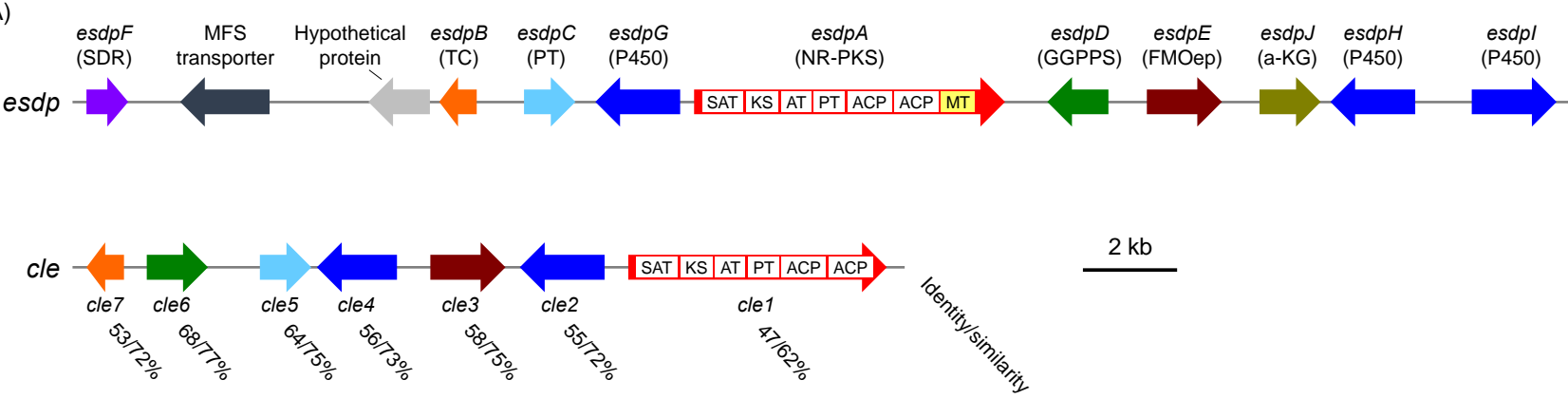

(B)
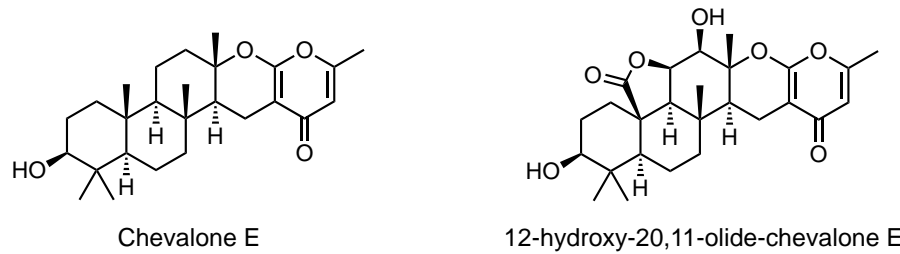

12-hydroxy-20,11-olide-chevalone $\mathrm{E}$

Figure S1. (A) Comparison of $e s d p$ cluster and cle cluster for chevalone E. (B) Chemical structures of chevalone E and its oxidized derivative.

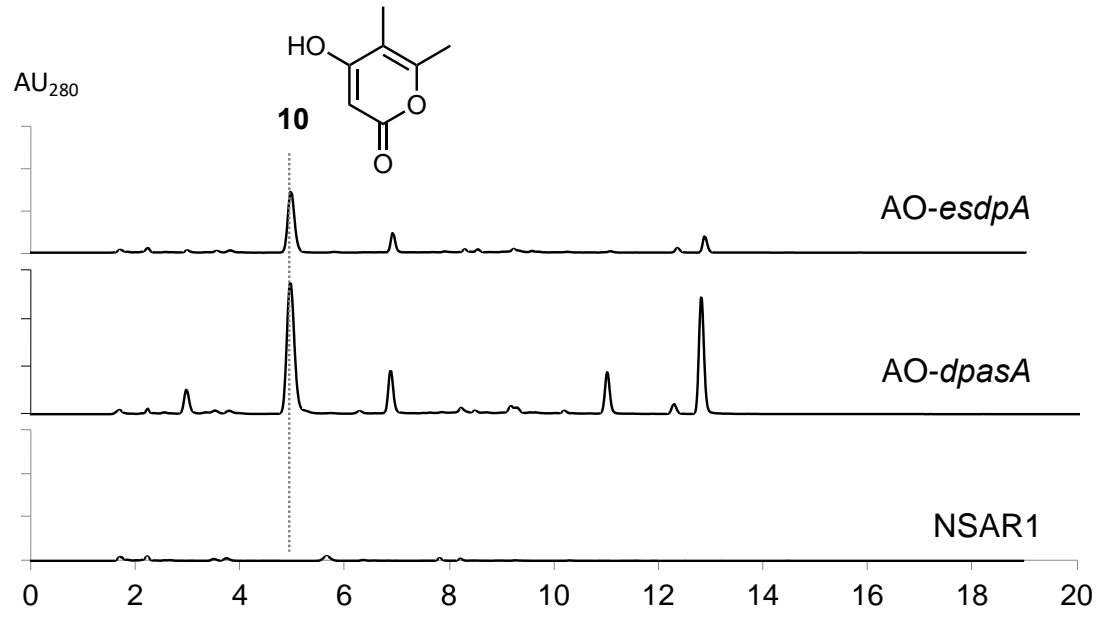

Figure S2. HPLC chromatograms of culture extracts of AO-esdpA and AO-dpasA ${ }^{\mathrm{S} 1}$ producing compound $\mathbf{1 0}$. 
(A) Culture supernatant, $\mathrm{AU}_{300}$

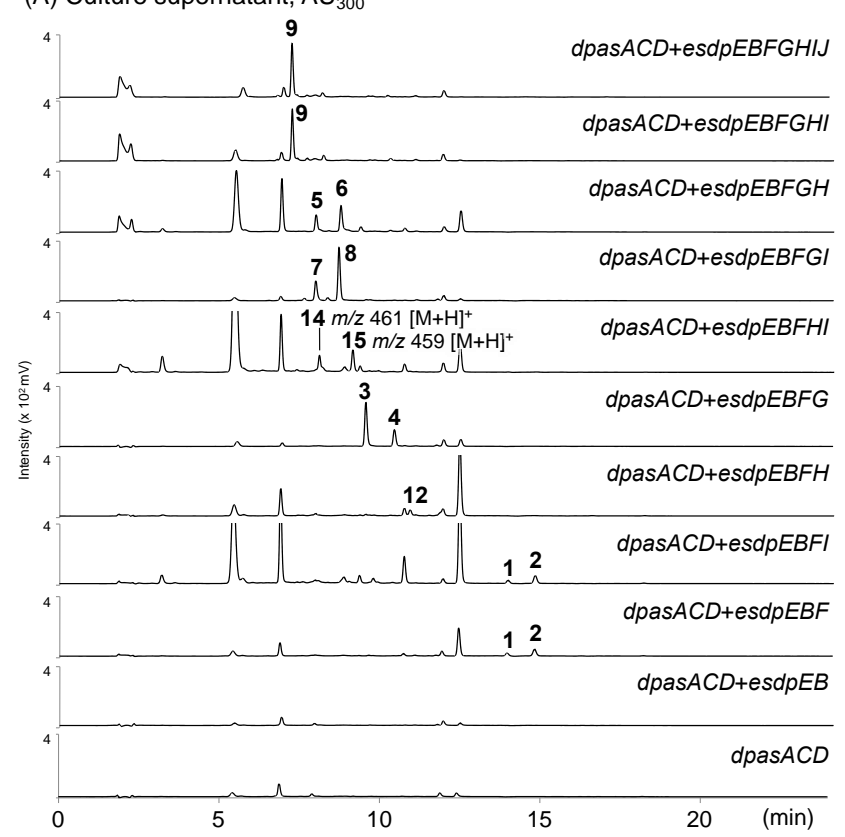

(C)<smiles>[2H]C[C@]12CC[C@@H](O)C(C)(C)[C@@H]1CC[C@H]1Oc3c(C)c(CO)oc(=O)c3C[C@@H]12</smiles>

12: $\mathrm{R}=\mathrm{H}$

14: $\mathrm{R}=\mathrm{OH}$
(B) Mycelium, $\mathrm{AU}_{300}$

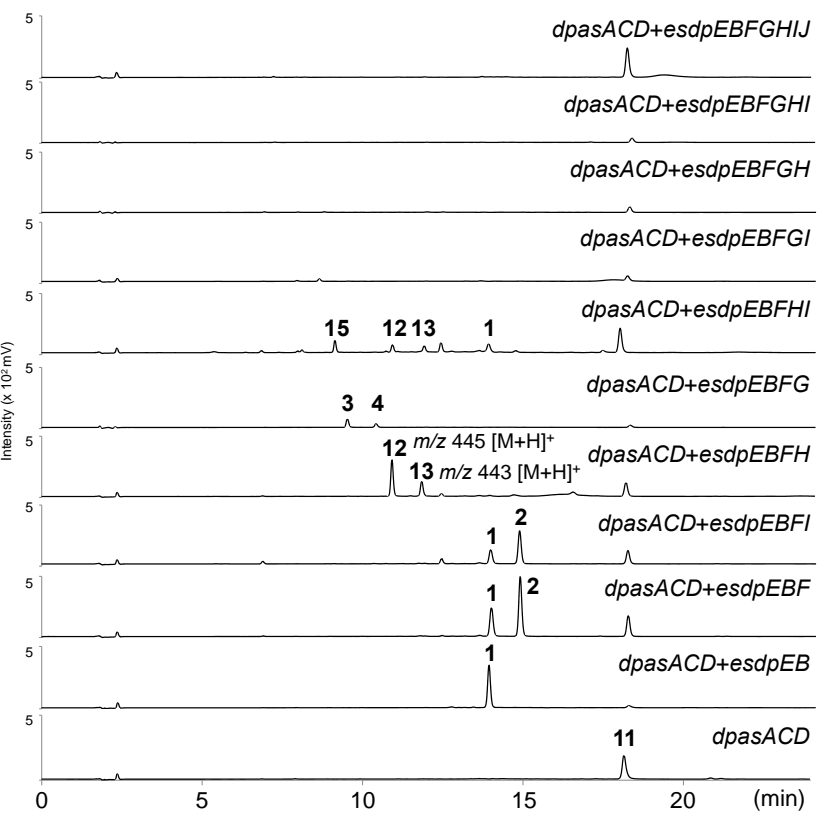

13: $\mathrm{R}=\mathrm{H}$

15: $\mathrm{R}=\mathrm{OH}$

Figure S3. HPLC chromatograms of extracts of (A) culture supernatants and (B) mycelia of the A. oryzae transformants. (C) Putative chemical structures of compounds 12-15.

Table S1. esdp cluster in Eupenicillium shearii IFM 42152 (Accession: LC600199).

\begin{tabular}{|c|c|c|c|c|c|}
\hline Gene & Accession & $\begin{array}{l}\text { Size } \\
\text { (bp) }\end{array}$ & $\begin{array}{l}\text { Protein homologue } \\
\text { (Accession) }\end{array}$ & $\begin{array}{l}\text { identity }(\%) / \\
\text { similarity (\%) }\end{array}$ & Predicted function \\
\hline esdpA & BCP96883 & 6,639 & $\begin{array}{l}\text { Polyketide synthase Sre6 } \\
\text { [Aspergillus felis] (BBG67008) }\end{array}$ & $45 / 63$ & Non-reducing polyketide synthase \\
\hline esdpB & BCP96886 & 801 & $\begin{array}{l}\text { Terpene cyclase Cle7 } \\
\text { [Aspergillus versicolor] (BBG28477) }\end{array}$ & $53 / 72$ & Integral membrane protein (terpene cyclase) \\
\hline esdpC & BCP96885 & 1,090 & $\begin{array}{l}\text { Prenyltransferase Sre1 } \\
\text { [Aspergillus felis] (BBG67003) }\end{array}$ & $63 / 74$ & Prenyltransferase \\
\hline esdpD & BCP96882 & 1,267 & $\begin{array}{l}\text { Geranylgeranyl pyrophosphate synthase Sre2 } \\
\text { [Aspergillus felis] (BBG67004) }\end{array}$ & $69 / 79$ & Geranylgeranyl pyrophosphate synthase \\
\hline esdpE & BCP96881 & 1,642 & $\begin{array}{l}\text { Flavin-dependent monooxygenase Cle3 } \\
\text { [Aspergillus versicolor] (BBG28473) }\end{array}$ & $58 / 75$ & Flavin-dependent monooxygenase (epoxidase) \\
\hline esdpF & BCP96887 & 946 & $\begin{array}{l}\text { Short-chain dehydrogenase/reductase CdmF } \\
\text { [Talaromyces verruculosus] (BBG28485) }\end{array}$ & $56 / 70$ & $\begin{array}{l}\text { Short-chain dehydrogenase/reductase (alcohol } \\
\text { oxidase) }\end{array}$ \\
\hline esdpG & BCP96884 & 1,769 & $\begin{array}{l}\text { Cytochrome P450 monooxygenase Cle } 4 \\
\text { [Aspergillus versicolor] (BBG28474) }\end{array}$ & $56 / 73$ & Cytochrome P450 oxidase \\
\hline esdpH & BCP96879 & 1,841 & $\begin{array}{l}\text { Cytochrome P450 monooxygenase PkfB } \\
\text { Aspergillus nidulans FGSC A4 (C8VI81) }\end{array}$ & $46 / 64$ & Cytochrome P450 oxidase \\
\hline esdpl & BCP96878 & 1,819 & $\begin{array}{l}\text { Cytochrome P450 monooxygenase Cle } 2 \\
\text { [Aspergillus versicolor] (BBG28472) }\end{array}$ & $55 / 72$ & Cytochrome P450 oxidase \\
\hline esdpJ & BCP96880 & 1,271 & $\begin{array}{l}\text { Hypothetical protein EYZ11_007144 } \\
\text { [Aspergillus tanneri] (THC93387) }\end{array}$ & $80 / 86$ & $\alpha$-Ketoglutarate-dependent dioxygenase \\
\hline
\end{tabular}


Table S2. Nutrient/antibiotic additives for transformant culture medium.

\begin{tabular}{|c|c|c|c|}
\hline Original strain & Selectable marker & Resulting transformant & Nutrient/antibiotic (concentration) \\
\hline$n i a D^{-}, s C^{-}, a d e A^{-}, \triangle \arg B$ & $\arg B$ & $n i a D^{-}, s C^{-}$, ade $A^{-}$ & adenine $(0.01 \%)$, L-methionine $(0.15 \%)$, ammonium sulfate $(0.05 \%)$ \\
\hline niaD,$s C^{-}$, adeA $A^{-}$ & adeA & $n i a D^{-}, s C^{-}$ & L-methionine $(0.15 \%)$, ammonium sulfate $(0.05 \%)$ \\
\hline$n i a D^{-}, s C^{-}$ & $s C$ & $n i a D^{-}$ & ammonium sulfate $(0.05 \%)$ \\
\hline niaD & ptrA & niaD $D^{-}, p_{t r} A^{+}$ & ammonium sulfate $(0.05 \%)$, pyrithiamine $(0.1 \mu \mathrm{g} / \mathrm{mL})^{\mathrm{a}}$ \\
\hline
\end{tabular}

${ }^{\text {a}}$ Pyrithiamine hydrobromide (Sigma-Aldrich)

Table S3. Primers used for cloning in this study.

\begin{tabular}{|c|c|c|}
\hline Primer & DNA sequence $5^{\prime}$ to $3^{\prime}$ & Template \\
\hline esdpA_IFpUNotl-FW & ITTGAGCTAGCGGCCATGCCTCTTCCATTGCCGTCC & Eupenicillium shearii IFM 42152 \\
\hline esdpA_IFpUNotl-RV & GTCACTAGTGCGGCCAAATCCTCTACTTCTTCAGC & Same above \\
\hline esdpB_IFpUNotl-FW & ITTGAGCTAGCGGCCACCATGGATGAGTTCGACTTC & Same above \\
\hline esdpB_IFpUNotl-RV & GTCACTAGTGCGGCCCTCTGGTGCATCGGTTATCG & Same above \\
\hline esdpE_IFpUKpnI-FW & CCGGAATTCGAGCTCGACAATGGGTGCAGAACGCTTG & Same above \\
\hline esdpE_IFpUKpnl-RV & ACTACAGATCCCCGGATTGAATCTACTGAGATACG & Same above \\
\hline esdpF_IFpUNotl-FW & ITTGAGCTAGCGGCCATCATGGCAACTCTTGAAGC & Same above \\
\hline esdpF_IFpUNotl-RV & GTCACTAGTGCGGCCATTCCATCAGATGGTTGACC & Same above \\
\hline esdpG_IFpUKpnl-FW & CCGGAATTCGAGCTCGATCATGGCTTTCTATTCCGC & Same above \\
\hline esdpG_IFpUKpnI-RV & ACTACAGATCCCCGGTGGTAGATTTGACTCCTTGC & Same above \\
\hline esdpH_IFpUNotl-FW & ITTGAGCTAGCGGCCAGTATGCTCAGCCAGAGAGTCG & Same above \\
\hline esdpH_IFpUNotl-RV & GTCACTAGTGCGGCCGCACGTCAGTCAGGCTGACC & Same above \\
\hline esdpl_IFpUKpnI-FW & CCGGAATTCGAGCTCGAATATGGACCCAGAAAGCCTCG & Same above \\
\hline esdpl_IFpUKpnI-RV & ACTACAGATCCCCGGAATAGAGGATGGCAGCTACG & Same above \\
\hline esdpJ_IFpUKpnI-FW & CCGGAATTCGAGCTCGACAATGGGCTCTATCAGTCAG & Same above \\
\hline esdpJ_IFpUKpnl-RV & ACTACAGATCCCCGGTTGATGCTGTACTACCTAGG & Same above \\
\hline
\end{tabular}

Table S4. Expression plasmid vector constructed in this study.

\begin{tabular}{llll}
\hline Plasmid name & Original vector & Gene 1 (Kpnl site) & Gene 2 (Notl site) \\
\hline pUARA2_esdpA & pUARA2 & & esdpA \\
pUADEA2_esdpBE & pUADEA2 & esdpE & esdpB \\
pUSCA2_esdpF & pUSCA2 & & esdpF \\
pUSCA2_esdpFG & pUSCA2 & esdpG & esdpF \\
pUPTRA2_esdpH & pUPTRA2 & & esdpH \\
pUPTRA2_esdpl & pUPTRA2 & esdpl & \\
pUPTRA2_esdpHI & pUPTRA2 & esdpl & esdpH \\
pUPTRA2_esdpHIJ & pUPTRA2 & esdpJ & esdpHI \\
\hline
\end{tabular}

\begin{tabular}{|c|c|c|c|c|c|}
\hline Transformant name & Parent strain & Plasmid 1 & Plasmid 2 & Plasmid 3 & Plasmid 3 \\
\hline AO-esdpA & A. oryzae NSAR1 & pUARA2-esdpA & & & \\
\hline AO-dpas $A C D+e s d p B E$ & AO-dpas $A C D^{S 1}$ & pUARA2-dpasACD & pUADEA2-esdpBE & & \\
\hline AO-dpas $A C D+e s d p B E F$ & AO-dpas $A C D+e s d p B E$ & Same above & Same above & pUSCA2-esdpF & \\
\hline AO-dpasACD+esdpBEFI & AO-dpas $A C D+e s d p B E F$ & Same above & Same above & Same above & pUPTRA2-esdpl \\
\hline AO-dpas $A C D+e s d p B E F H$ & Same above & Same above & Same above & Same above & pUPTRA2-esdpH \\
\hline AO-dpasACD+esdpBEFHI & Same above & Same above & Same above & Same above & pUPTRA2-esdpHI \\
\hline AO-dpas $A C D+e s d p B E F G$ & AO-dpas $A C D+e s d p B E$ & Same above & Same above & pUSCA2-esdpFG & \\
\hline AO-dpasACD+esdpBEFGH & Same above & Same above & Same above & Same above & pUPTRA2-esdpH \\
\hline AO-dpasACD+esdpBEFGI & AO-dpasACD+esdpBEFG & Same above & Same above & Same above & pUPTRA2-esdpl \\
\hline AO-dpas $A C D+e s d p B E F G H I$ & Same above & Same above & Same above & Same above & pUPTRA2-esdpHI \\
\hline AO-dpasACD+esdpBEFGHIJ & Same above & Same above & Same above & Same above & pUPTRA2-esdpHIJ \\
\hline
\end{tabular}


Table S5. A. oryzae transformants constructed in this study.
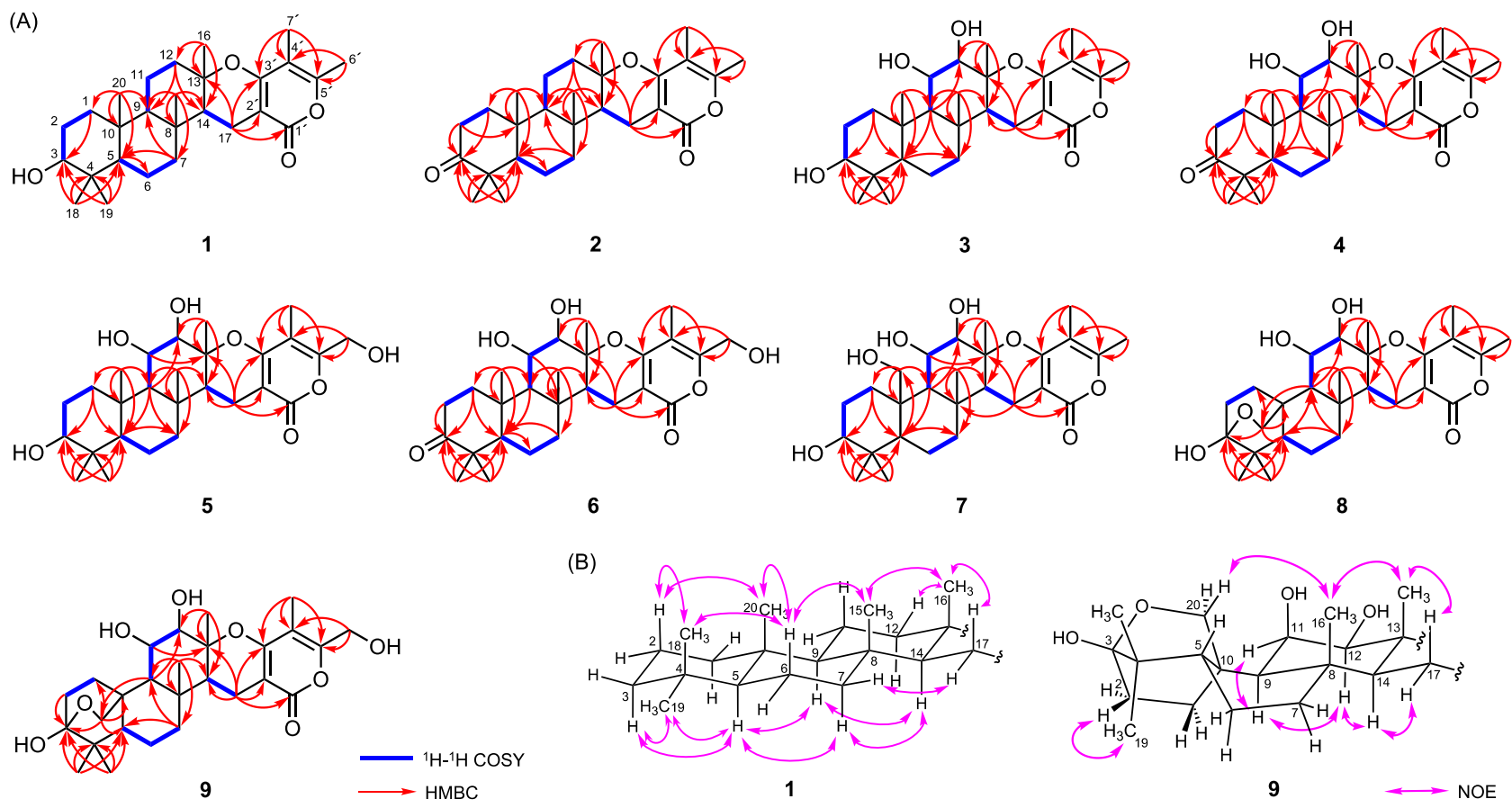

Figure S4. (A) Key ${ }^{1} \mathrm{H}-{ }^{1} \mathrm{H}$ COSY and HMBC correlations of 1-9. (B) Key NOE correlations of $\mathbf{1}$ and 9.

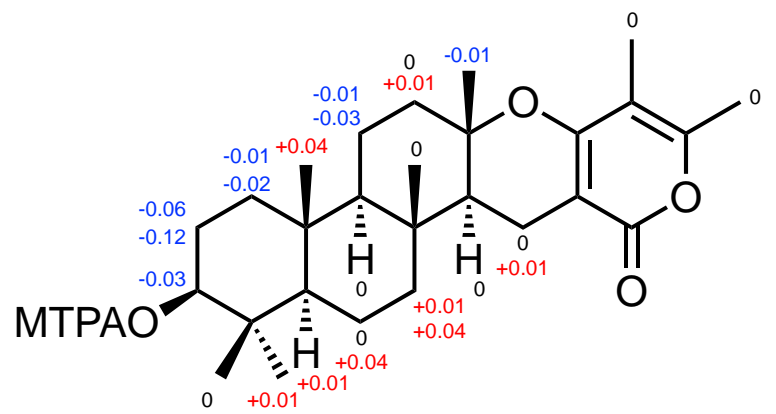

Figure S5. $\Delta \delta_{\mathrm{H}(S-R)}$ values (parts per million) of the MTPA derivatives of $\mathbf{1}$. 


\section{Isolation of shearone A (1) and shearone B (2)}

AO-dpasACD+esdpEBF was cultivated in CPS medium $(1.5 \mathrm{~L} ; 150 \mathrm{~mL} \times 10)$ at $30^{\circ} \mathrm{C}$ for 5 days. The cultured mycelia were harvested, freeze-dried, crushed to powder $(11 \mathrm{~g})$ and extracted with EtOAc (20\% $\mathrm{MeOH})$. The EtOAc extracts was separated by $\mathrm{MeOH}\left(0.1 \% \mathrm{H}_{2} \mathrm{O}\right) / n$-hexane and the $\mathrm{MeOH}$ layer was concentrated under reduced pressure to obtain mycelial extracts $(212 \mathrm{mg})$. The $\mathrm{MeOH}$ extracts $(212 \mathrm{mg})$ was separated by consecutive column chromatography to obtain $\mathbf{1}(9 \mathrm{mg})$ and $\mathbf{2}(17 \mathrm{mg})$ using silica gel as stationary phase and mixtures of $n$-hexane/EtOAc and $\mathrm{CHCl}_{3} / \mathrm{MeOH}$ as mobile phase.

\section{D structure determination of shearone $A(1)$}

Shearone A (1) has a molecular formula of $\mathrm{C}_{27} \mathrm{H}_{40} \mathrm{O}_{4}$, as established by its positive HRESIMS $(\mathrm{m} / z 451.2814$ $[\mathrm{M}+\mathrm{Na}]^{+}$, calcd 451.2819), and was also supported by ${ }^{1} \mathrm{H}$ and ${ }^{13} \mathrm{C}$ NMR data. IR spectrum indicated absorbance for ester carbonyl $\left(v_{\max } 1690 \mathrm{~cm}^{-1}\right)$ and hydroxy $\left(v_{\max } 3446 \mathrm{~cm}^{-1}\right)$ groups. The direct connectivity between each proton and carbon was established by the HMQC spectrum (Table 1 and 2). The ${ }^{1} \mathrm{H}$ and ${ }^{13} \mathrm{C}$ NMR of $\mathbf{1}$ are quite similar to those of chevalone $\mathrm{E}^{\mathrm{S} 2}$ except for the presence of an additional methyl carbon $\left(\mathrm{C}^{-} 7^{\prime}\right)$ and the absence of an olefin proton, suggesting that it has an identical diterpene structure and a methylated pyrone unit. The HMBC correlations at H-17/C-1', 2' and $3^{\prime}, \mathrm{H}-7^{\prime} / \mathrm{C}-3^{\prime}, 4^{\prime}$ and $5^{\prime}$, and $\mathrm{H}-6^{\prime} / \mathrm{C}-4^{\prime}$ and $5^{\prime}$ showed that 1 has a C-4'-methylated $\alpha$-pyrone. The other COSY and HMBC correlations supported that $\mathbf{1}$ has the identical diterpene structure as chevalone E. The relative configuration was determined based on NOESY spectrum and the absolute configuration was assigned by Mosher's method described below.

\section{D structure determination of shearone B (2)}

Shearone B (2) has a molecular formula of $\mathrm{C}_{24} \mathrm{H}_{40} \mathrm{O}_{6}$, as indicated by its positive HRESIMS $(\mathrm{m} / z 447.2726$ $[\mathrm{M}+\mathrm{Na}]^{+}$, calcd 447.2717), implying nine degrees of unsaturation. The direct connectivity between each proton and carbon was established by the HMQC spectrum (Table 1 and 2). Comparing the ${ }^{1} \mathrm{H}$ and ${ }^{13} \mathrm{C}$ NMR spectra, the overall structure of $\mathbf{2}$ is the same as that of $\mathbf{1}$, except for the existence of carbonyl carbon at $\delta_{\mathrm{C}} 217.4(\mathrm{C}-3)$ and the absence of an oxymethine proton and carbon, indicating that $\mathbf{2}$ has a ketone group at C-3 instead of a hydroxy group. The COSY and HMBC correlations supported the chemical structure of $\mathbf{2}$ as shown above. The absolute configuration was determined as same as $\mathbf{1}$ based on the biosynthetic manner. 


\section{Isolation of shearone C (3) and shearone D (4)}

AO-dpasACD+esdpEBFG was cultivated in CPS medium $(1.5 \mathrm{~L} ; 150 \mathrm{~mL}$ x 10$)$ at $30^{\circ} \mathrm{C}$ for 5 days. The cultured broth was extracted with EtOAc twice, and the extracts $(131 \mathrm{mg})$ were obtained. The EtOAc extracts (131 mg) was separated by consecutive column chromatography to obtain $\mathbf{3}(10 \mathrm{mg})$ and $\mathbf{4}(4 \mathrm{mg})$ using silica gel as stationary phase and mixtures of $n$-hexane/EtOAc and $\mathrm{CHCl}_{3} / \mathrm{MeOH}$ as mobile phase.

\section{D structure determination of shearone C (3)}

Shearone C (3) has a molecular formula of $\mathrm{C}_{27} \mathrm{H}_{40} \mathrm{O}_{6}$, as indicated by its positive HRESIMS $(\mathrm{m} / z 483.2714$ $[\mathrm{M}+\mathrm{Na}]^{+}$, calcd 483.2717). The direct connectivity between each proton and carbon was established by the HMQC spectrum (Table 1 and 2). Comparing the ${ }^{1} \mathrm{H}$ and ${ }^{13} \mathrm{C}$ NMR spectra, the overall macrolide skeleton of $\mathbf{3}$ is the same as that of $\mathbf{1}$, except for the existence of two additional oxymethylene protons at $\delta_{\mathrm{H}} 4.41(\mathrm{H}-11)$ and $\delta_{\mathrm{H}} 3.58(\mathrm{H}-12)$ and carbons at $\delta_{\mathrm{C}} 70.4(\mathrm{C}-11)$ and $\delta_{\mathrm{C}} 77.8(\mathrm{C}-12)$, indicating 3 has a hydroxy group at $\mathrm{C}-11$ and 12 each. The COSY and HMBC correlations supported the chemical structure of $\mathbf{3}$ as shown above. The absolute configuration was determined as same as $\mathbf{1}$ and $\mathbf{9}$ based on the biosynthetic manner.

\section{D structure determination of shearone $D(4)$}

Shearone D (4) has a molecular formula of $\mathrm{C}_{27} \mathrm{H}_{38} \mathrm{O}_{6}$, as indicated by its positive HRESIMS $(\mathrm{m} / z 481.2559$ $[\mathrm{M}+\mathrm{Na}]^{+}$, calcd 481.2561), implying nine degrees of unsaturation. The direct connectivity between each proton and carbon was established by the HMQC spectrum (Table 1 and 2). Comparing the ${ }^{1} \mathrm{H}$ and ${ }^{13} \mathrm{C}$ NMR spectra, the overall structure of $\mathbf{4}$ is the same as that of $\mathbf{3}$, except for the existence of a carbonyl carbon at $\delta_{\mathrm{C}} 217.0(\mathrm{C}-3)$ and the absence of an oxymethine proton and carbon at C-3, indicating that $\mathbf{4}$ has a ketone group at C-3 instead of a hydroxy group. The COSY and HMBC correlations supported the chemical structure of $\mathbf{4}$ as shown above. The absolute configuration was determined as same as $\mathbf{1}$ and $\mathbf{9}$ based on the biosynthetic manner.

\section{Isolation of shearone $E(5)$ and shearone $F(6)$}

AO-dpasACD+esdpEBFGH was cultivated in CPS medium $(1.5 \mathrm{~L} ; 150 \mathrm{~mL}$ x 10$)$ at $30^{\circ} \mathrm{C}$ for 5 days. The cultured broth was extracted with EtOAc twice, and the extracts were obtained. The EtOAc extracts was separated by consecutive column chromatography to obtain $5(5 \mathrm{mg})$ and $\mathbf{6}(7 \mathrm{mg})$ using silica gel as stationary phase and mixtures of $n$-hexane/EtOAc and $\mathrm{CHCl}_{3} / \mathrm{MeOH}$ as mobile phase. 


\section{D structure determination of shearone $E(5)$}

Shearone E (5) has a molecular formula of $\mathrm{C}_{27} \mathrm{H}_{40} \mathrm{O}_{7}$, as indicated by its positive HRESIMS $(\mathrm{m} / z 499.2663$ $[\mathrm{M}+\mathrm{Na}]^{+}$, calcd 499.2666). The direct connectivity between each proton and carbon was established by the HMQC spectrum (Table 1 and 2). Comparing the ${ }^{1} \mathrm{H}$ and ${ }^{13} \mathrm{C}$ NMR spectra, the overall macrolide skeleton of 5 is the same as that of $\mathbf{3}$, except for the existence of additional oxymethylene protons at $\delta_{\mathrm{H}} 4.66\left(\mathrm{H}-6^{\prime}\right)$ and a carbon at $\delta_{\mathrm{C}} 58.9\left(\mathrm{C}^{-6} 6^{\prime}\right)$, indicating 5 has a hydroxy group at C-6'. The COSY and HMBC correlations supported the chemical structure of $\mathbf{5}$ as shown above. The absolute configuration was determined as same as $\mathbf{1}$ and 9 based on the biosynthetic manner.

\section{D structure//e determination of shearone $F(6)$}

Shearone $\mathrm{F}(6)$ has a molecular formula of $\mathrm{C}_{27} \mathrm{H}_{38} \mathrm{O}_{7}$, as indicated by its positive HRESIMS $(\mathrm{m} / z$, 497.2508 $[\mathrm{M}+\mathrm{Na}]^{+}$, calcd 497.2510), implying nine degrees of unsaturation. The direct connectivity between each proton and carbon was established by the HMQC spectrum (Table 1 and 2). Comparing the ${ }^{1} \mathrm{H}$ and ${ }^{13} \mathrm{C}$ NMR spectra, the overall structure of $\mathbf{6}$ is the same as that of $\mathbf{4}$, except for the existence of carbonyl carbon at $\delta_{\mathrm{C}} 216.0(\mathrm{C}-3)$ and the absence of an oxymethine proton and carbon at C-3, indicating that 6 has a ketone group at C-3 instead of hydroxy group. The COSY and HMBC correlations supported the chemical structure of $\mathbf{6}$ as shown above. The absolute configuration was determined as same as $\mathbf{1}$ and $\mathbf{9}$ based on the biosynthetic manner.

\section{Isolation of shearone $\mathrm{G}(7)$ and shearone $\mathrm{H}(8)$}

AO-dpasACD+esdpEBFGI was cultivated in CPS medium $(3.2 \mathrm{~L} ; 150 \mathrm{~mL} \times 24)$ at $30^{\circ} \mathrm{C}$ for 5 days. The culture broth was extracted with EtOAc twice, and the extracts $(375 \mathrm{mg}$ ) were obtained. The EtOAc extracts was separated with $\mathrm{CHCl}_{3}-\mathrm{MeOH}(40 / 1-20 / 1)$ to give Fr.1 and Fr. 2. The Fr.1 and Fr. 2 was subjected to reversed-phase column chromatography eluted with water-MeOH (1/1-1/2) to give 8 (19 mg) and 7 (8 mg) respectively. 


\section{D structure determination of shearone G (7)}

Shearone $\mathrm{G}$ (7) has a molecular formula of $\mathrm{C}_{27} \mathrm{H}_{40} \mathrm{O}_{7}$, as indicated by its positive HRESIMS $(\mathrm{m} / z$ 499.2662 $[\mathrm{M}+\mathrm{Na}]^{+}$, calcd 499.2666). The direct connectivity between each proton and carbon was established by the HMQC spectrum (Table 1 and 2). Comparing the ${ }^{1} \mathrm{H}$ and ${ }^{13} \mathrm{C}$ NMR spectra, the overall macrolide skeleton of 7 is the same as that of $\mathbf{3}$, except for the existence of additional oxymethylene protons at $\delta_{\mathrm{H}} 4.23$ and $4.35(\mathrm{H}-20)$ and carbons at $\delta_{\mathrm{C}} 59.7(\mathrm{C}-20)$, indicating 7 has a hydroxy group at C-20. The COSY and HMBC correlations supported the chemical structure of $\mathbf{7}$ as shown above. The absolute configuration was determined as same as $\mathbf{1}$ and 9 based on the biosynthetic manner.

\section{D structure determination of shearone $H(8)$}

Shearone $\mathrm{H}(8)$ has a molecular formula of $\mathrm{C}_{27} \mathrm{H}_{38} \mathrm{O}_{7}$, as indicated by its positive HRESIMS $(\mathrm{m} / \mathrm{z} 497.2508$ $[\mathrm{M}+\mathrm{Na}]^{+}$, calcd 497.2510), implying nine degrees of unsaturation. The direct connectivity between each proton and carbon was established by the HMQC spectrum (Table 1 and 2). Comparing the ${ }^{1} \mathrm{H}$ and ${ }^{13} \mathrm{C}$ NMR spectra, the overall structure of $\mathbf{8}$ is the same as that of 7, except for the existence of an anomeric carbon at $\delta_{\mathrm{C}} 97.6(\mathrm{C}-3)$ and the absence of an oxymethine proton and a carbon at C-3. The HMBC correlation at $\mathrm{H}-20\left(\delta_{\mathrm{H}} 5.01\right) / \mathrm{C}-3$ indicated that $\mathrm{C}-3$ and anomeric $\mathrm{C}-20$ is connected by an ether bond. The COSY and the other HMBC correlations supported the chemical structure of $\mathbf{8}$ as shown above. The absolute configuration was determined as same as $\mathbf{1}$ and $\mathbf{9}$ based on the biosynthetic manner.

\section{Isolation of shearone I (9)}

AO-dpasACD+esdpEBFGHI was cultivated in CPS medium $(3.6 \mathrm{~L} ; 150 \mathrm{~mL}$ x 24$)$ at $30^{\circ} \mathrm{C}$ for 5 days. The cultured broth was extracted with EtOAc twice and the extracts $(422 \mathrm{mg}$ ) were obtained. The EtOAc extracts were subjected to silica gel column chromatography eluted with $\mathrm{CHCl}_{3}-\mathrm{MeOH}(20 / 1-10 / 1)$ and $\mathrm{MeOH}$ to give Fr.1 (50 mg). The Fr.1 (50 mg) was separated by reversed-phase column chromatography eluted with water-MeOH (1/1-1/3) to afford $9(11 \mathrm{mg})$. 


\section{D structure determination of shearone I (9)}

Shearone I (9) has a molecular formula of $\mathrm{C}_{27} \mathrm{H}_{38} \mathrm{O}_{8}$, as indicated by its positive HRESIMS $(\mathrm{m} / z, 513.2455$ $[\mathrm{M}+\mathrm{Na}]^{+}$, calcd 513.2459), implying nine degrees of unsaturation. The direct connectivity between each proton and carbon was established by the HMQC spectrum (Table 1 and 2). Comparing the ${ }^{1} \mathrm{H}$ and ${ }^{13} \mathrm{C}$ NMR spectra, the overall structure of $\mathbf{9}$ is the same as that of $\mathbf{8}$, except for the existence of additional oxymethylene protons at $\delta_{\mathrm{H}} 4.67\left(\mathrm{H}^{-} 6^{\prime}\right)$ and a carbon at $\delta_{\mathrm{C}} 59.0\left(\mathrm{C}^{\prime}-6^{\prime}\right)$, indicating 9 has a hydroxy group at C-6'. The HMBC correlation at $\mathrm{H}-20\left(\delta_{\mathrm{H}} 5.01\right) / \mathrm{C}-3$ indicated that an oxymethylene carbon C-3 and an anomeric carbon C-20 is connected by an ether bond. The COSY and the other HMBC correlations supported the chemical structure of 9 as shown above. The absolute configuration was determined as same as $\mathbf{1}$ except for at C-11 and 12. The NOESY correlations at $\mathrm{H}-11 / \mathrm{H}-9$ and $\mathrm{H}-12 / \mathrm{H}-9,14$ showed that $\mathrm{C}-11$ has $R$ and C-12 has $S$ configurations, respectively. The NOESY correlation at $\mathrm{H}-20 / \mathrm{H}-16$ also supported the $R$ configuration at $\mathrm{C}-10$.

\section{Synthesis of MTPA derivatives of 1}
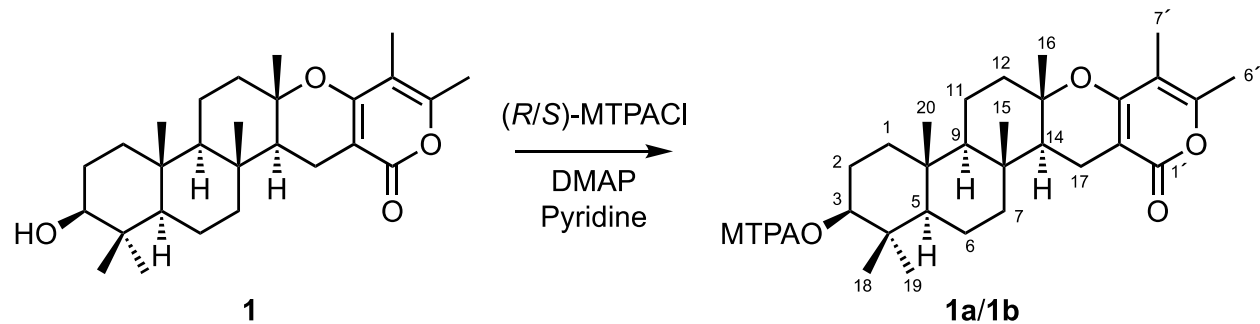

For the preparation of the $(S)$-MTPA ester $(\mathbf{1 a}), \mathbf{1}(0.5 \mathrm{mg}, 1.17 \mu \mathrm{mol})$ was dissolved in $50 \mu \mathrm{L}$ pyridine and (R)-MTPA chloride $(0.65 \mu \mathrm{L}, 3.51 \mu \mathrm{mol})$ and dimethyl aminopyridine (DMAP) (cat) were added. The mixture was incubated at room temperature for 1.5 hours and then EtOAc and $0.5 \mathrm{M} \mathrm{HCl}$ solution were added. The water layer was extracted with EtOAc twice and concentrated. The resulting mixture was separated by silica gel column chromatography $(n$-hexane-EtOAc $=4 / 1-2 / 1)$ to give $(S)$-MTPA ester 1a. The $(R)$-MTPA ester $\mathbf{1 b}$ was prepared in the same manner by the addition of $(S)$-MTPA chloride. The assignment of all protons was achieved using ${ }^{1} \mathrm{H}-{ }^{1} \mathrm{H}$ COSY experiment and comparing ${ }^{1} \mathrm{H}$ NMR of $\mathbf{1 a}$ and $\mathbf{1 b}$. The $\Delta \delta_{\mathrm{H}(S-R)}$ values (parts per million) of $\mathbf{1 a}$ and $\mathbf{1 b}$ were shown below in red or blue. 
Compound 1a: Colorless powder, Chemical formula $\mathrm{C}_{37} \mathrm{H}_{47} \mathrm{~F}_{3} \mathrm{O}_{6} \mathrm{Na}$, HRESIMS: $m / z$ 667.3213 [M+Na] (667.3217 calcd. for $\mathrm{C}_{37} \mathrm{H}_{47} \mathrm{~F}_{3} \mathrm{O}_{6} \mathrm{Na}$ ). ${ }^{1} \mathrm{H}$ NMR (600 MHz, $\mathrm{CD}_{3} \mathrm{Cl}_{3}$ ); $\delta=1.09$ (m, Ha-1), 1.76 (m, Hb-1), 1.66 (m, Ha-2), 1.80 (m, Hb-2), 4.68 (dd, 4.8, 12.0, H-3), 0.90 (m, H-5), 1.49 (m, Ha-6), 1.58 (m, Hb-6), 1.04 (m, Ha-7), 1.87 (brd, 12.6, Hb-7), 0.95 (d, 11.4, H-9), 1.36 (m, Ha-11), 1.68 (m, Hb-11), 1.66 (m, Ha-12), 2.10 (m, Hb-12), 1.44 (m, H-14), 0.88 (s, H-15), 1.18 (s, H3-16), 2.18 (m, Ha-17), 2.45 (dd, 4.8, 16.2, Hb-17), 0.81 (s, $\mathrm{H}_{3}-18$ ), 0.89 (s, $\left.\mathrm{H}_{3}-19\right), 0.85$ (s, $\left.\mathrm{H}_{3}-20\right), 1.82$ ( $\mathrm{s}, \mathrm{H}_{3}-6^{\prime}$ ), 2.19 ( $\mathrm{s}, \mathrm{H}_{3}-7^{\prime}$ ).

Compound 1b: Colorless powder, Chemical formula $\mathrm{C}_{37} \mathrm{H}_{47} \mathrm{~F}_{3} \mathrm{O}_{6} \mathrm{Na}$, HRESIMS: $m / z$ 667.3211 [M+Na] ${ }^{+}$ (667.3217 calcd. for $\left.\mathrm{C}_{37} \mathrm{H}_{47} \mathrm{~F}_{3} \mathrm{O}_{6} \mathrm{Na}\right) .{ }^{1} \mathrm{H} \mathrm{NMR}\left(600 \mathrm{MHz}, \mathrm{CD}_{3} \mathrm{Cl}_{3}\right) ; \delta=1.10$ (m, Ha-1), 1.78 (m, Hb-1), 1.78 (m, Ha-2), 1.86 (m, Hb-2), 4.71 (dd, 4.8, 12.0, H-3), 0.89 (m, H-5), 1.45 (m, Ha-6), 1.58 (m, Hb-6), 1.03 (m, Ha-7), 1.86 (brd, 12.6, Hb-7), 0.95 (d, 11.4, H-9), 1.37 (m, Ha-11), 1.71 (m, Hb-11), 1.65 (m, Ha-12), 2.10 (m, Hb-12), 1.44 (m, H-14), 0.88 (s, H $\left.\mathrm{H}_{3}-15\right), 1.19$ (s, H-16), 2.17 (m, Ha-17), 2.45 (m, Hb-17), 0.81 (s, H3-18), 0.88 (s, $\left.\mathrm{H}_{3}-19\right), 0.81$ (s, $\left.\mathrm{H}_{3}-20\right), 1.82$ (s, $\left.\mathrm{H}_{3}-6^{\prime}\right), 2.19$ (s, $\mathrm{H}_{3} \mathbf{7}^{\prime}$ ).

\section{References}

(S1) Tsukada, K.; Shinki, S.; Kaneko, A.; Murakami, K.; Irie, K.; Murai, M.; Miyoshi, H.; Dan, S.; Kawaji, K.; Hayashi, H.; Kodama, E. N.; Hori, A.; Salim, E.; Kuraishi, T.; Hirata, N.; Kanda, Y.; Asai, T. Nat. Commun. 2020, 11, 1830.

(S2) Wang, W.G.; Du, L. Q.; Sheng, S. L.; Li, A.; Li, Y. P.; Cheng, G. G.; Li, G. P.; Sun, G.; Hu Q. F.; Matsuda, Y. Org. Chem. Front., 2019, 6, 571-578. 
${ }^{1} \mathrm{H}$ NMR spectrum $\left(600 \mathrm{MHz}, \mathrm{CDCl}_{3}\right)$ of shearone A (1)

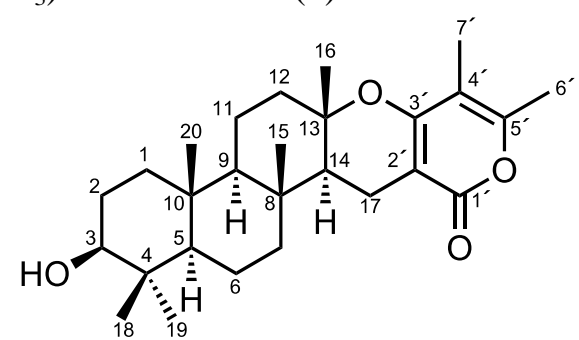

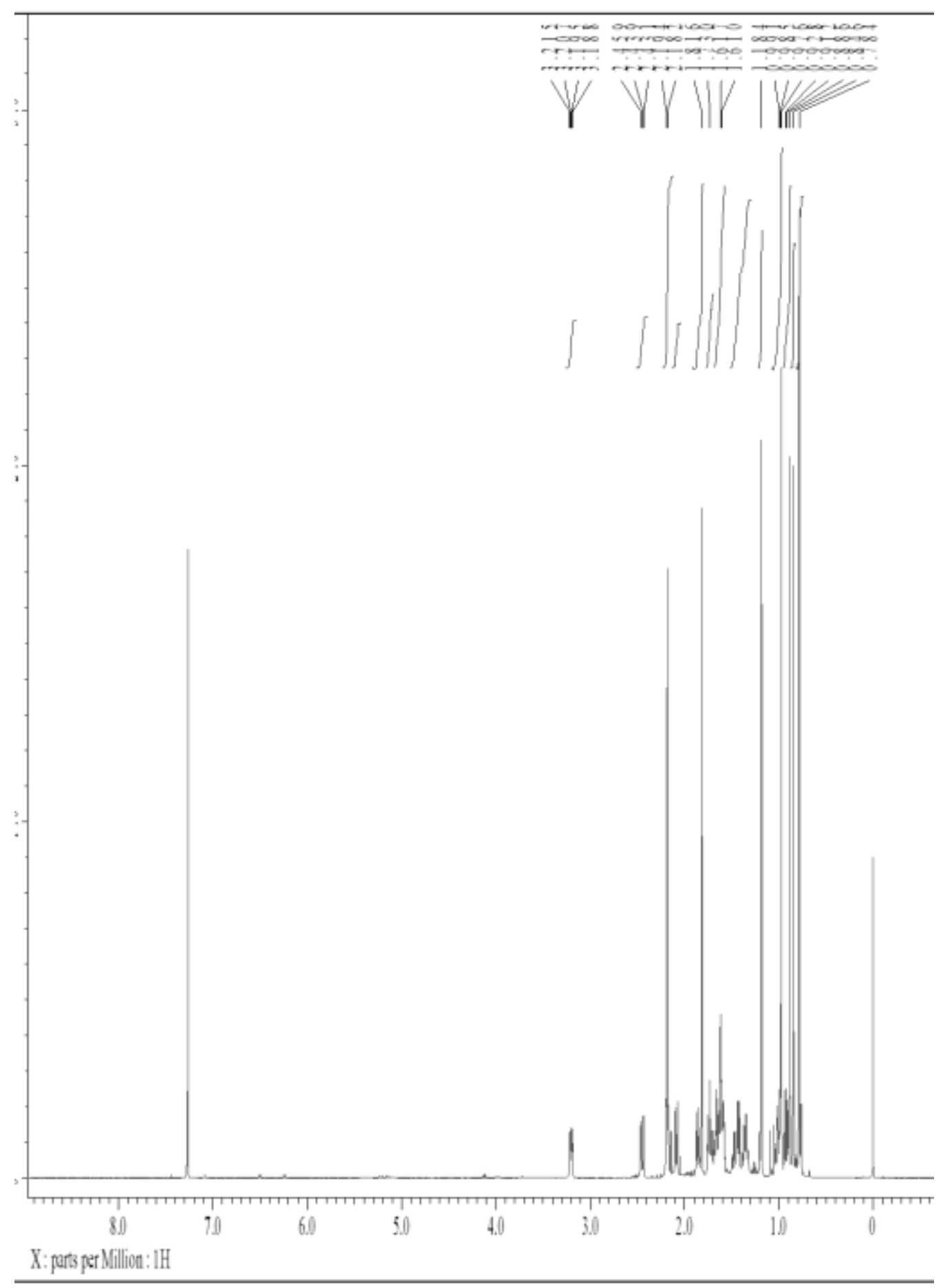


${ }^{13} \mathrm{C}$ NMR spectrum $\left(150 \mathrm{MHz}, \mathrm{CDCl}_{3}\right)$ of shearone $\mathrm{A}(\mathbf{1})$

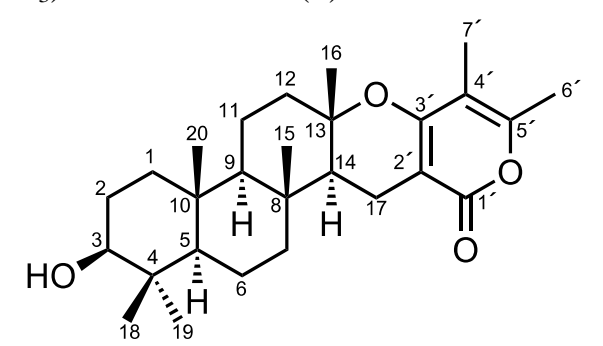

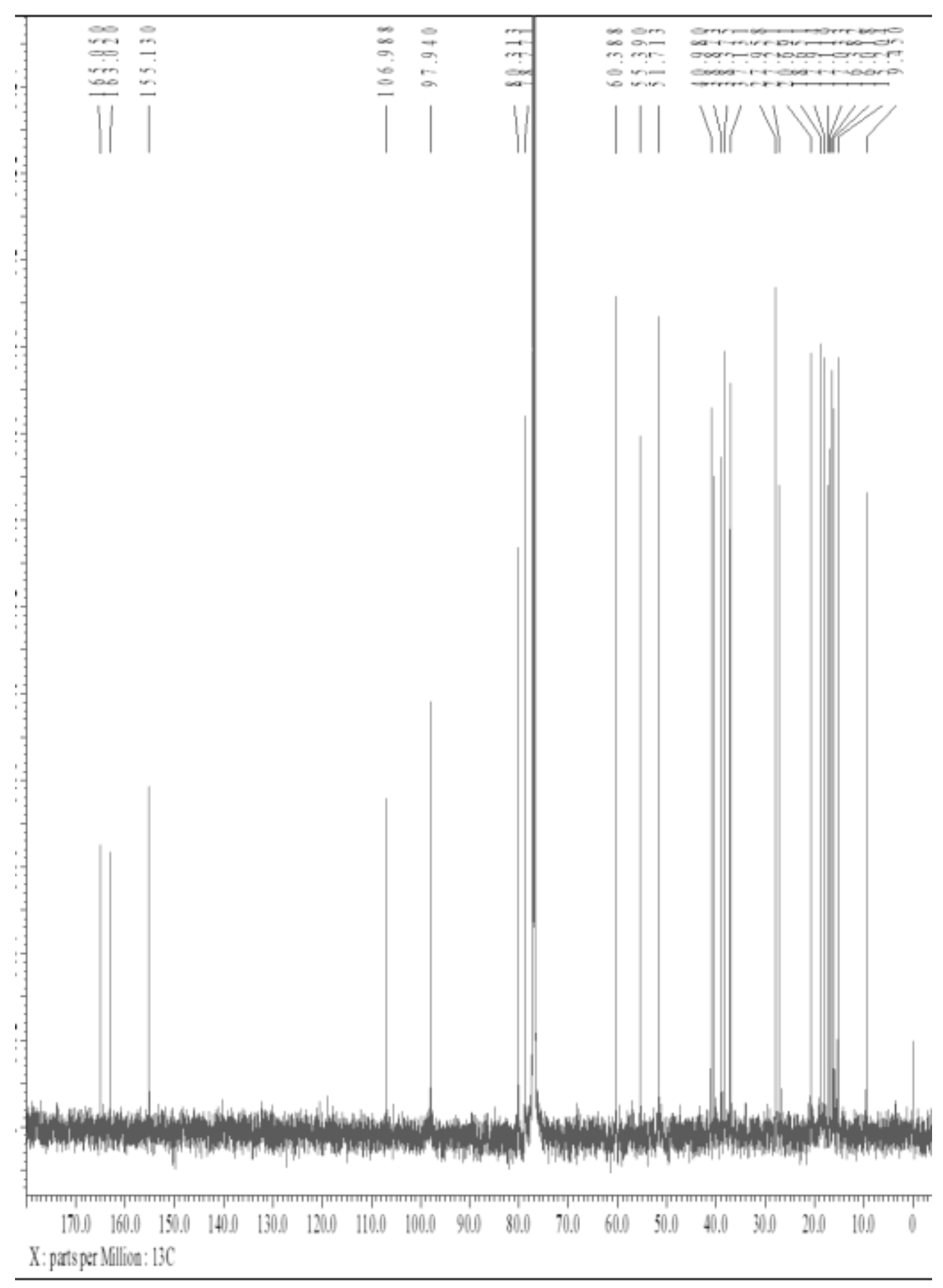


${ }^{1} \mathrm{H}-{ }^{1} \mathrm{H}$ COSY spectrum $\left(\mathrm{CDCl}_{3}\right)$ of shearone A (1)

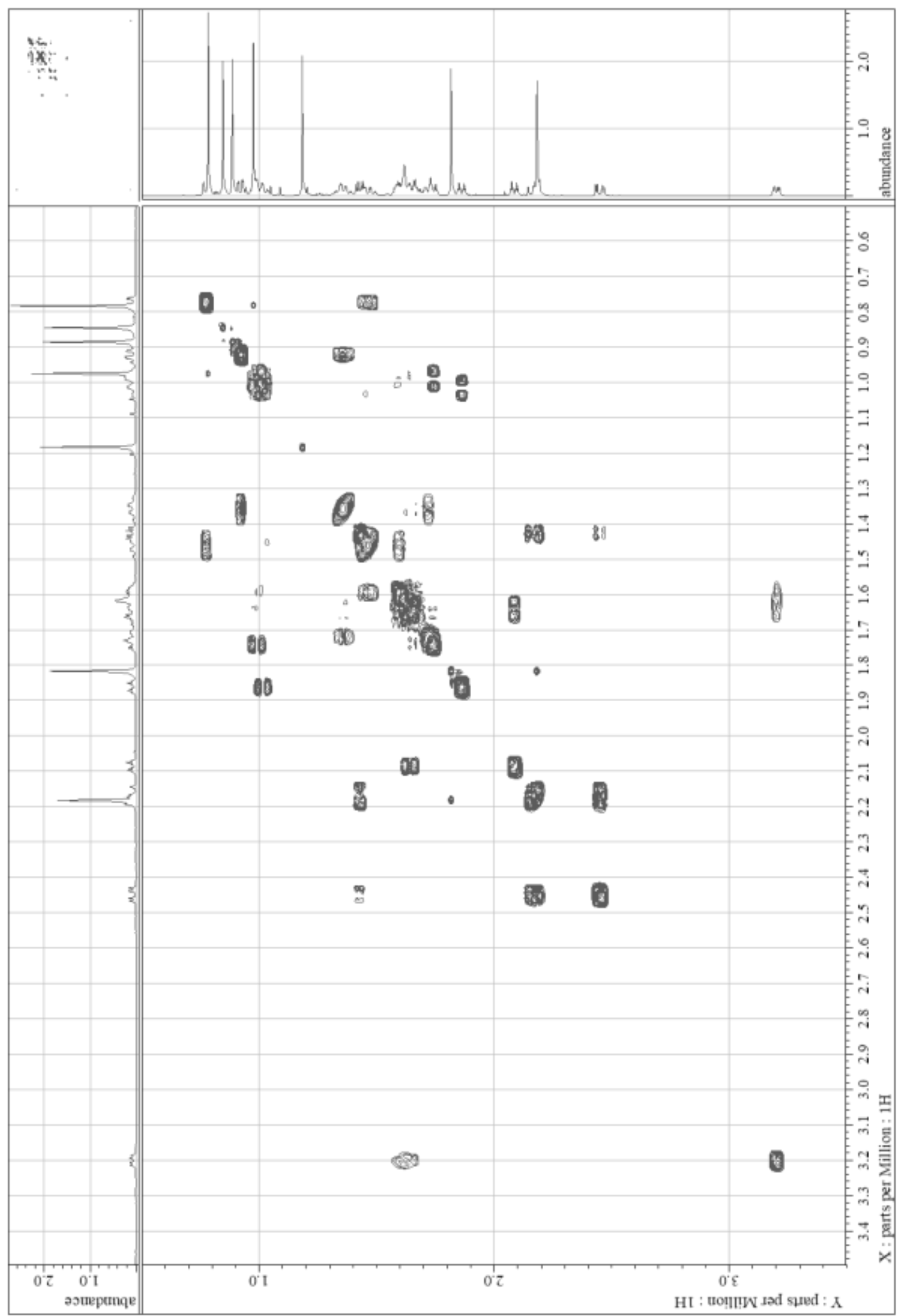


HMQC spectrum $\left(\mathrm{CDCl}_{3}\right)$ of shearone A (1)

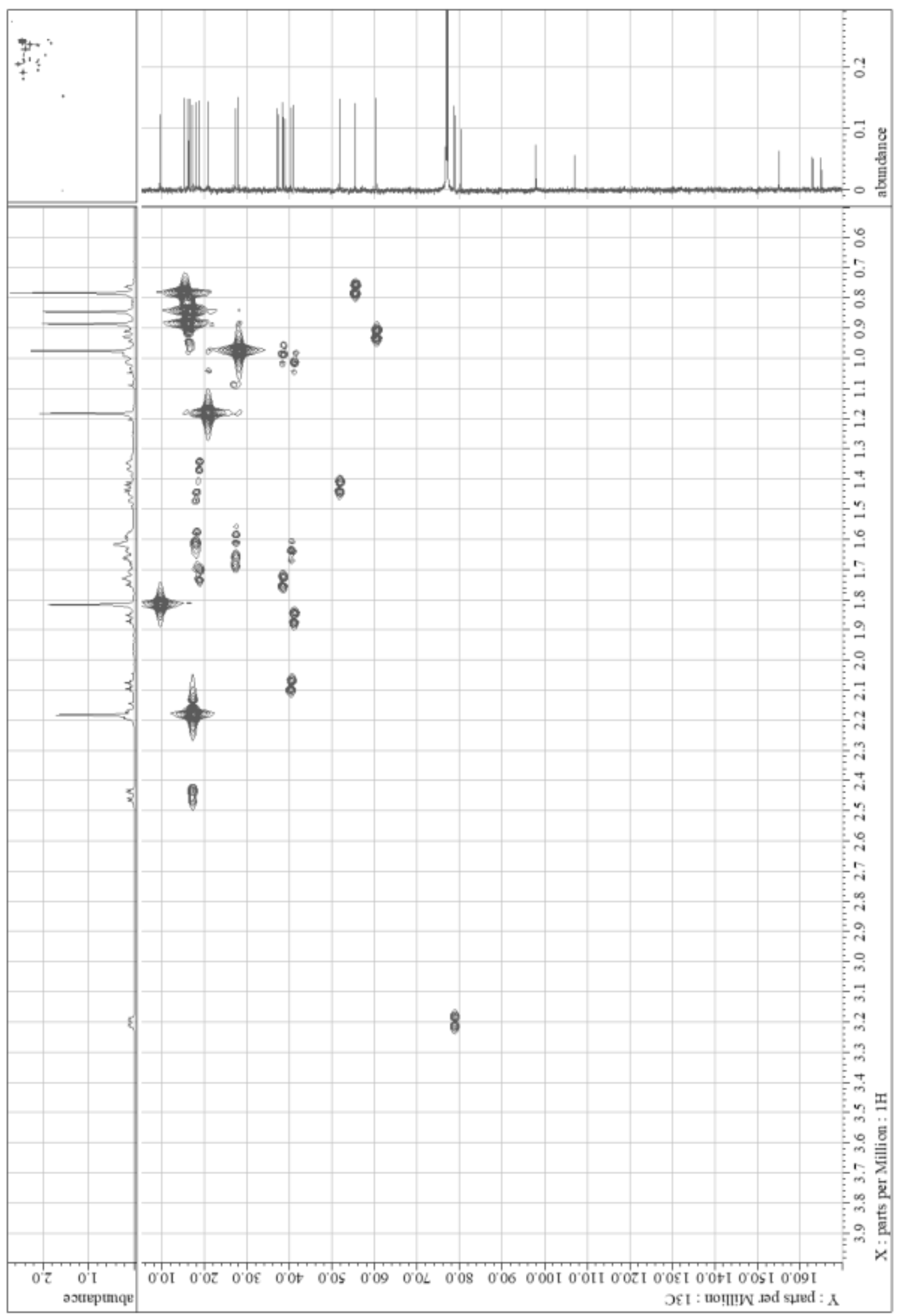




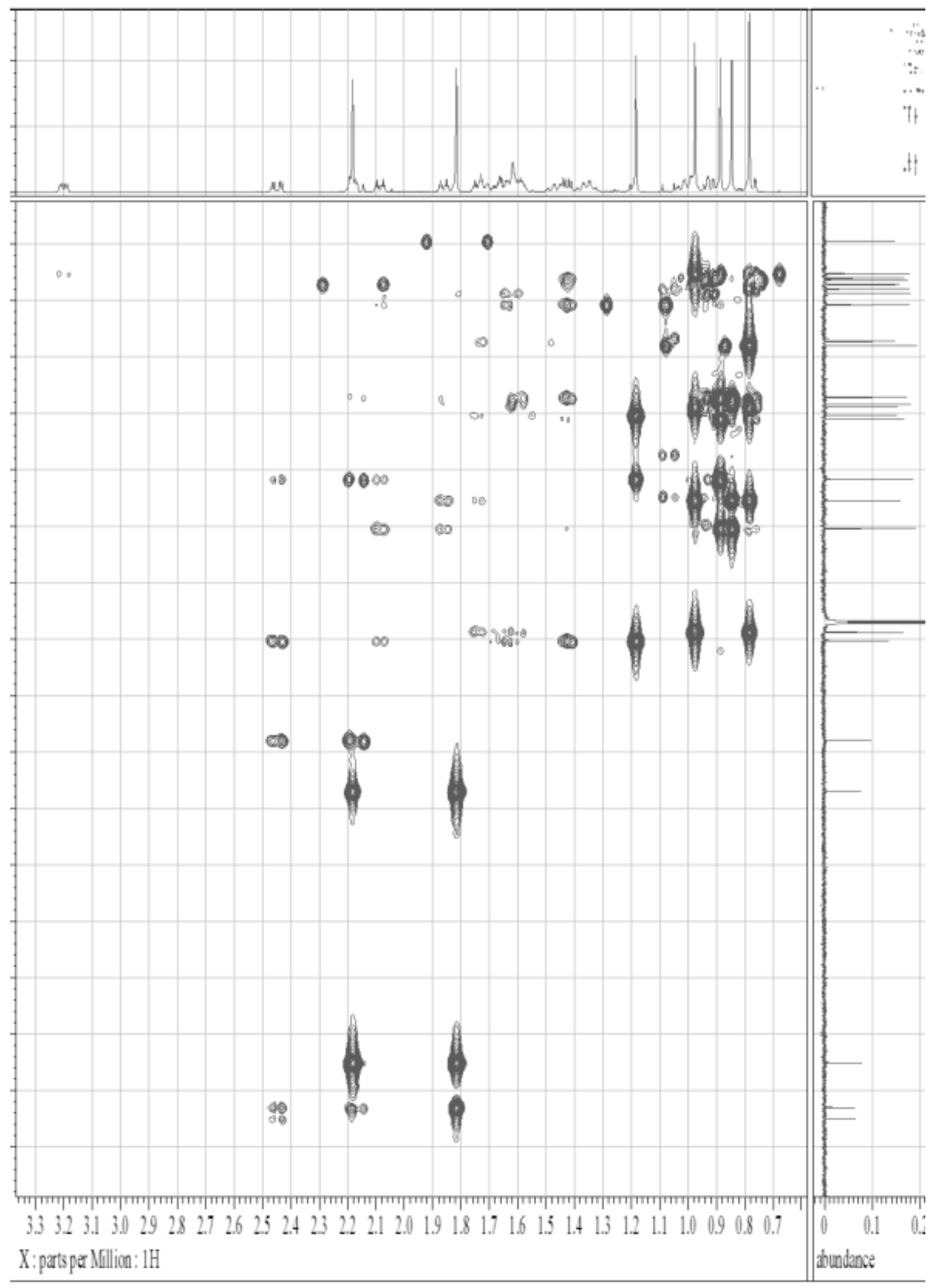


NOESY spectrum $\left(\mathrm{CDCl}_{3}\right)$ of shearone A (1)

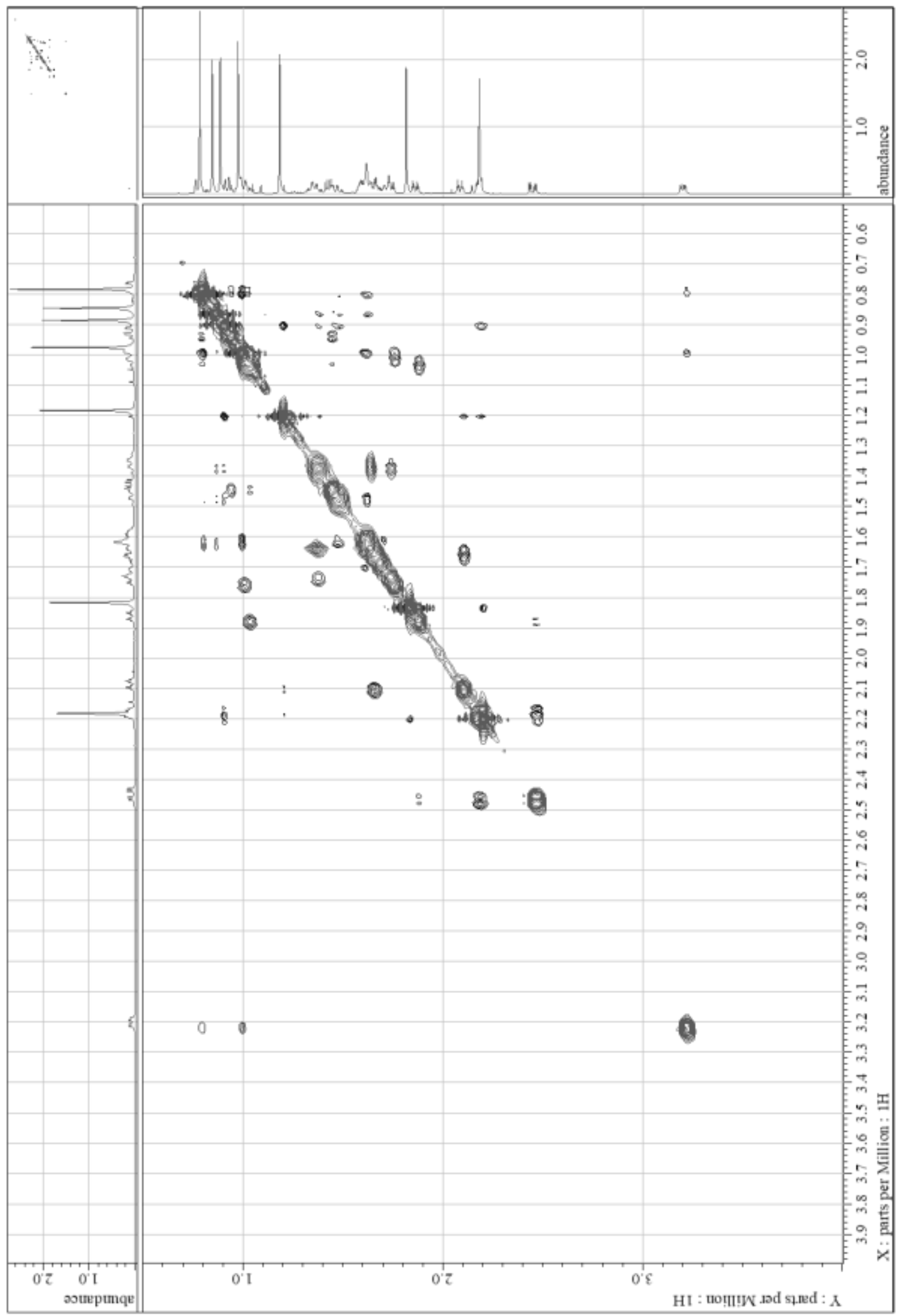


${ }^{1} \mathrm{H}$ NMR spectrum $\left(600 \mathrm{MHz}, \mathrm{CDCl}_{3}\right)$ of shearone B (2)
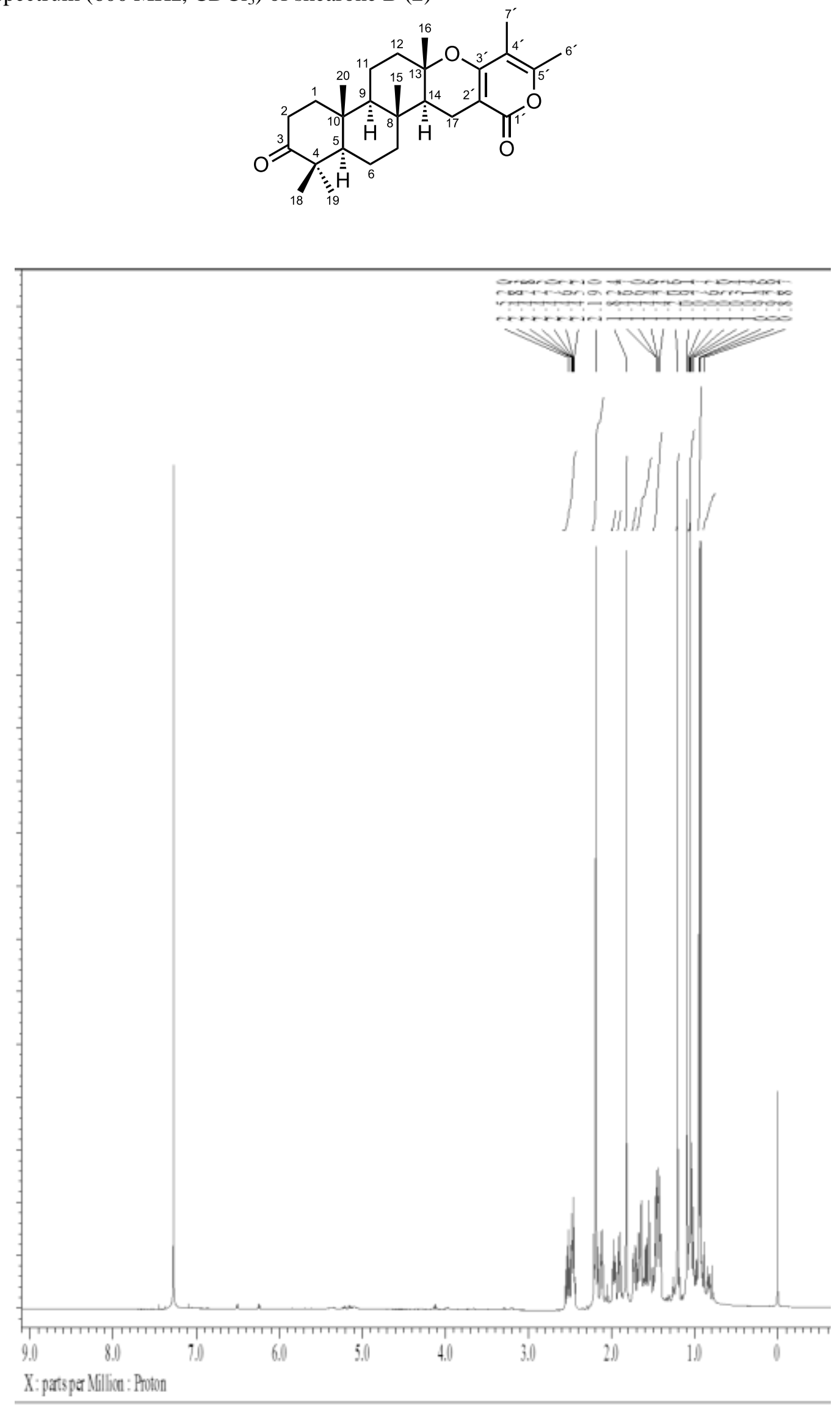
${ }^{13} \mathrm{C}$ NMR spectrum $\left(150 \mathrm{MHz}, \mathrm{CDCl}_{3}\right)$ of shearone B (2)

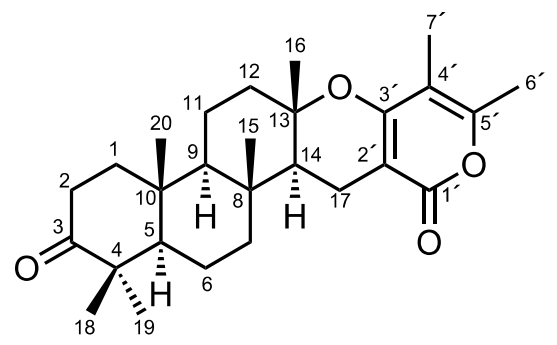

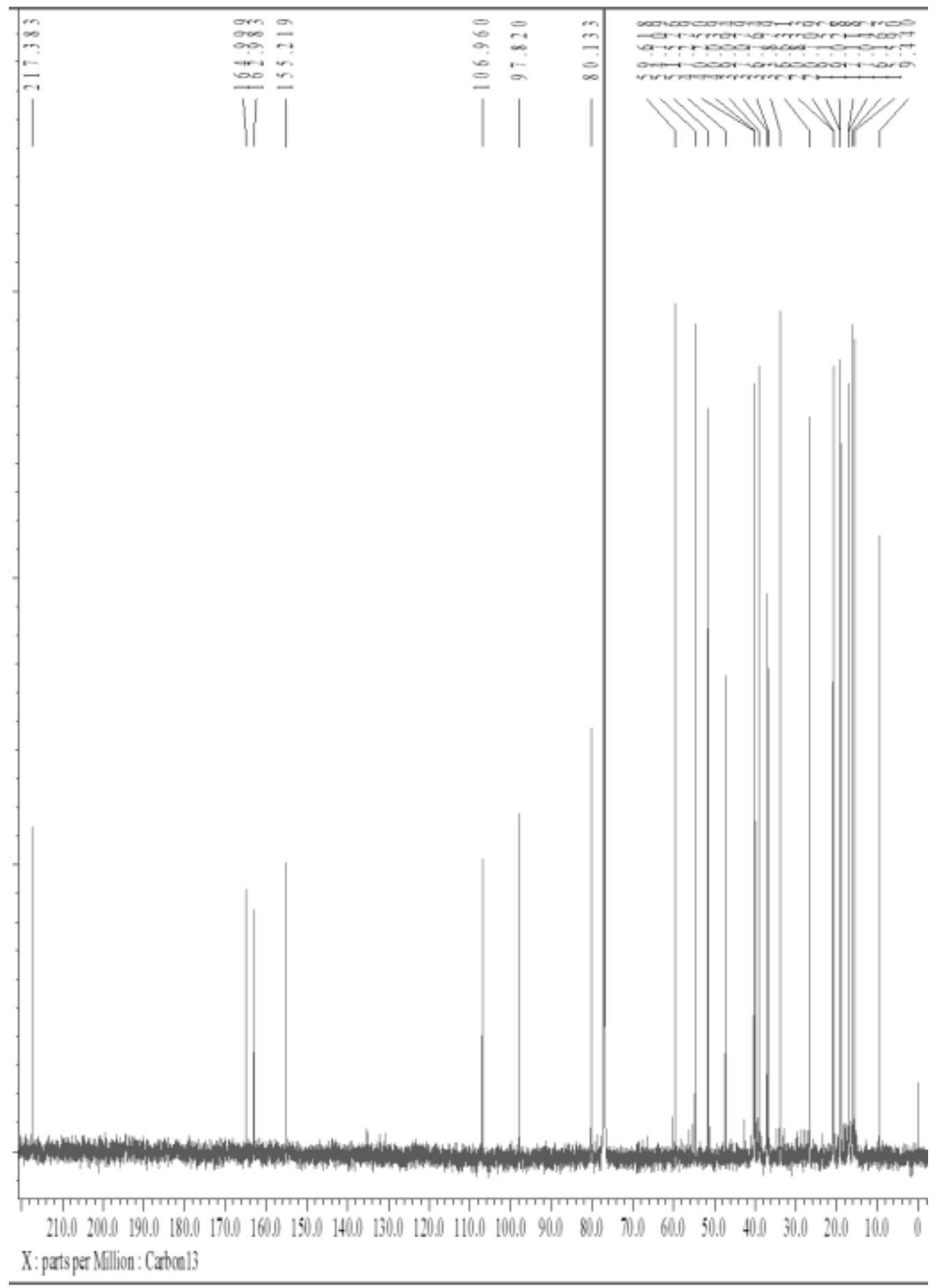


${ }^{1} \mathrm{H}-{ }^{1} \mathrm{H}$ COSY spectrum $\left(\mathrm{CDCl}_{3}\right)$ of shearone B (2)

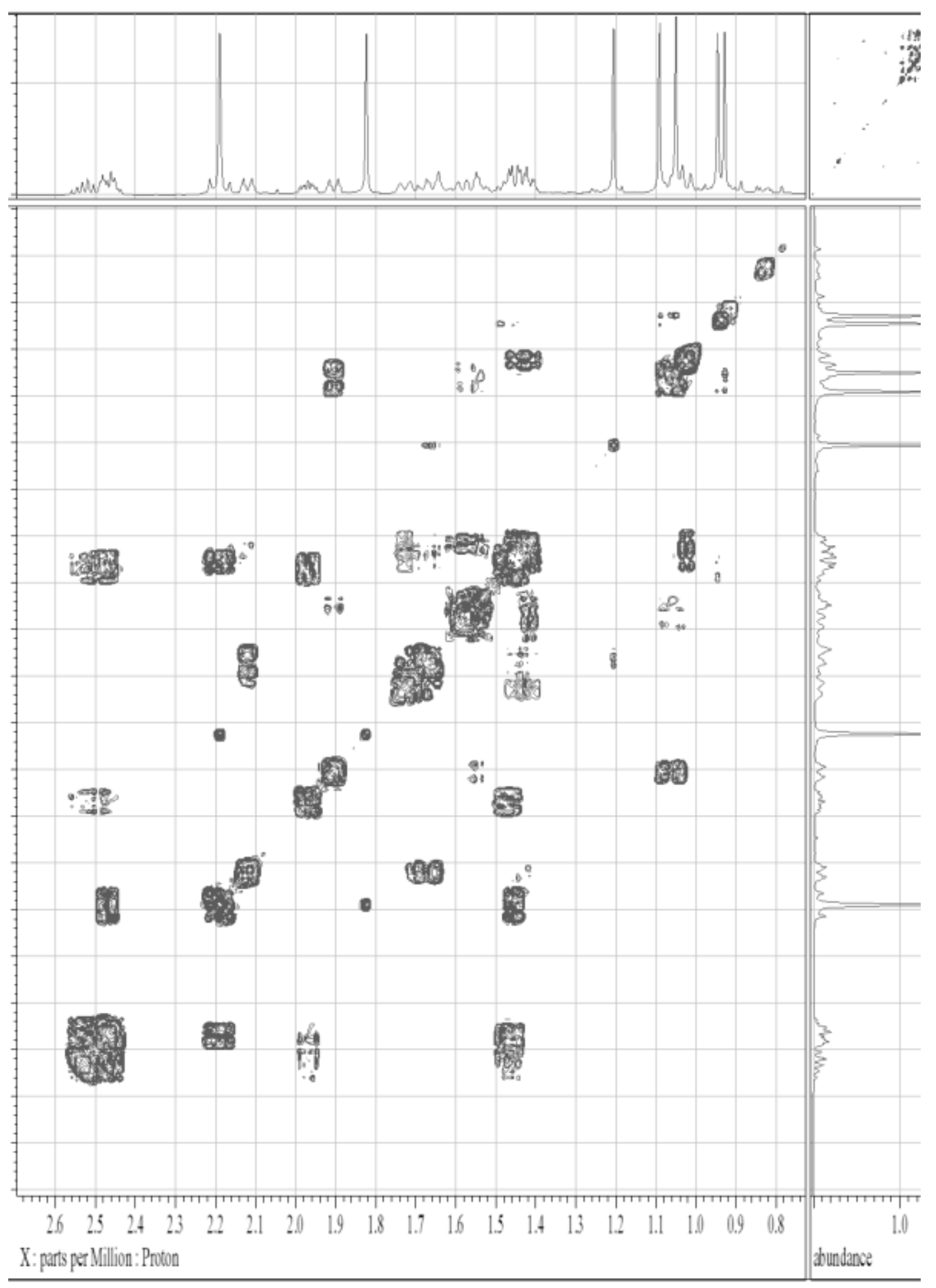


HMQC spectrum $\left(\mathrm{CDCl}_{3}\right)$ of shearone B (2)

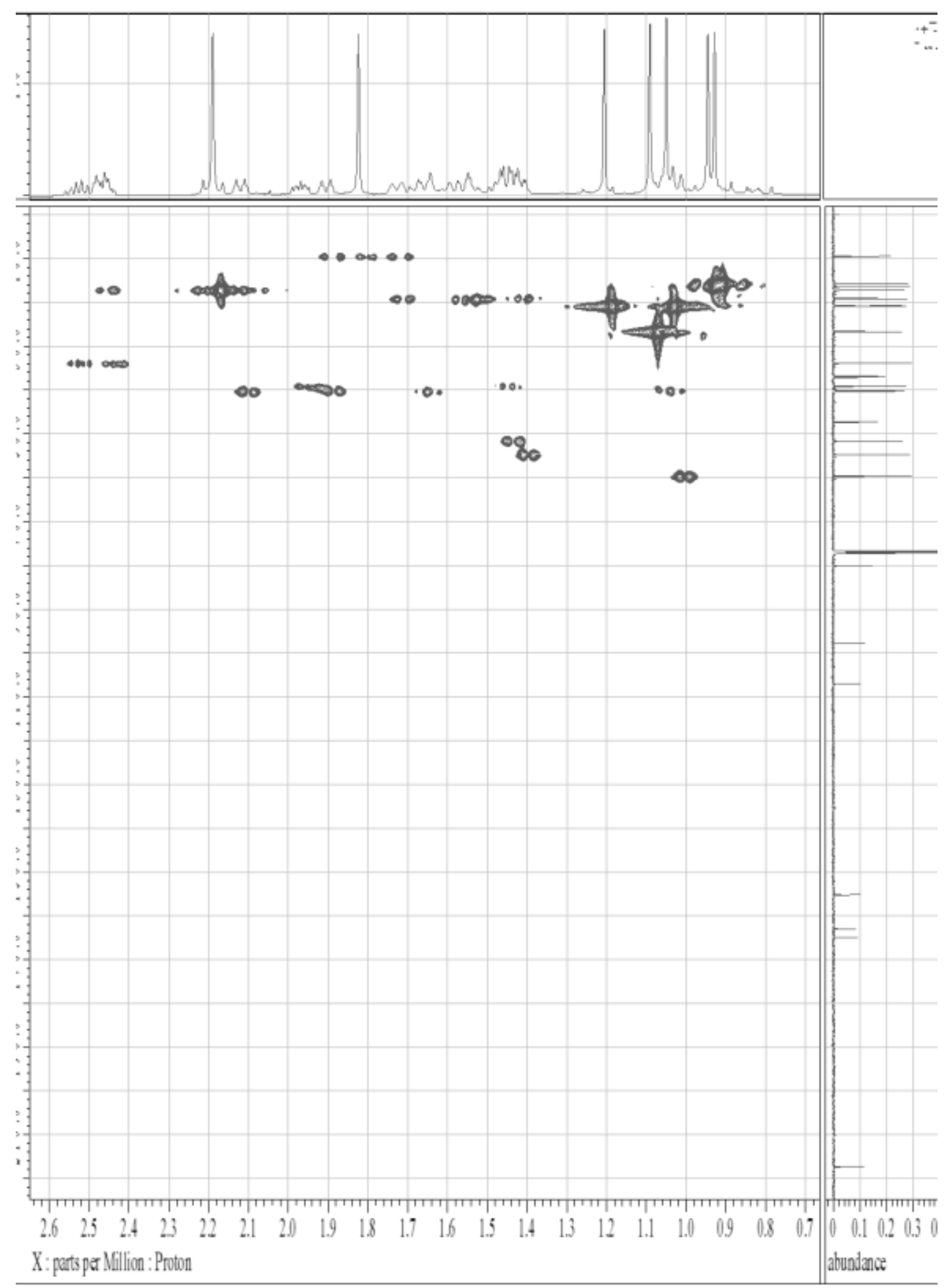


HMBC spectrum $\left(\mathrm{CDCl}_{3}\right)$ of shearone B (2)

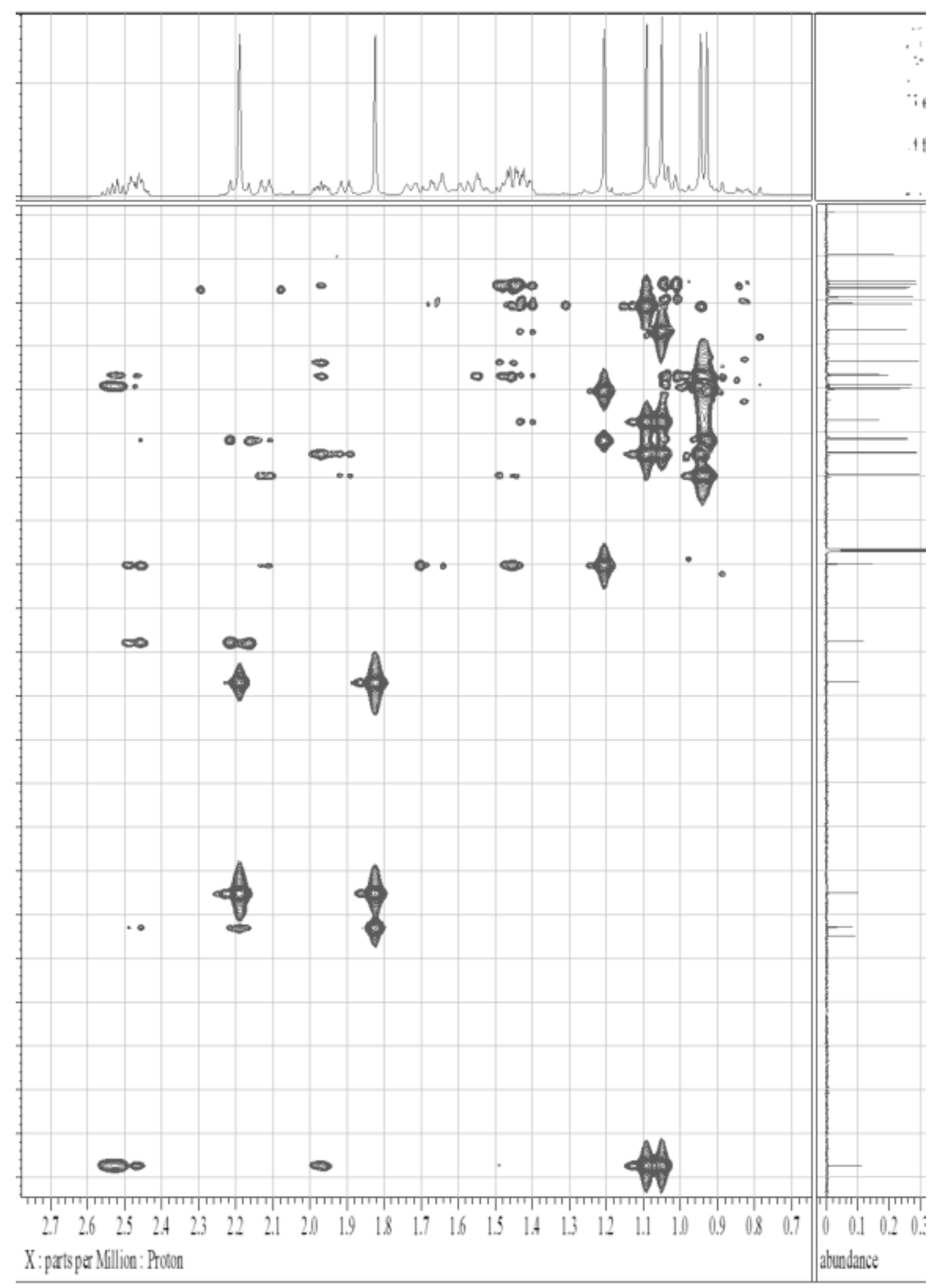


${ }^{1} \mathrm{H}$ NMR spectrum $\left(600 \mathrm{MHz}, \mathrm{CDCl}_{3}+10 \% \mathrm{CD}_{3} \mathrm{OD}\right)$ of shearone $\mathrm{C}(\mathbf{3})$

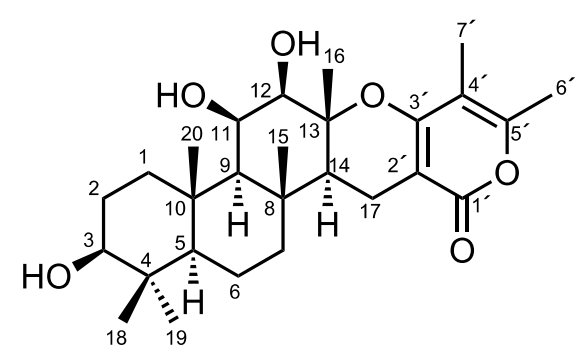

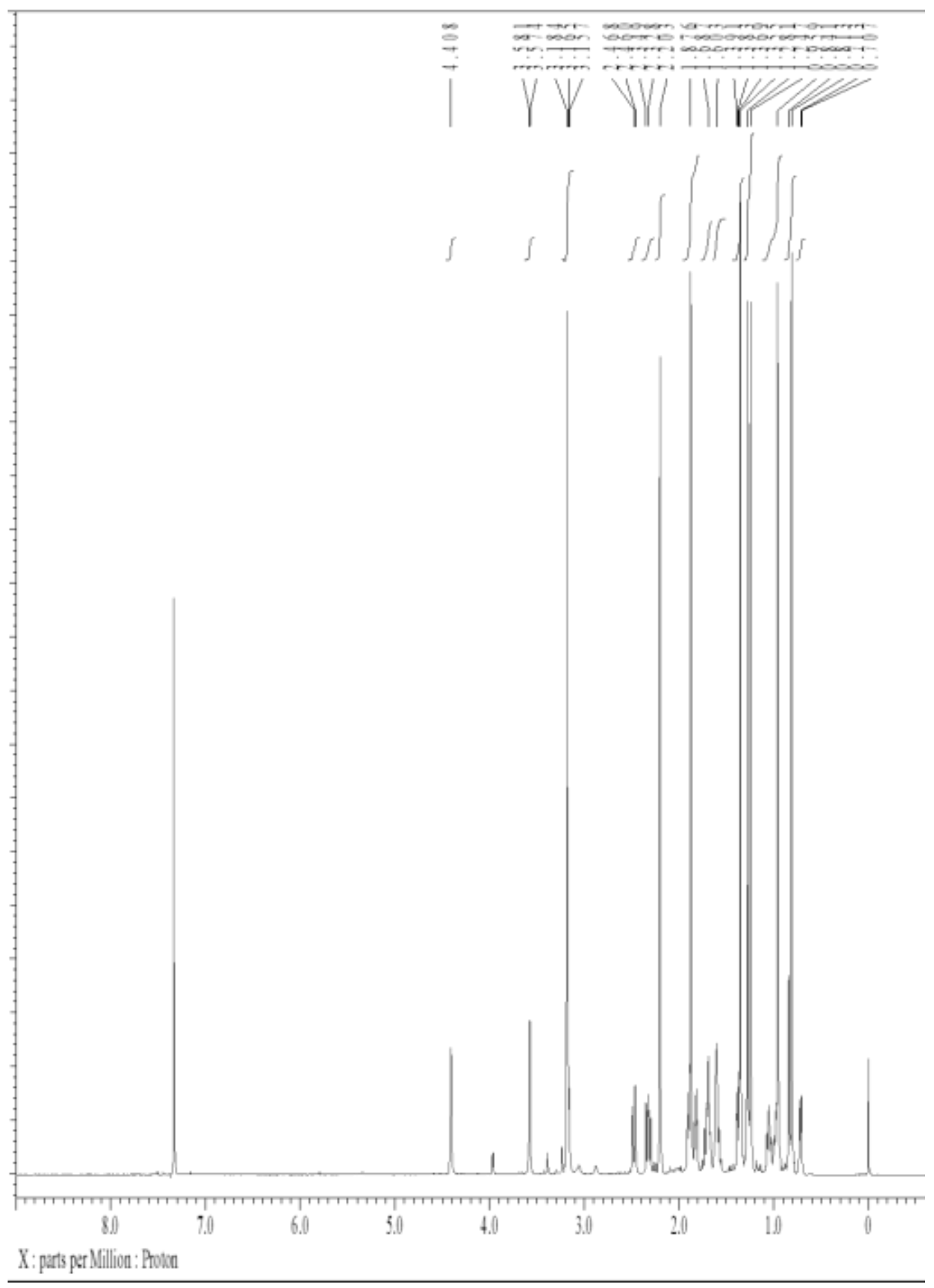


${ }^{13} \mathrm{C}$ NMR spectrum $\left(150 \mathrm{MHz}, \mathrm{CDCl}_{3}+10 \% \mathrm{CD}_{3} \mathrm{OD}\right)$ of shearone $\mathrm{C}(\mathbf{3})$

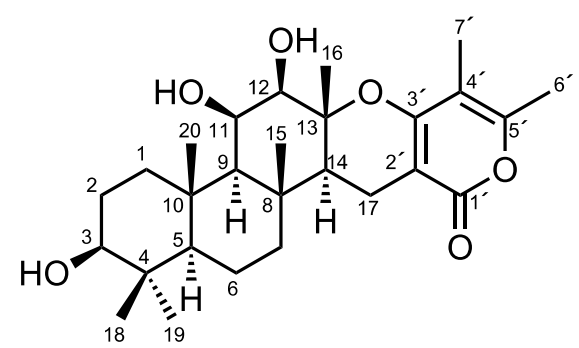

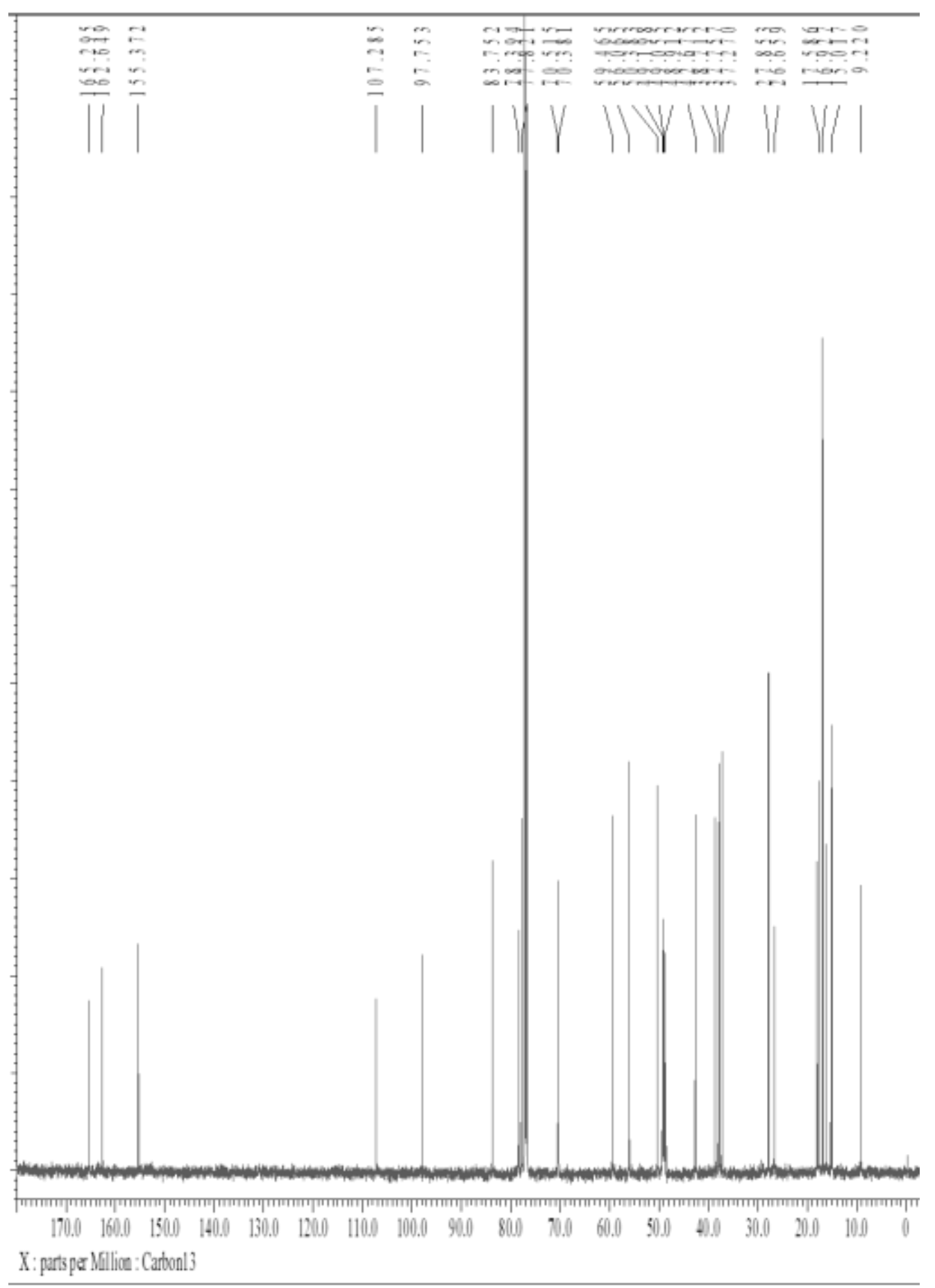


${ }^{1} \mathrm{H}-{ }^{1} \mathrm{H}$ COSY spectrum $\left(\mathrm{CDCl}_{3}+10 \% \mathrm{CD}_{3} \mathrm{OD}\right)$ of shearone $\mathrm{C}(\mathbf{3})$

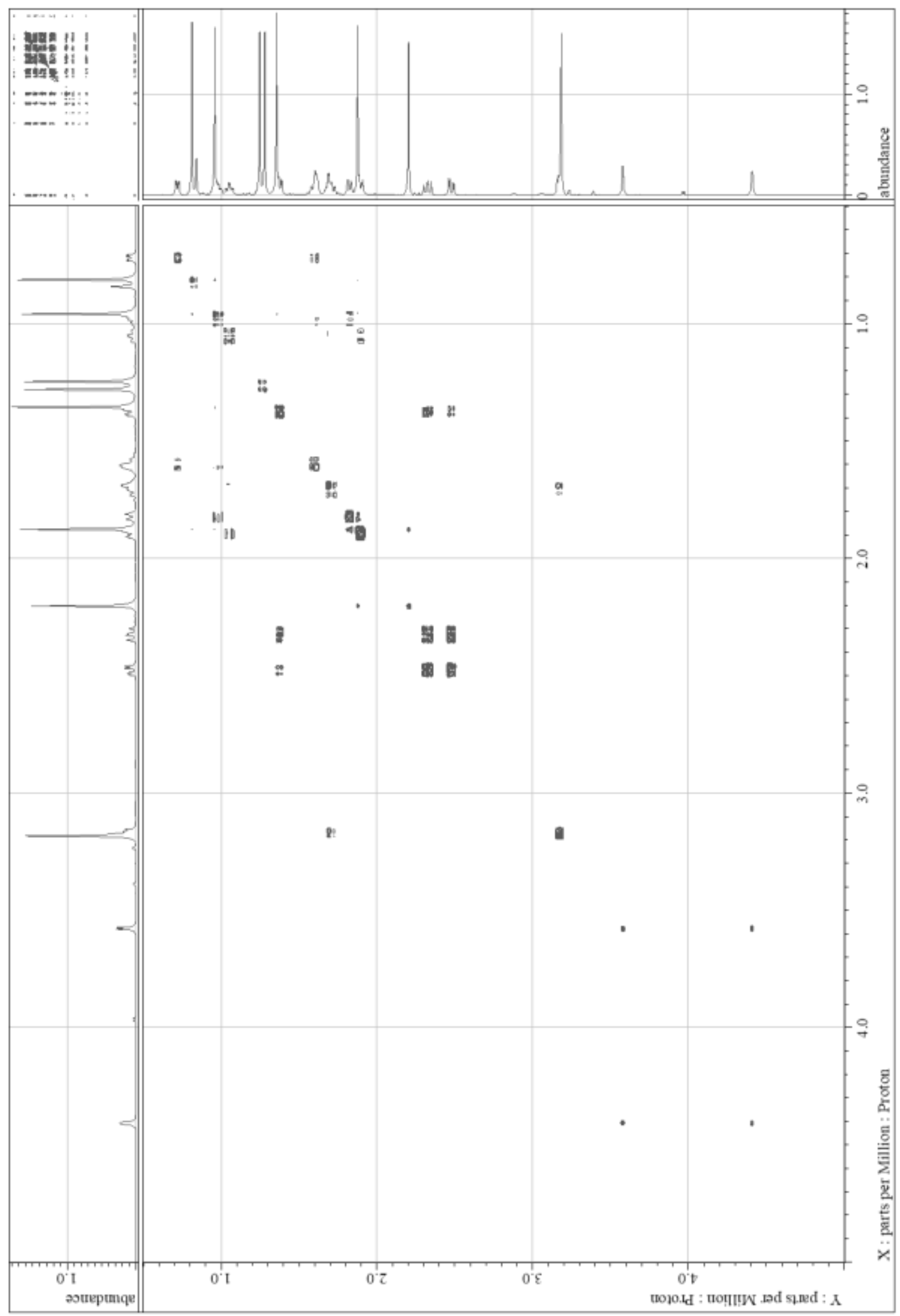


HMQC spectrum $\left(\mathrm{CDCl}_{3}+10 \% \mathrm{CD}_{3} \mathrm{OD}\right)$ of shearone $\mathrm{C}(\mathbf{3})$

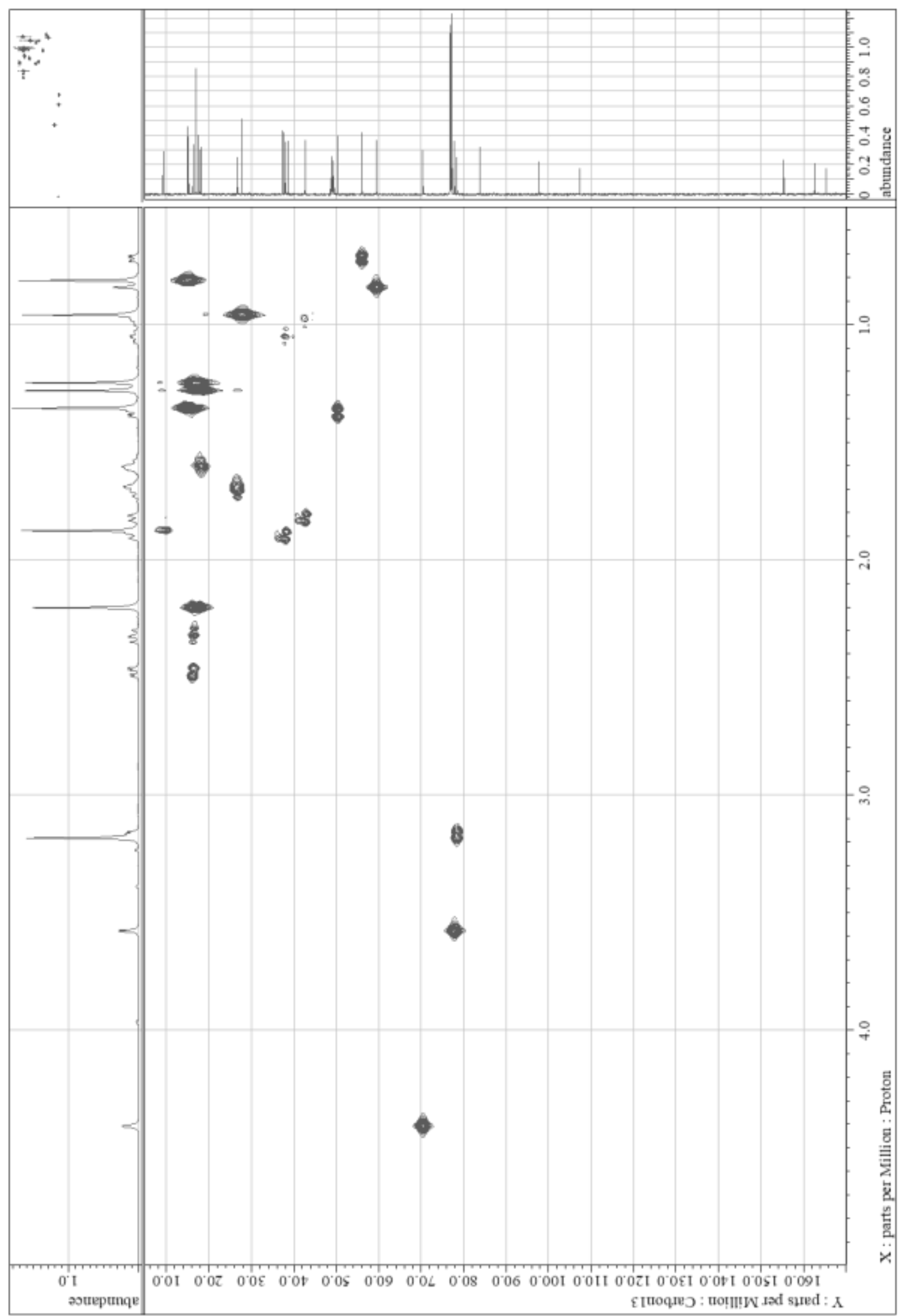


HMBC spectrum $\left(\mathrm{CDCl}_{3}+10 \% \mathrm{CD}_{3} \mathrm{OD}\right)$ of shearone $\mathrm{C}(\mathbf{3})$

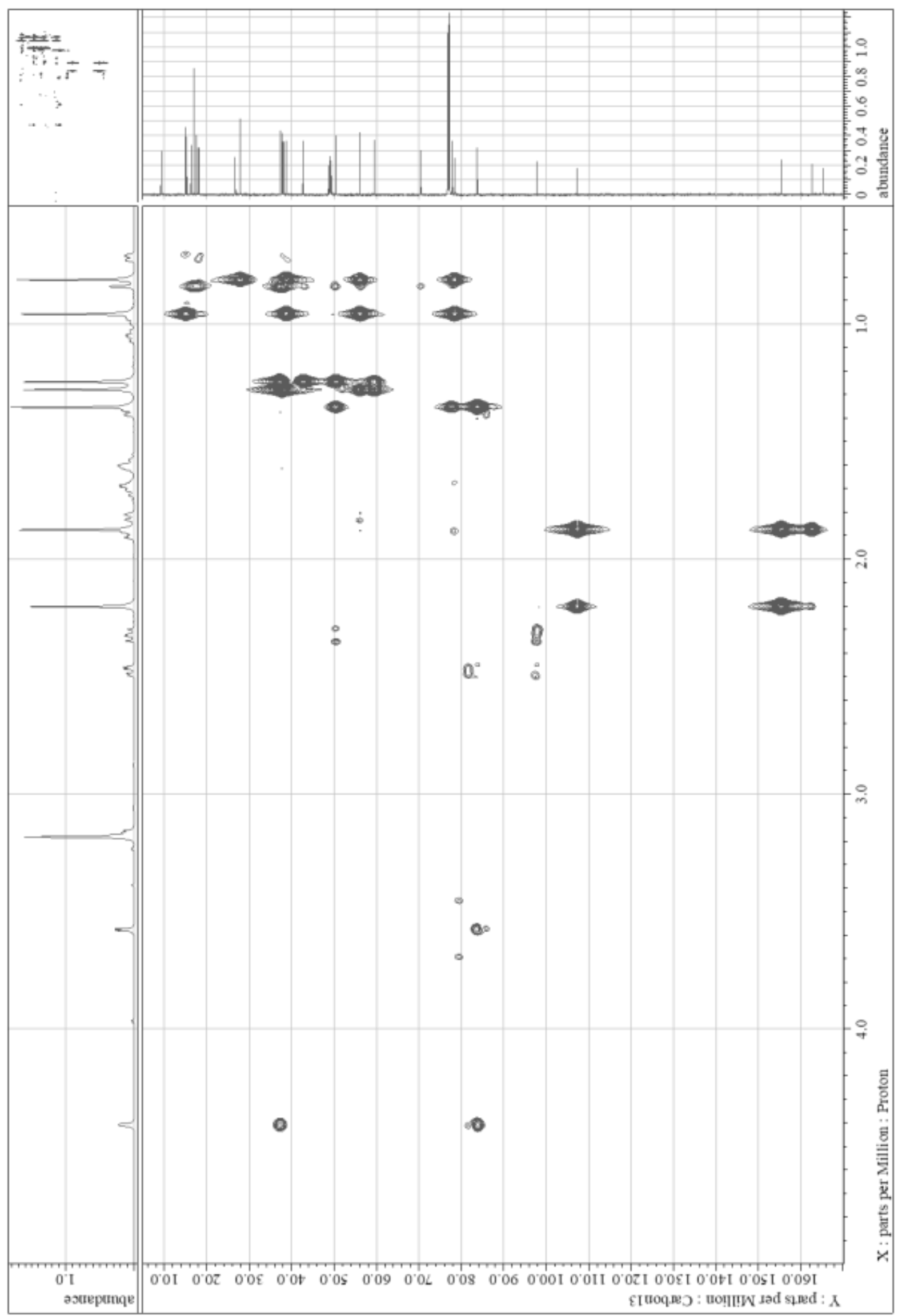


${ }^{1} \mathrm{H}$ NMR spectrum $\left(600 \mathrm{MHz}, \mathrm{CDCl}_{3}\right)$ of shearone $\mathrm{D}(4)$
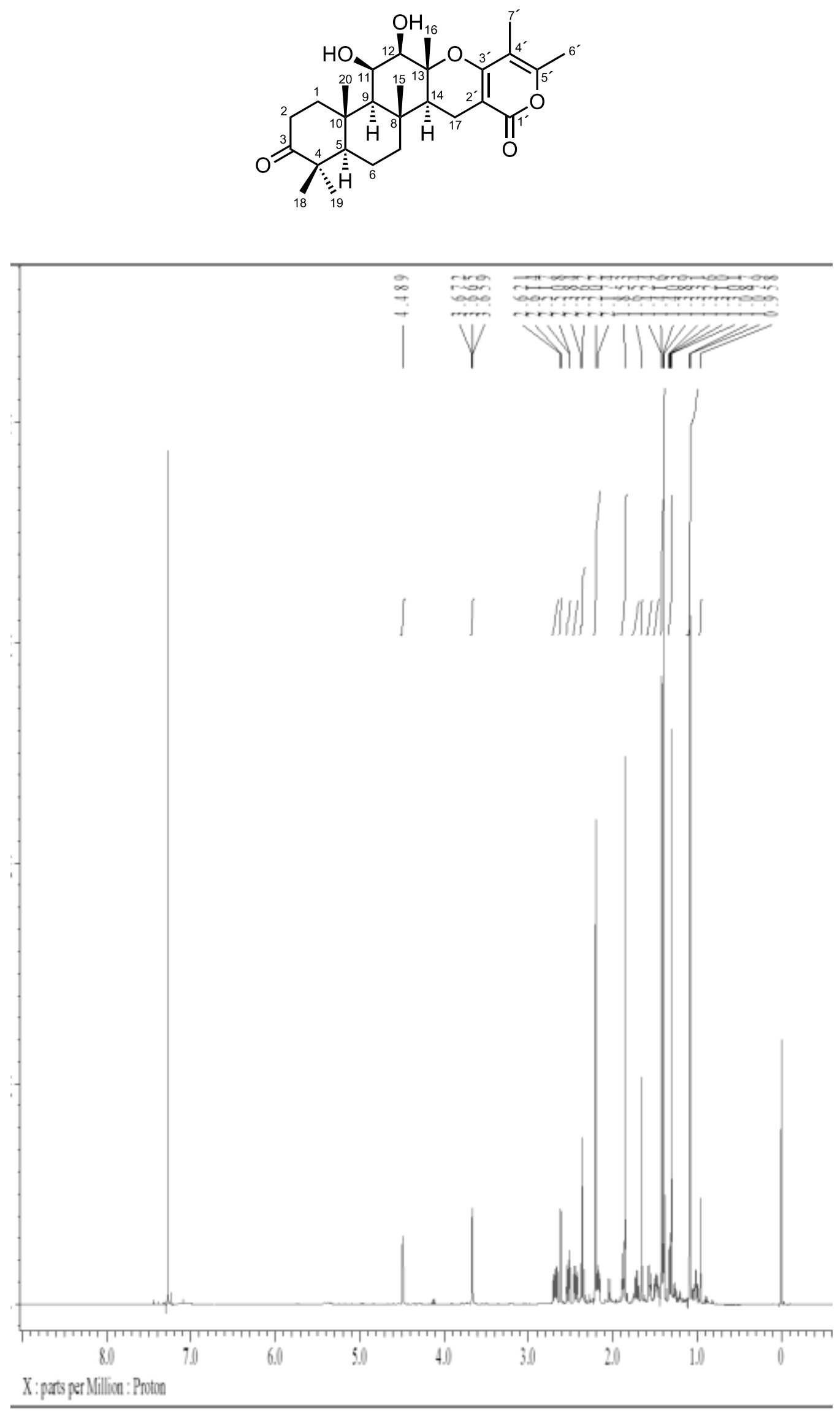
${ }^{13} \mathrm{C}$ NMR spectrum $\left(150 \mathrm{MHz}, \mathrm{CDCl}_{3}\right)$ of shearone $\mathrm{D}(4)$

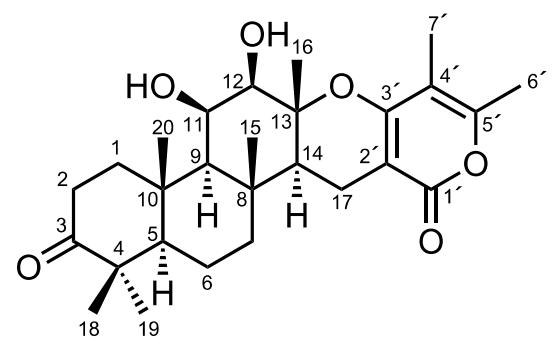

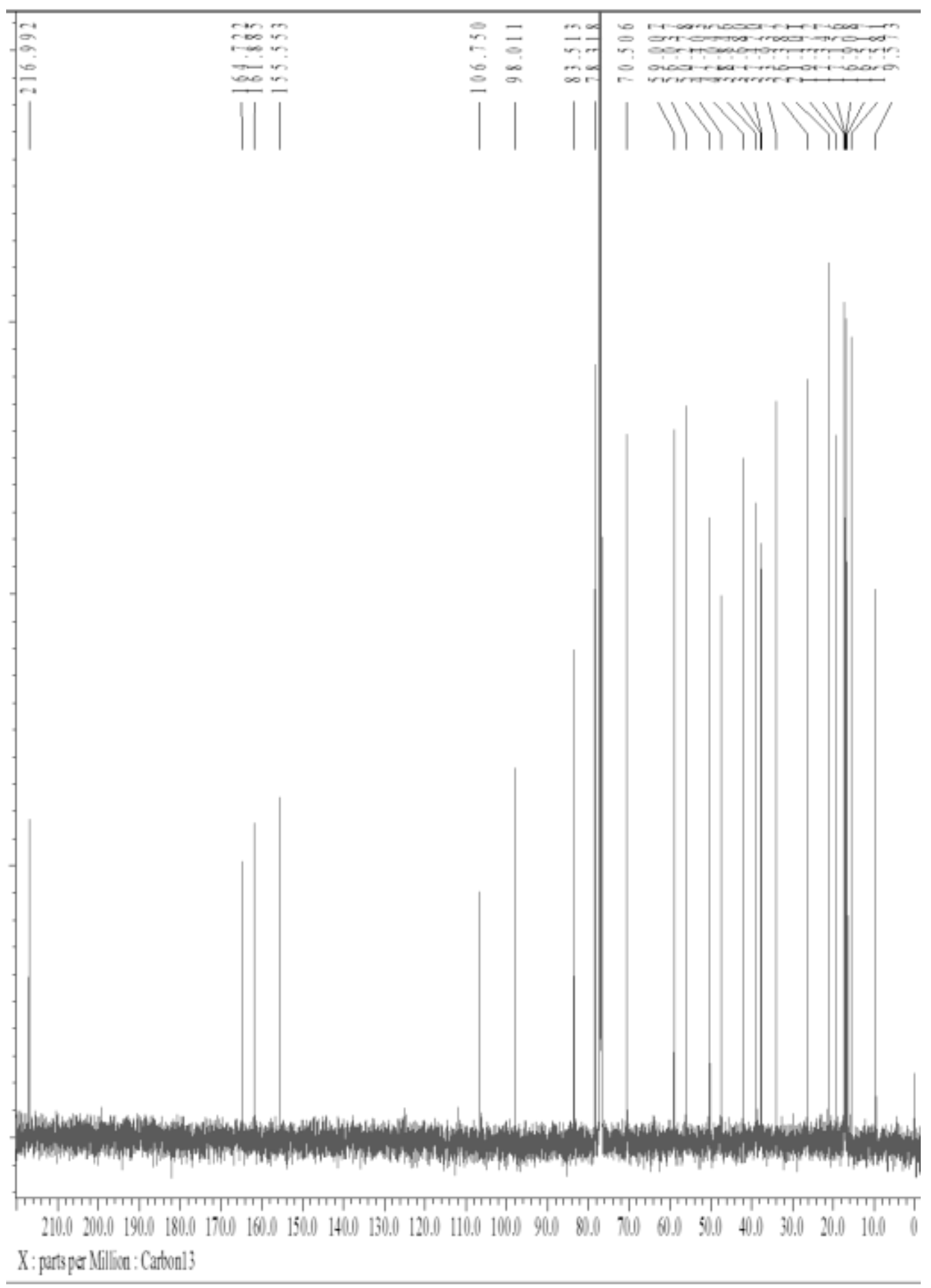


${ }^{1} \mathrm{H}-{ }^{1} \mathrm{H}$ COSY spectrum $\left(\mathrm{CDCl}_{3}\right)$ of shearone D (4)

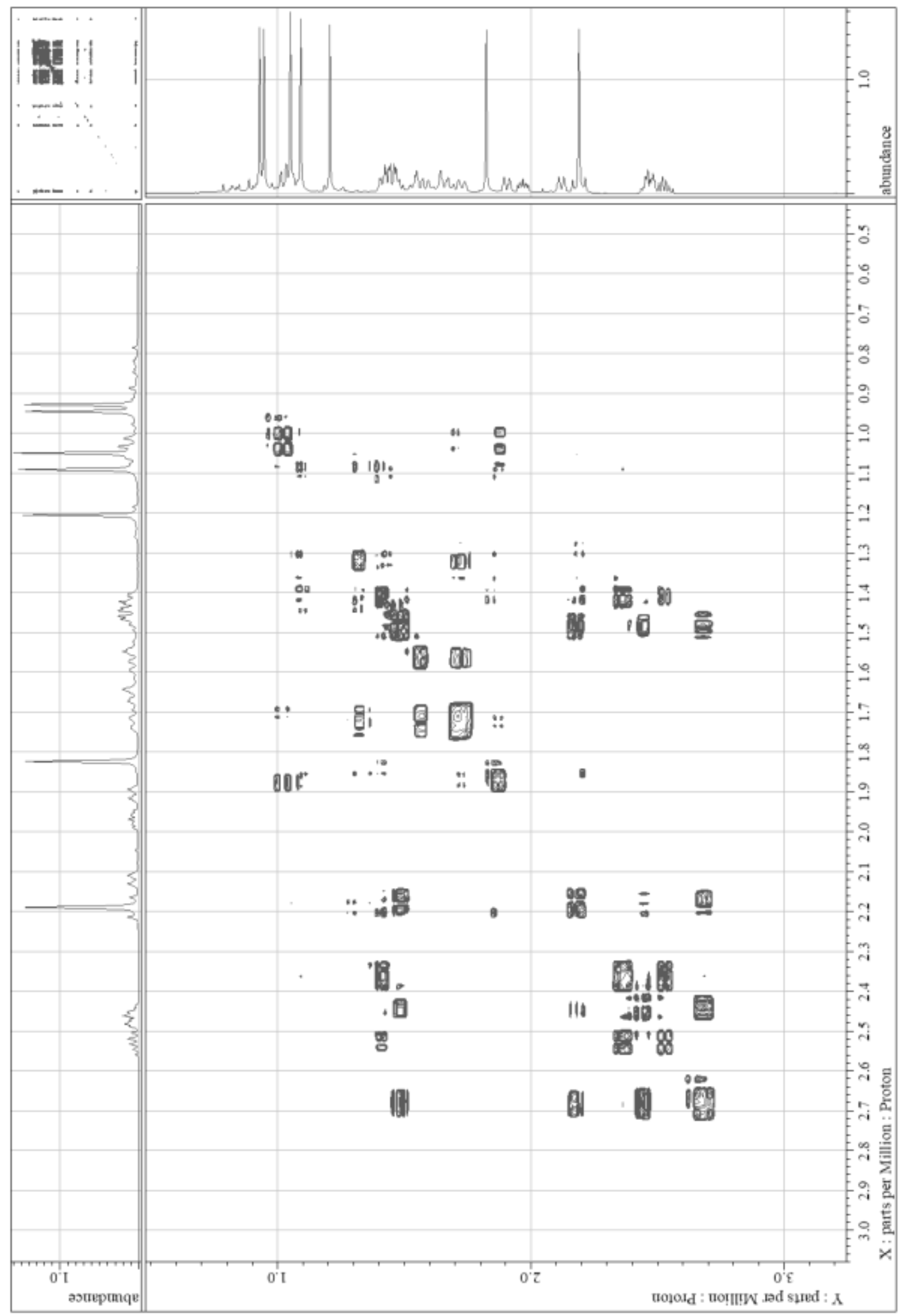


HMQC spectrum $\left(\mathrm{CDCl}_{3}\right)$ of shearone $\mathrm{D}(\mathbf{4})$

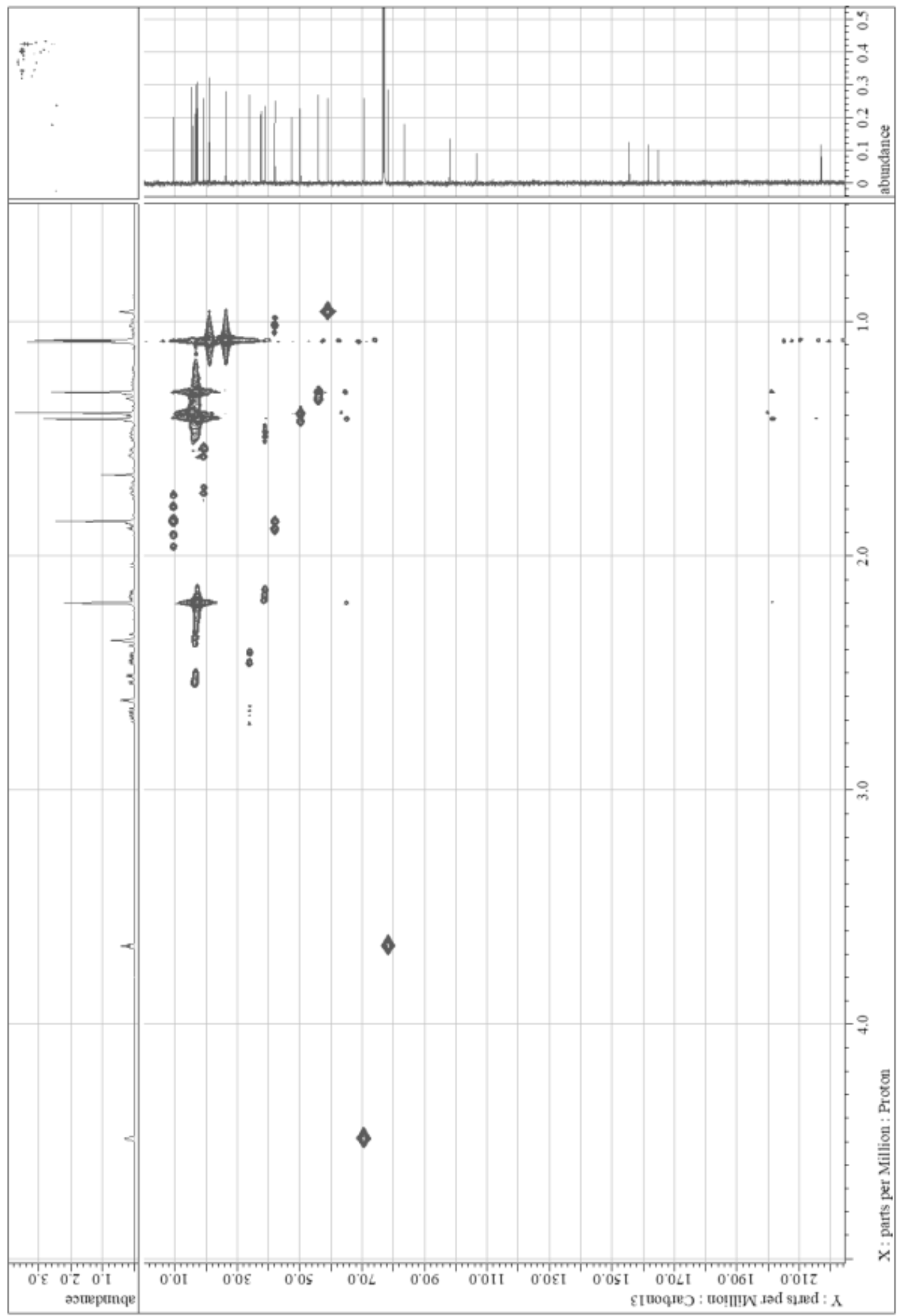


HMBC spectrum $\left(\mathrm{CDCl}_{3}\right)$ of shearone D (4)

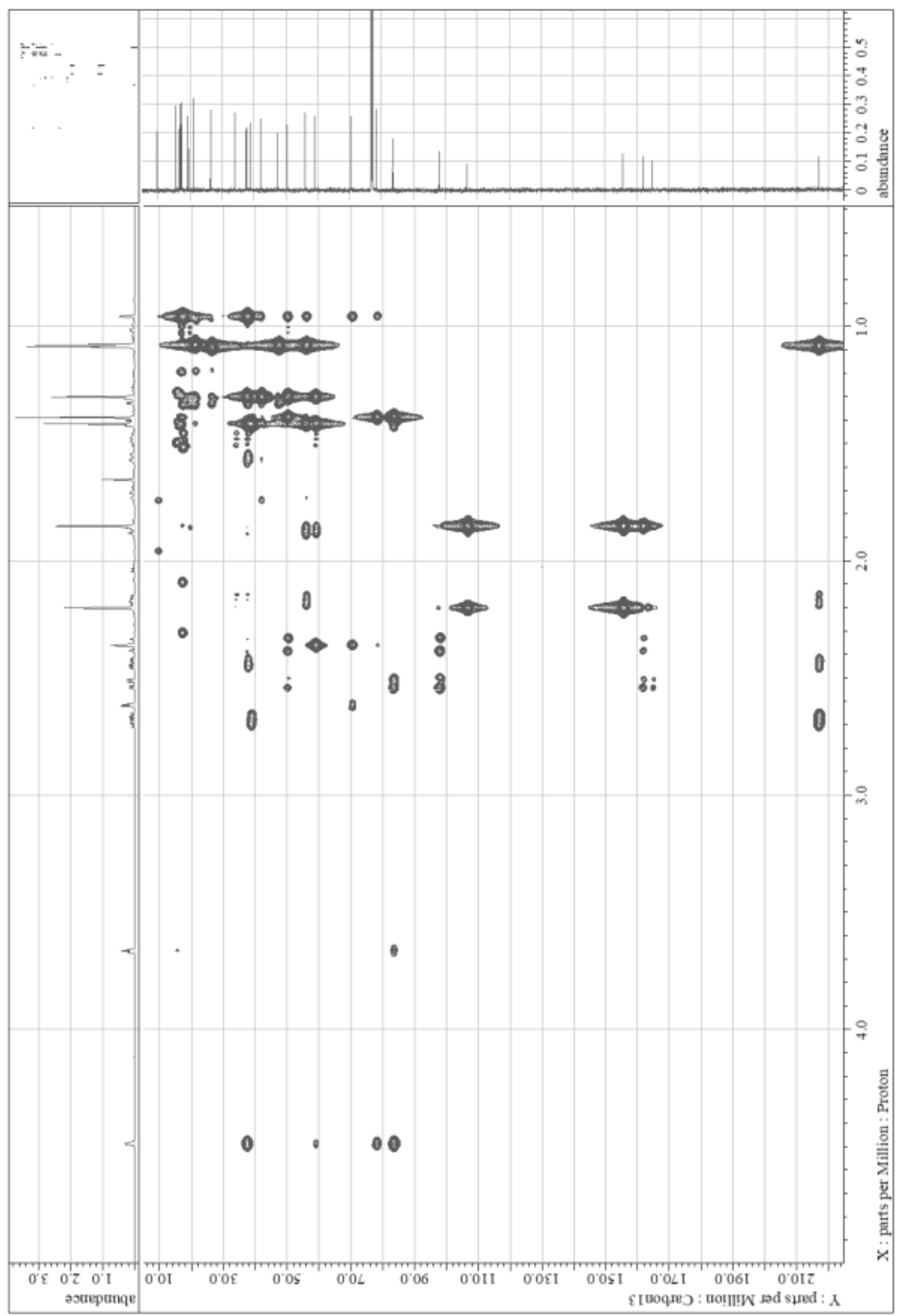


${ }^{1} \mathrm{H}$ NMR spectrum (600 MHz, pyridine- $\mathrm{d}_{5}$ ) of shearone E (5)

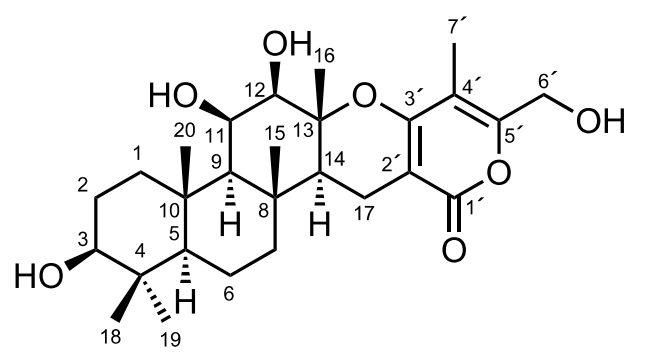

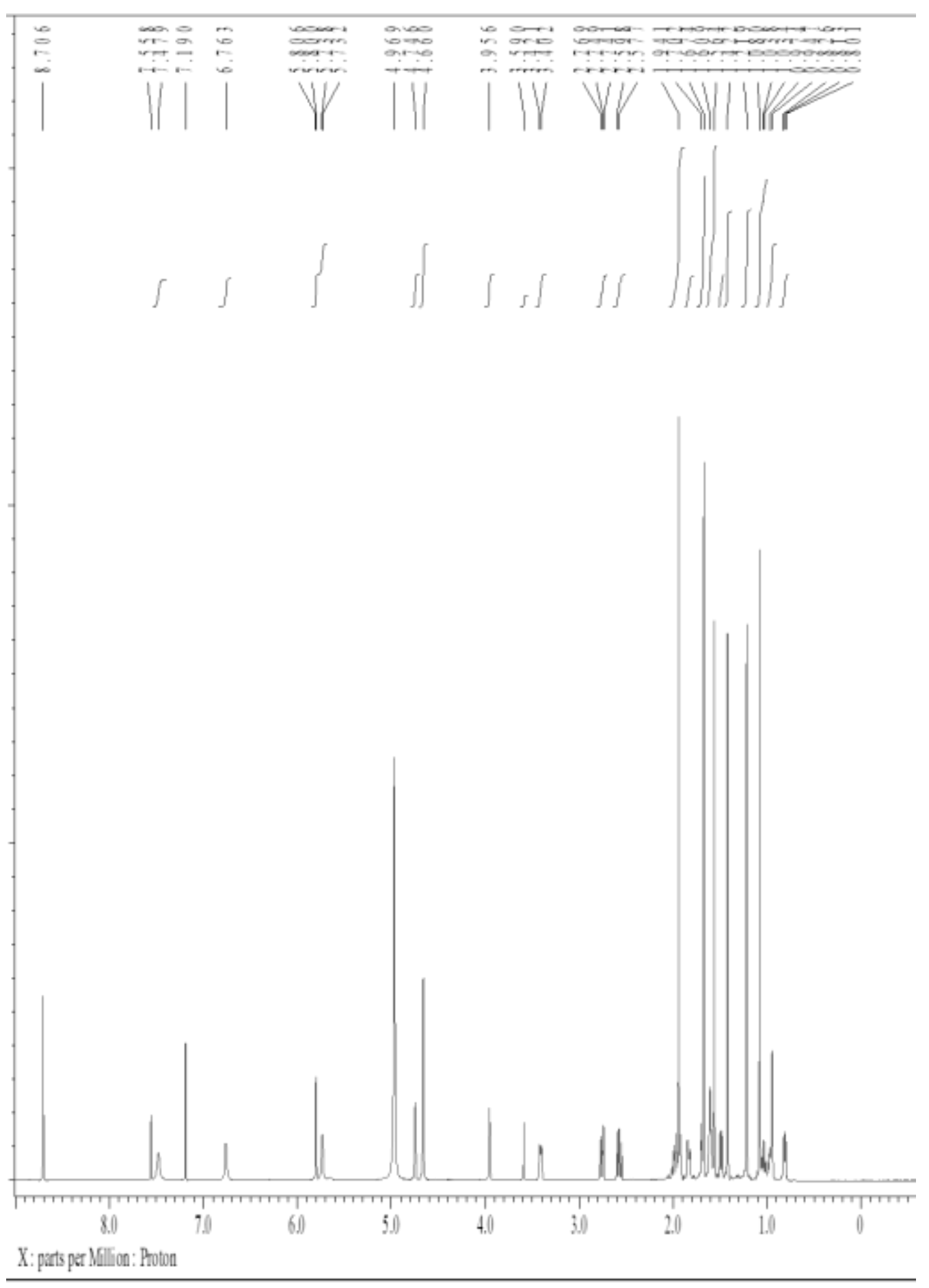


${ }^{13} \mathrm{C}$ NMR spectrum (150 MHz, pyridine- $\mathrm{d}_{5}$ ) of shearone $\mathrm{E}(\mathbf{5})$

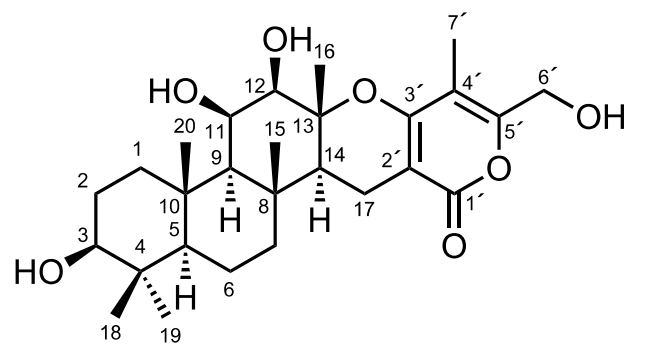

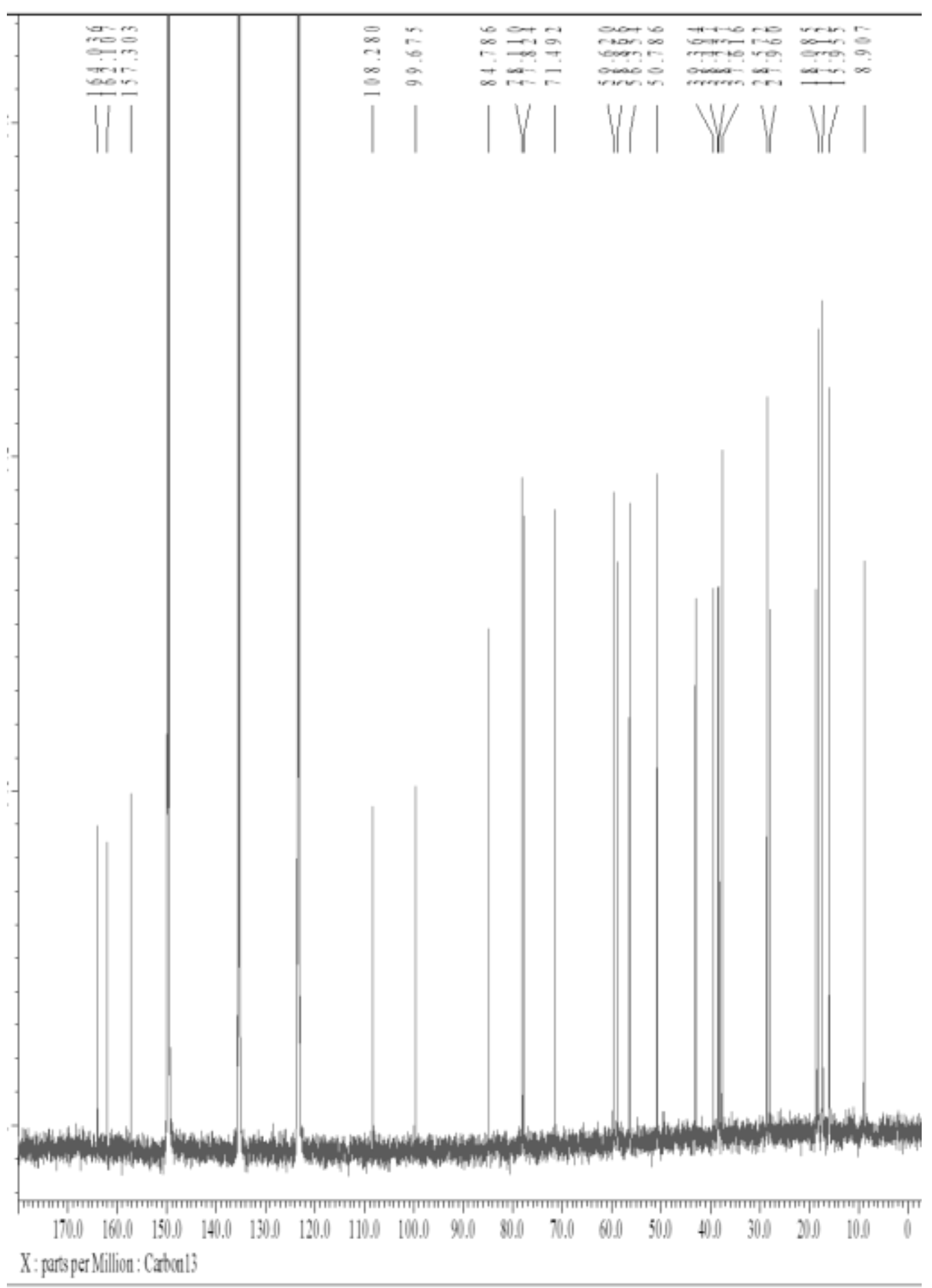


${ }^{1} \mathrm{H}-{ }^{1} \mathrm{H}$ COSY spectrum (pyridine- $\mathrm{d}_{5}$ ) of shearone E (5)

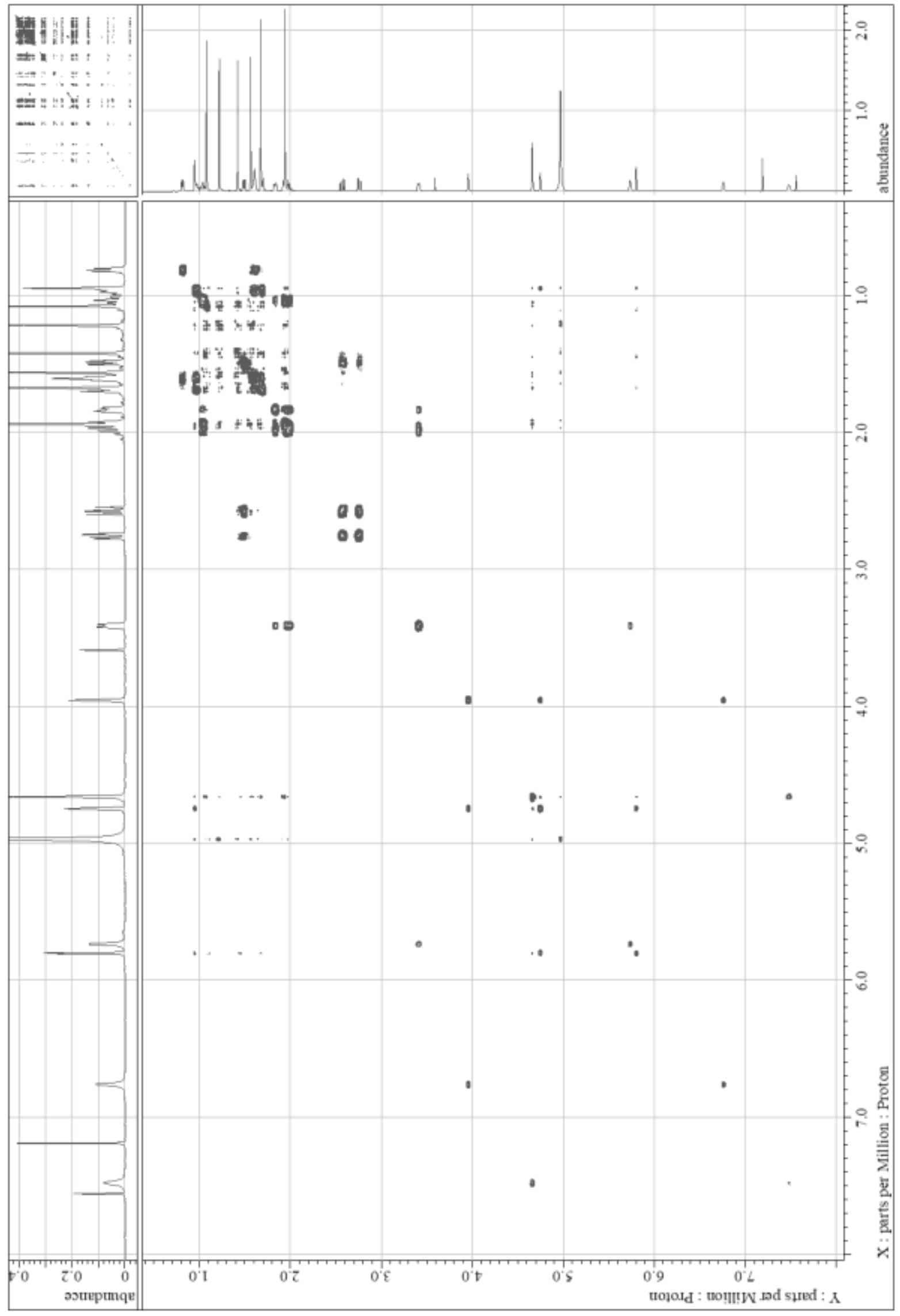


HMQC spectrum (pyridine- $\mathrm{d}_{5}$ ) of shearone E (5)

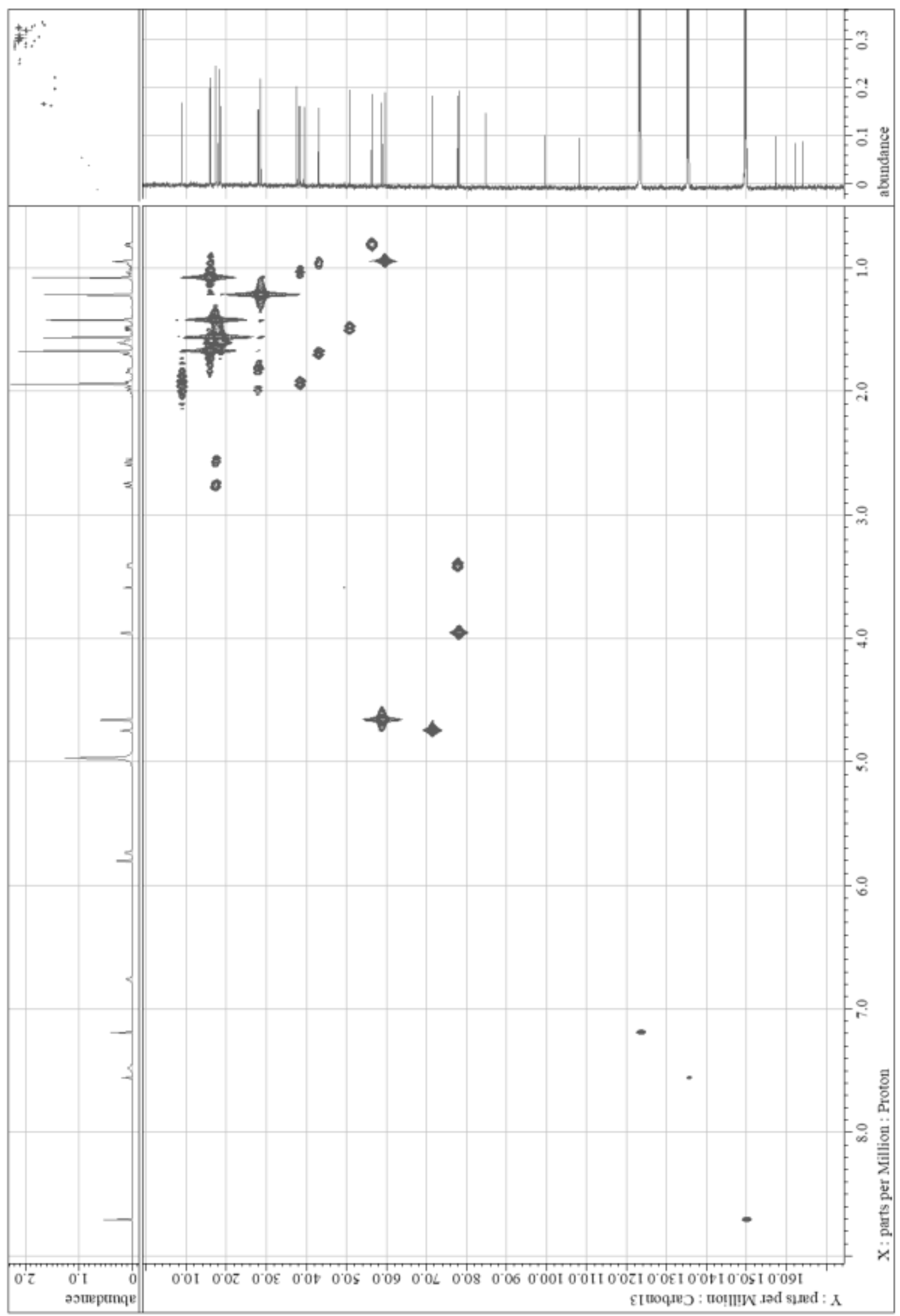


HMBC spectrum (pyridine- $\mathrm{d}_{5}$ ) of shearone E (5)

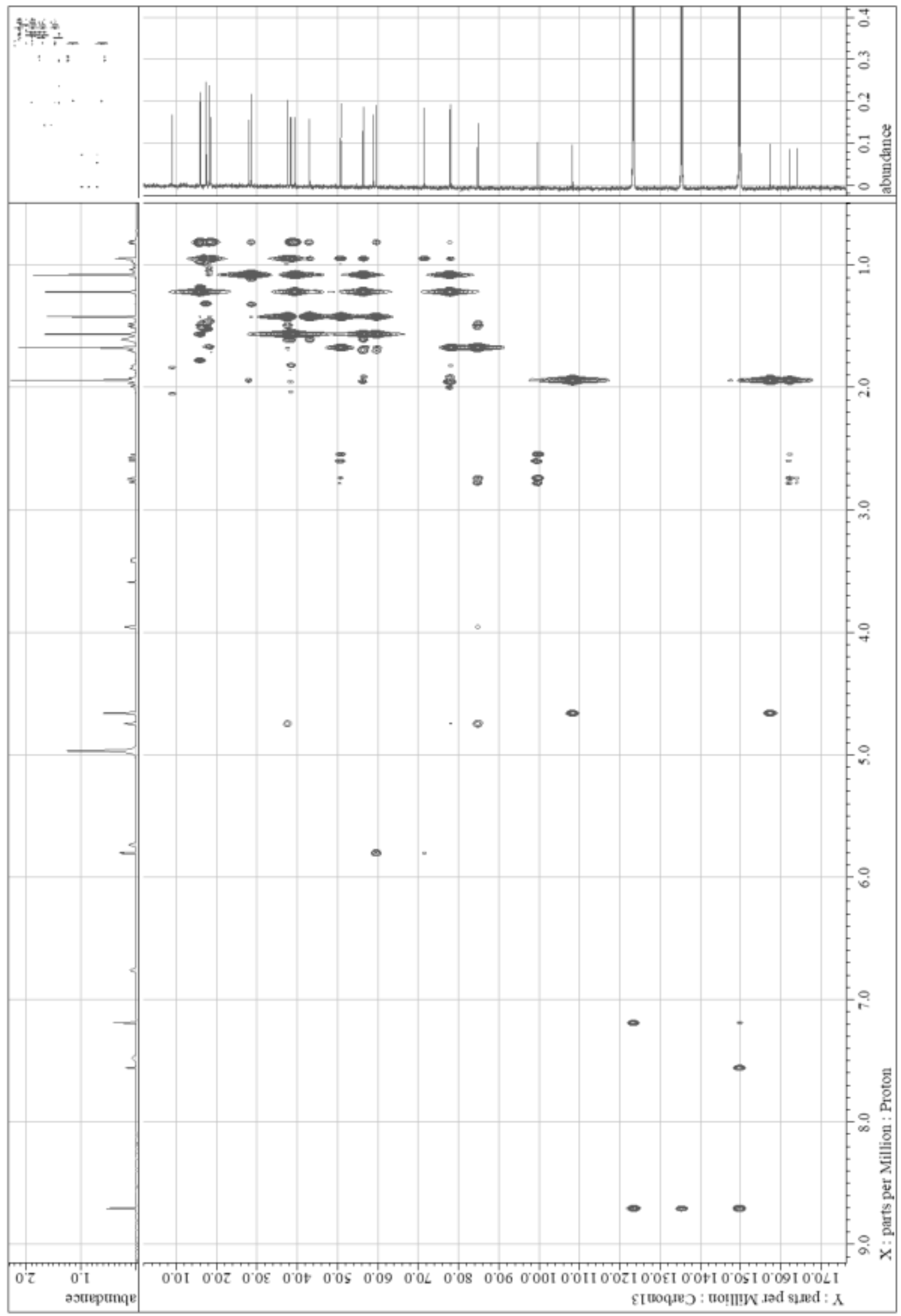


${ }^{1} \mathrm{H}$ NMR spectrum (600 MHz, pyridine- $\mathrm{d}_{5}$ ) of shearone F (6)
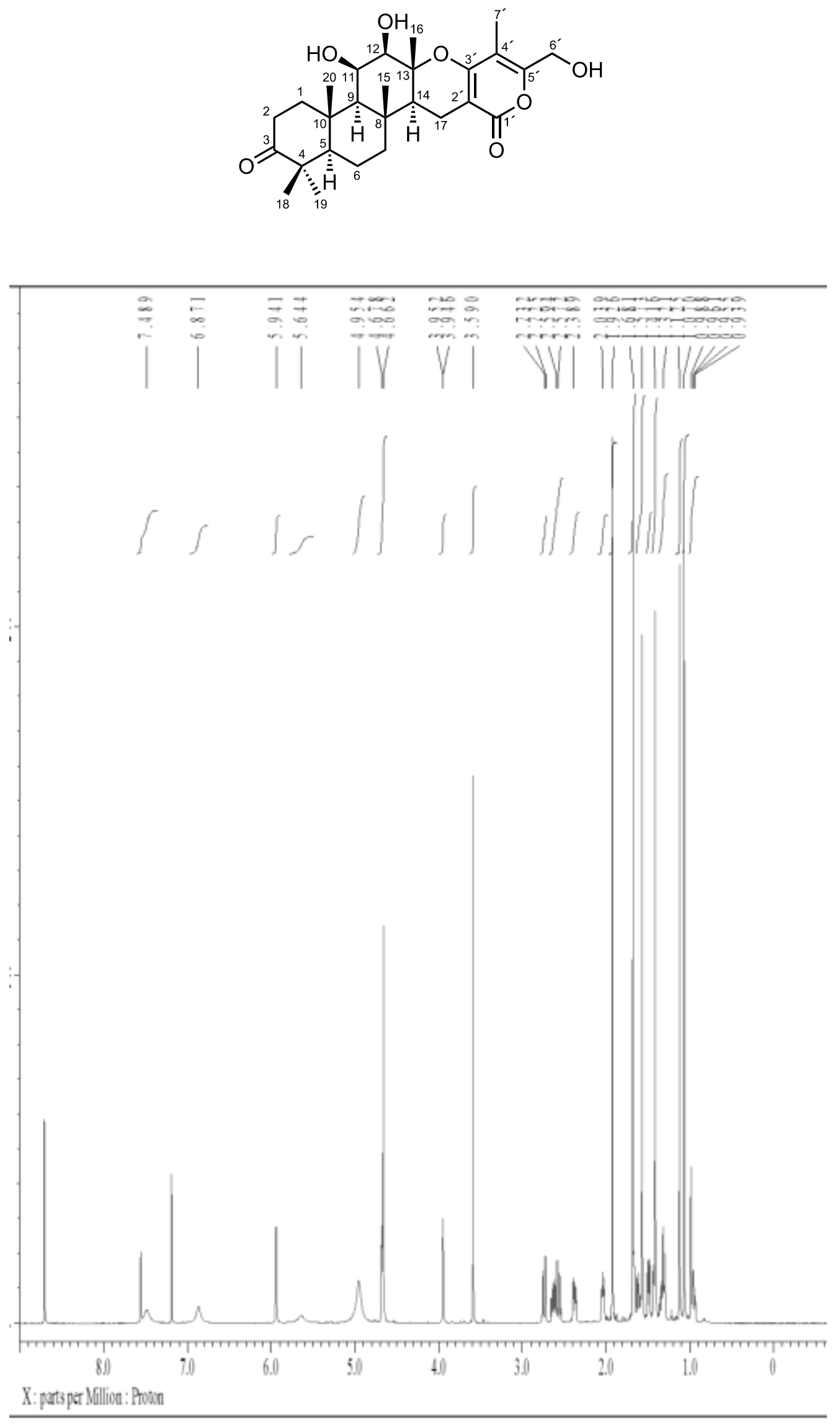
${ }^{13} \mathrm{C}$ NMR spectrum (150 MHz, pyridine- $\mathrm{d}_{5}$ ) of shearone $\mathrm{F}(\mathbf{6})$

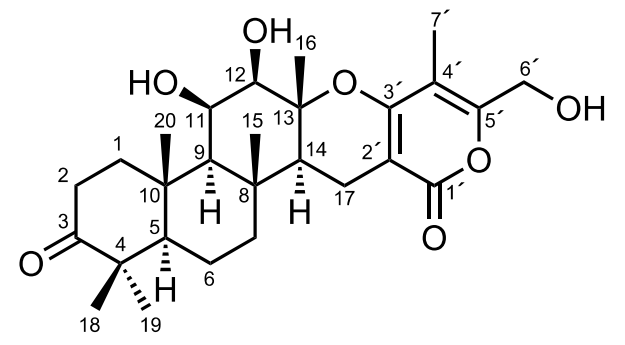

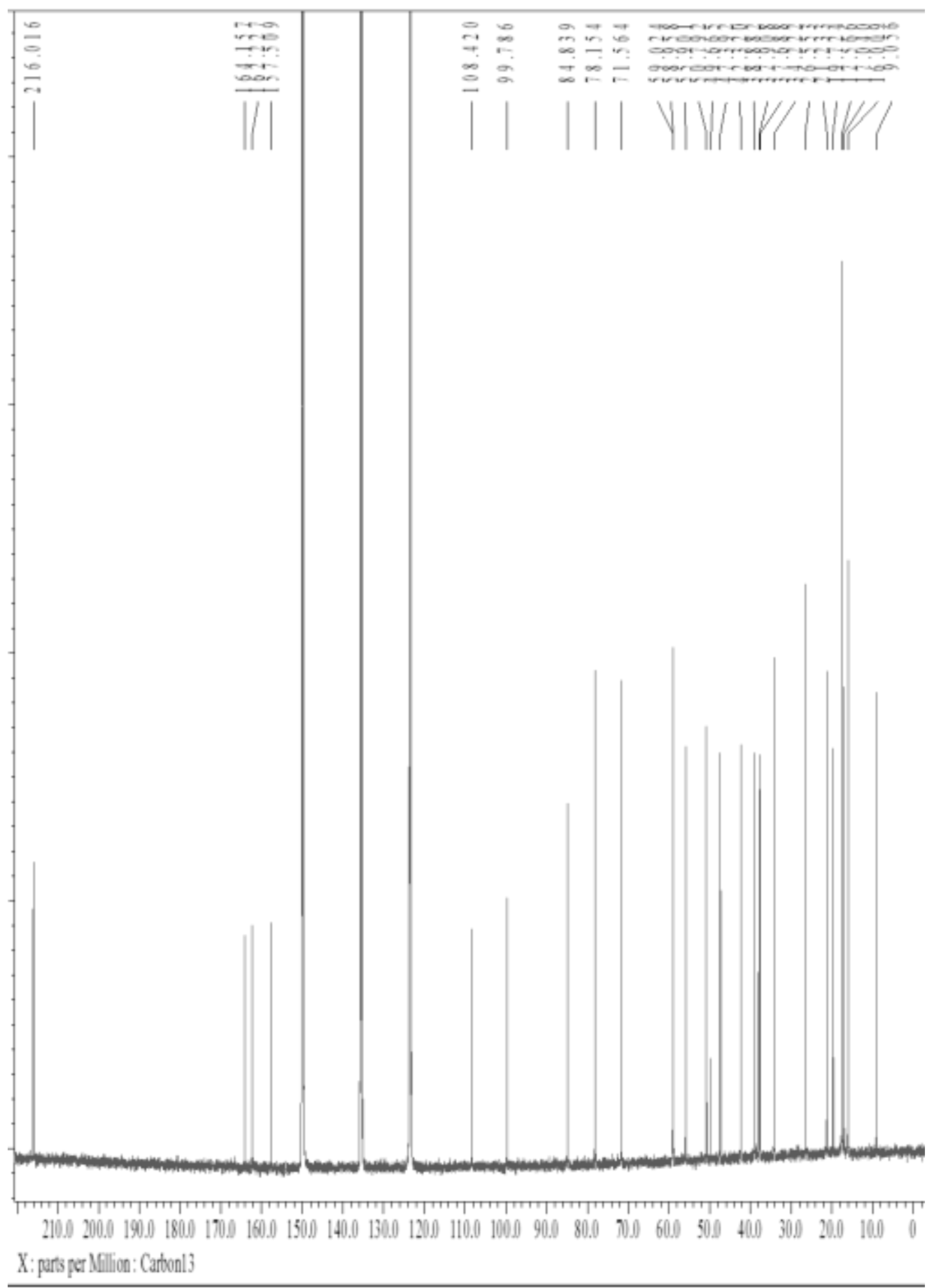


${ }^{1} \mathrm{H}-{ }^{1} \mathrm{H}$ COSY spectrum (pyridine- $\mathrm{d}_{5}$ ) of shearone $\mathrm{F}(\mathbf{6})$

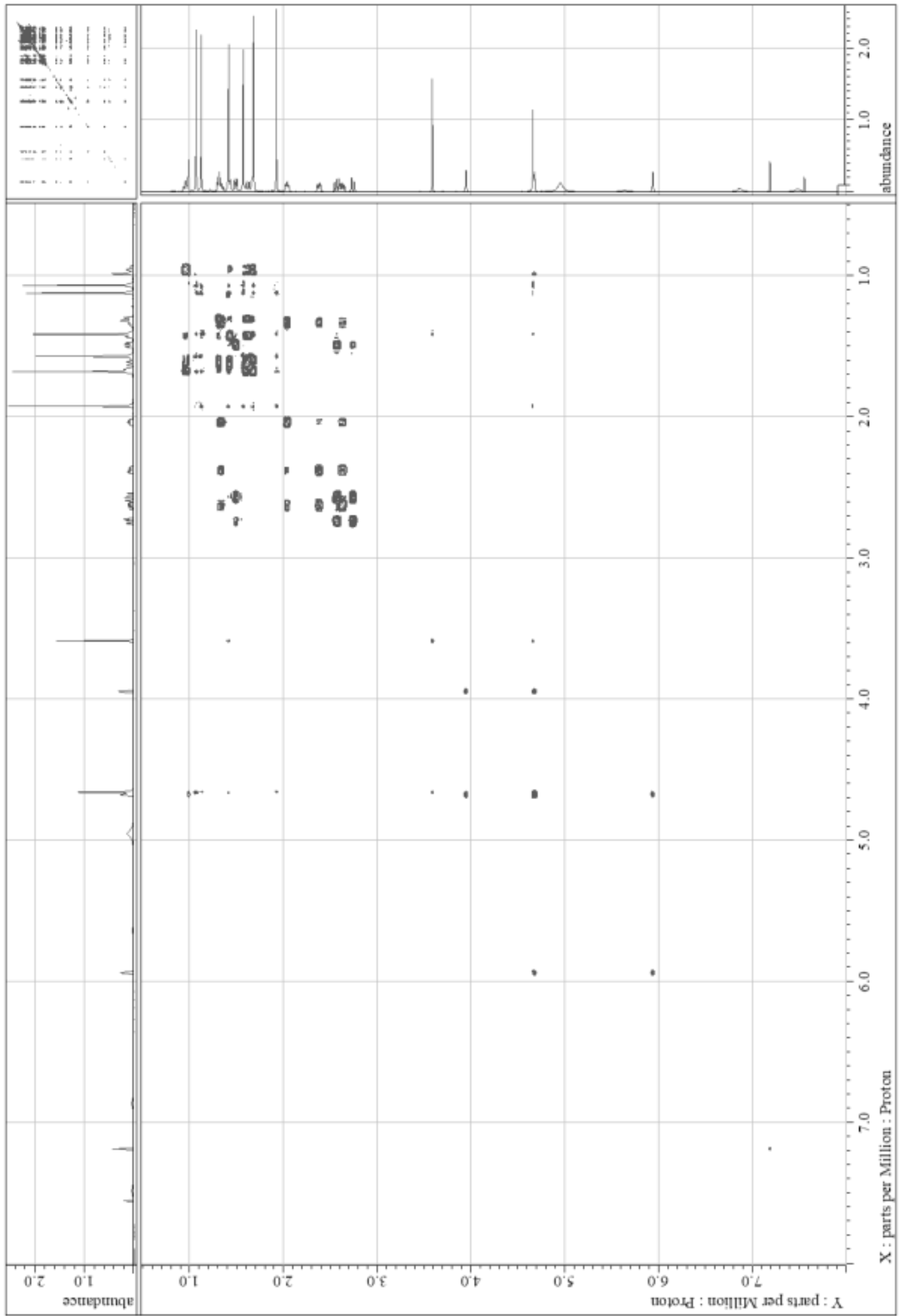


HMQC spectrum (pyridine- $\mathrm{d}_{5}$ ) of shearone $\mathrm{F}(\mathbf{6})$

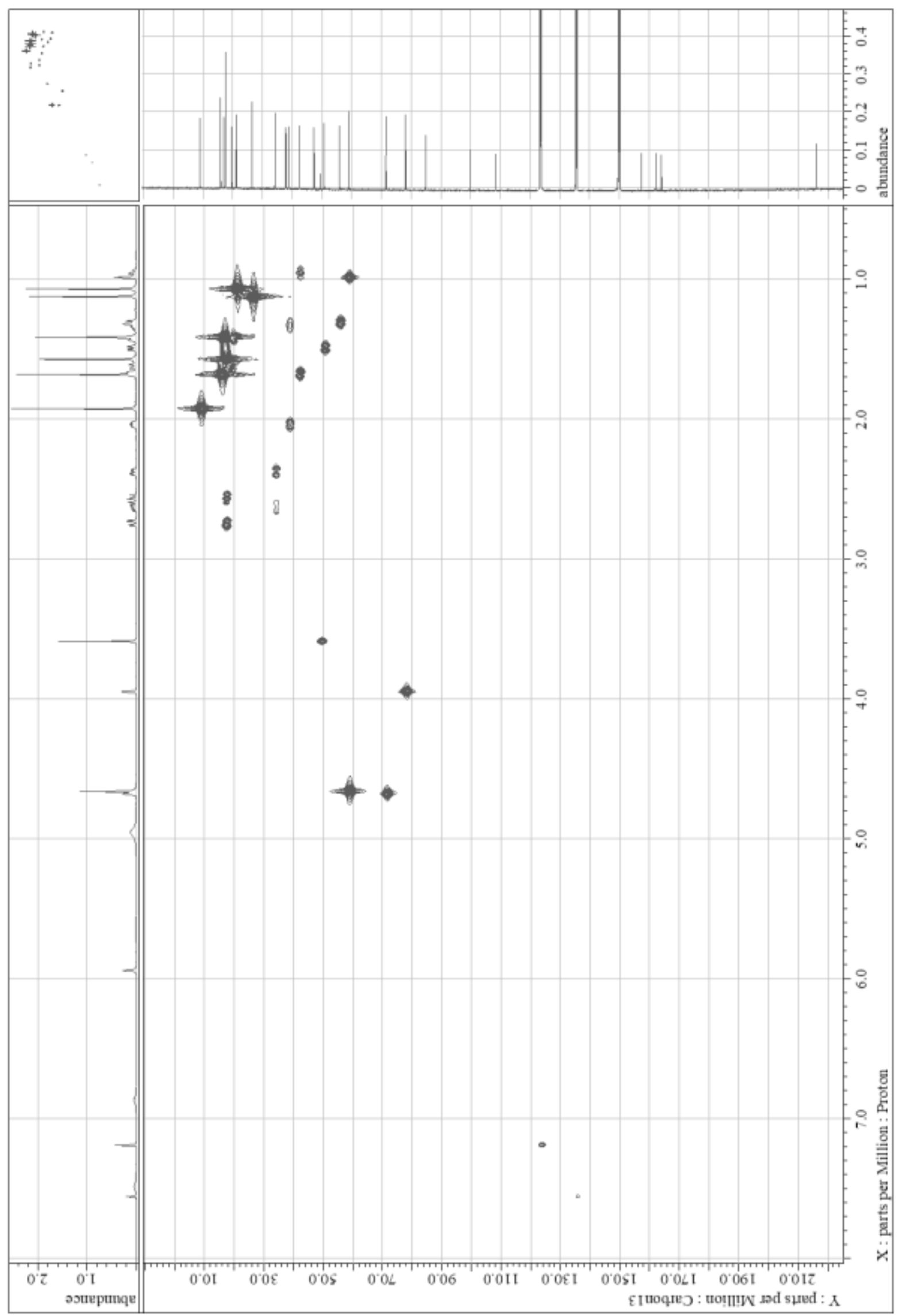


HMBC spectrum (pyridine- $\mathrm{d}_{5}$ ) of shearone $\mathrm{F}(\mathbf{6})$

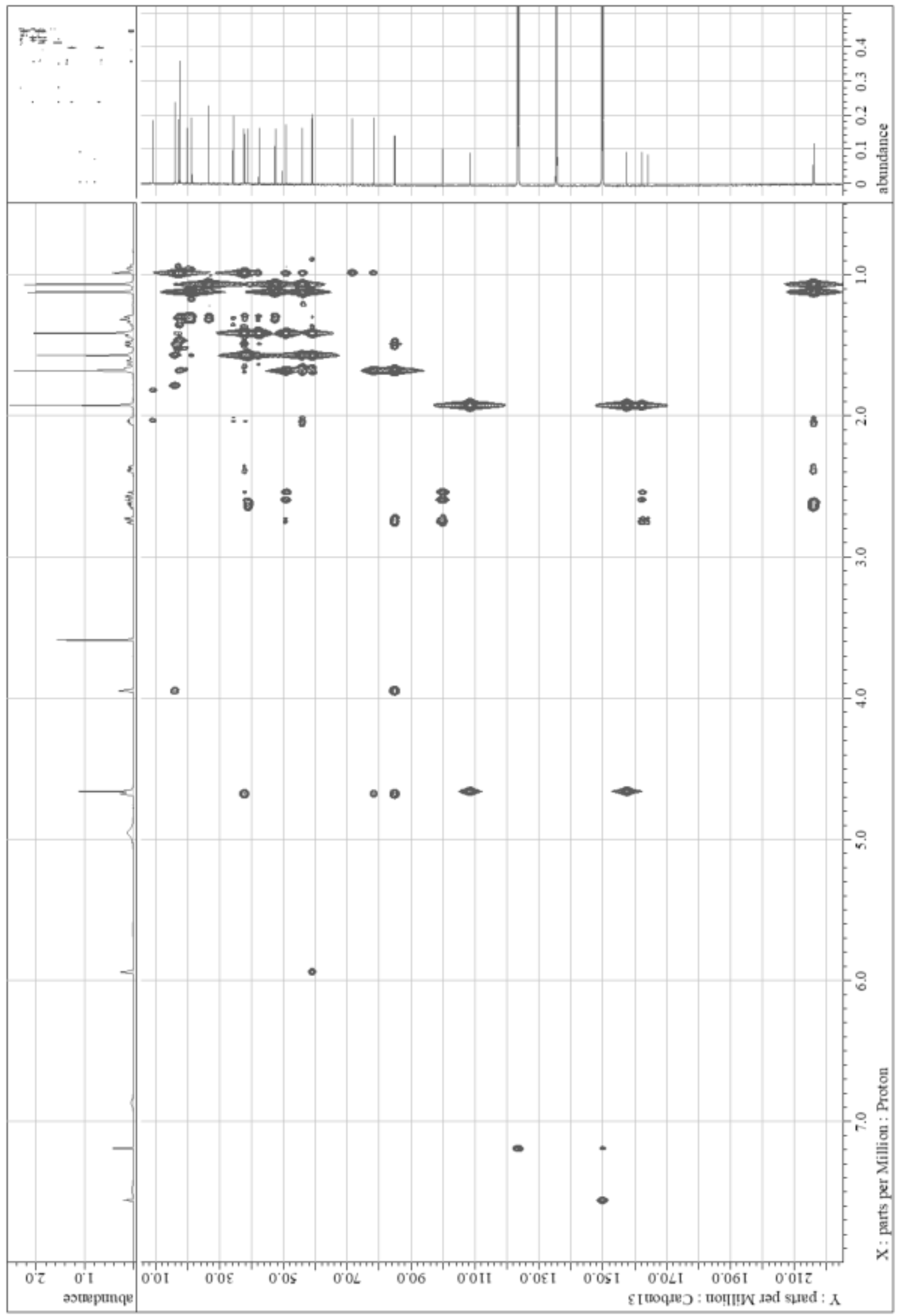


${ }^{1} \mathrm{H}$ NMR spectrum (600 MHz, pyridine- $\mathrm{d}_{5}$ ) of shearone G (7)
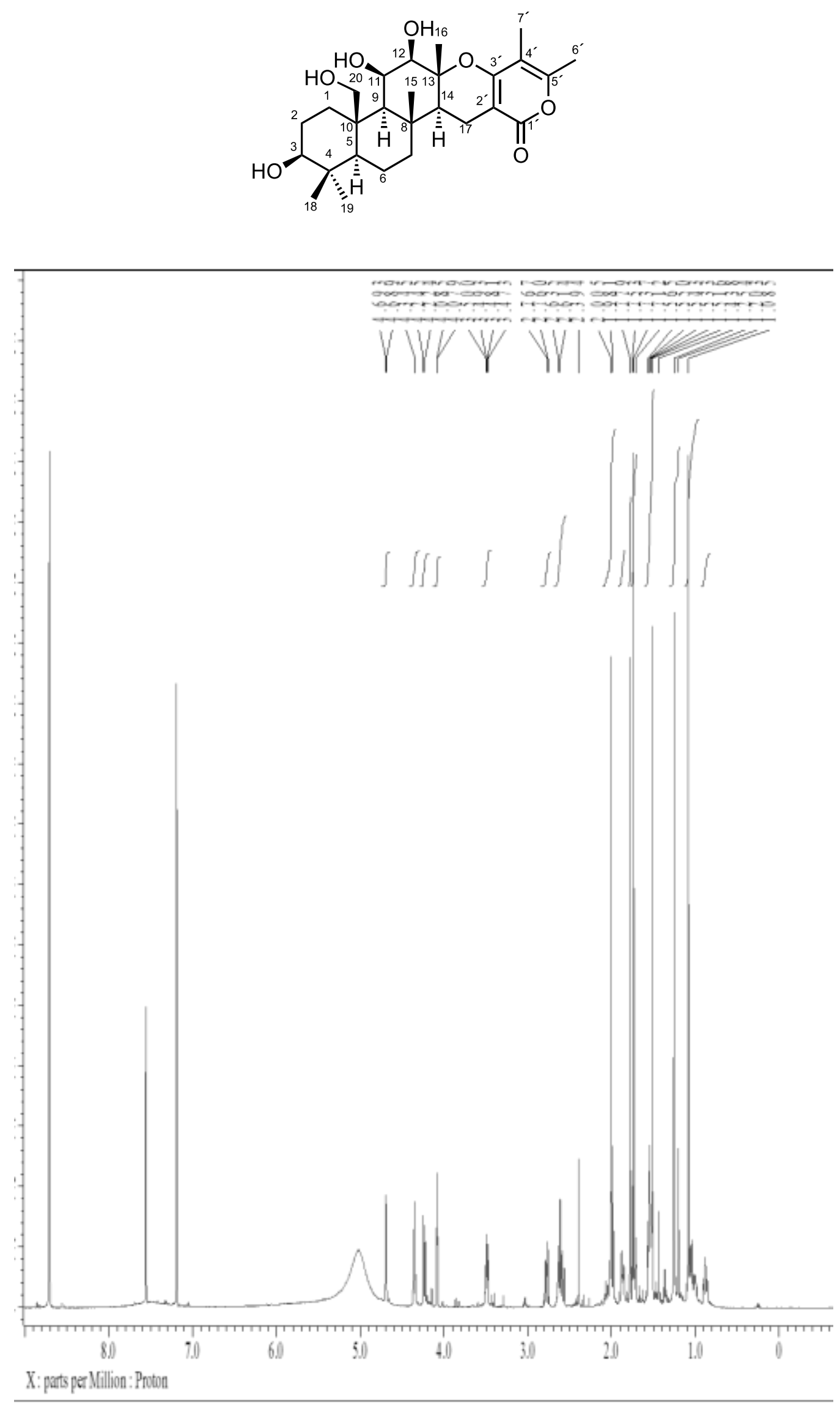
${ }^{13} \mathrm{C}$ NMR spectrum (150 MHz, pyridine- $\mathrm{d}_{5}$ ) of shearone G (7)
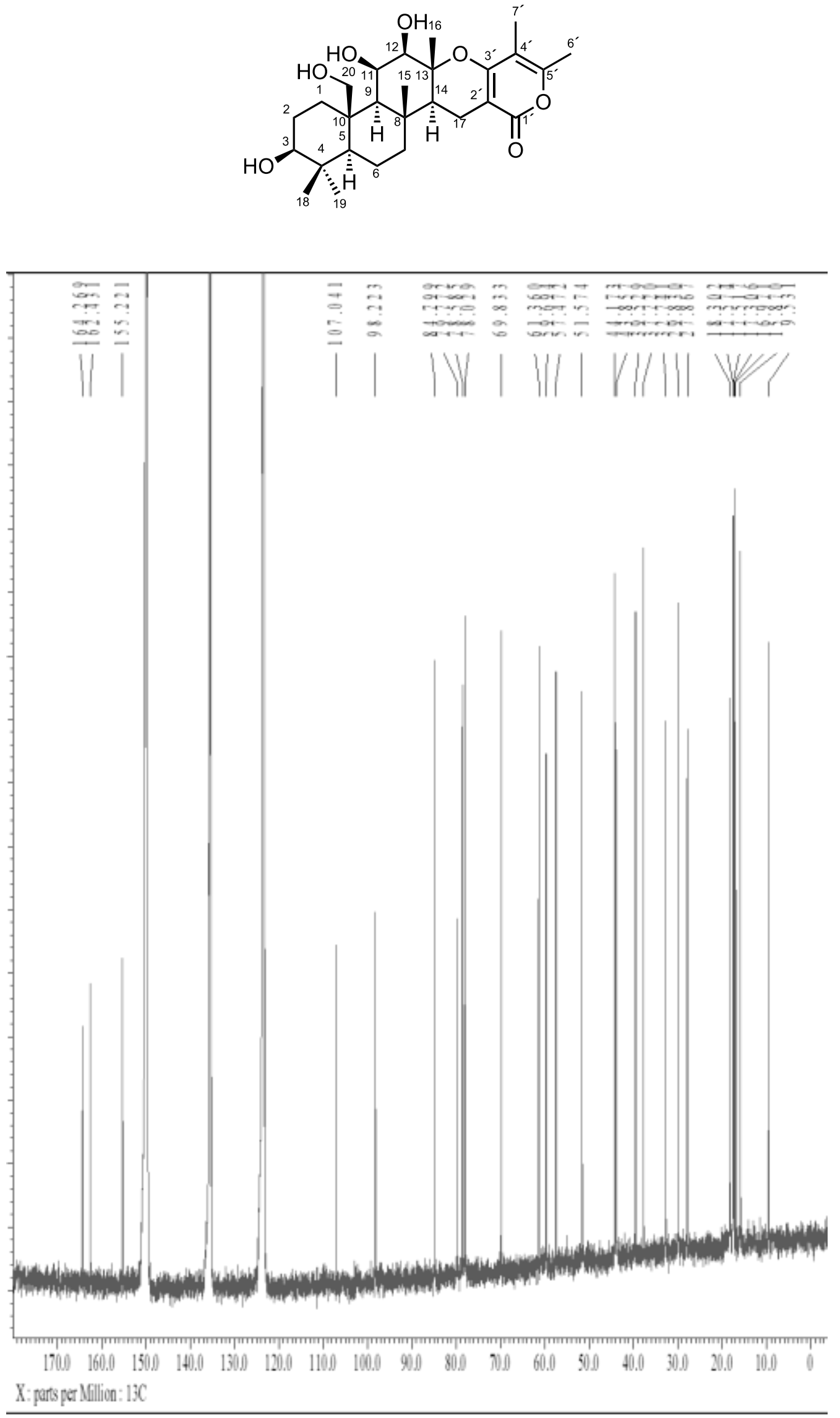
${ }^{1} \mathrm{H}-{ }^{1} \mathrm{H}$ COSY spectrum (pyridine- $\mathrm{d}_{5}$ ) of shearone G (7)

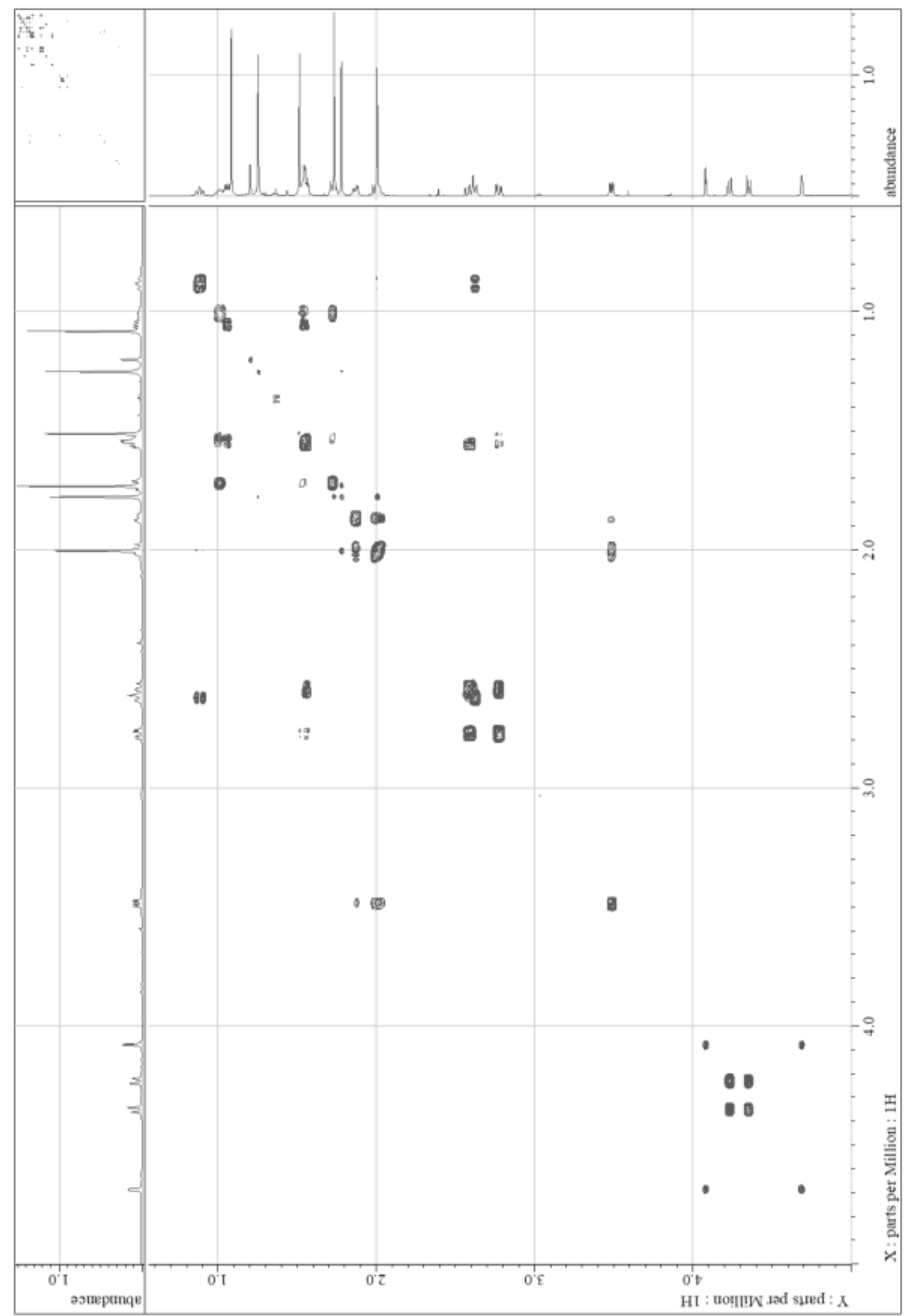


HMQC spectrum (pyridine- $\mathrm{d}_{5}$ ) of shearone G (7)

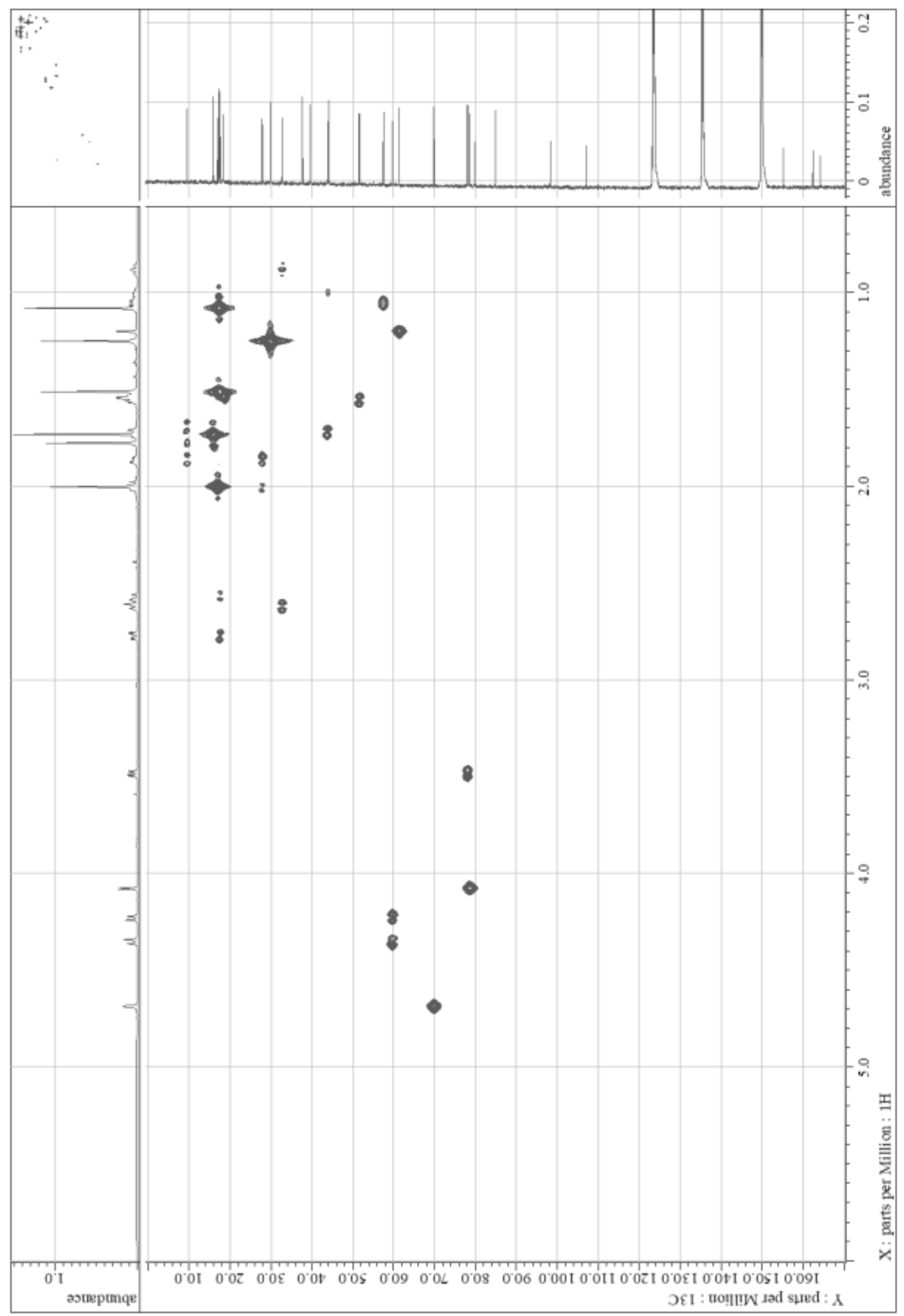


HMBC spectrum (pyridine- $\mathrm{d}_{5}$ ) of shearone $\mathrm{G}(\mathbf{7})$

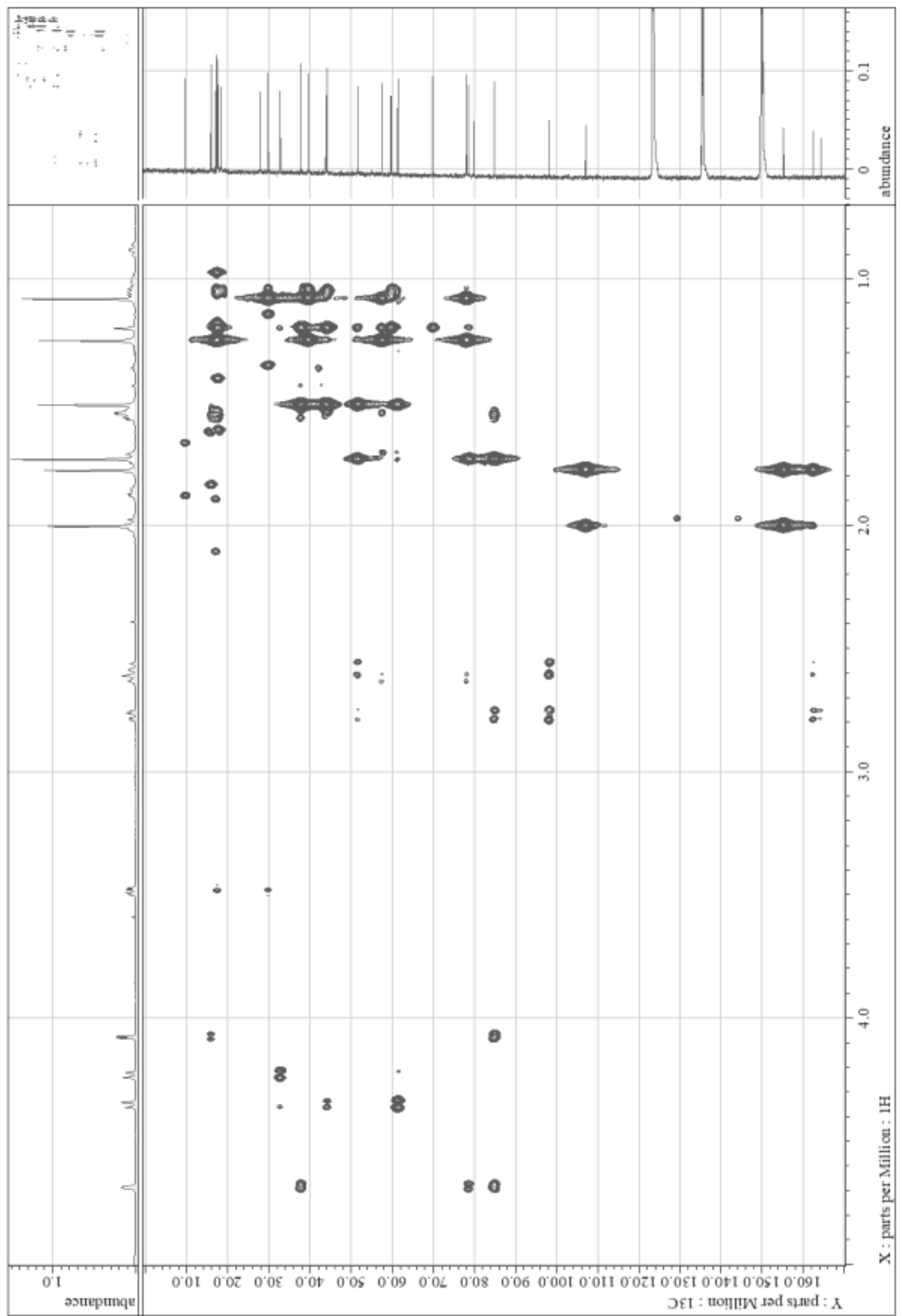


${ }^{1} \mathrm{H}$ NMR spectrum (600 MHz, pyridine- $\mathrm{d}_{5}$ ) of shearone $\mathrm{H}(\mathbf{8})$
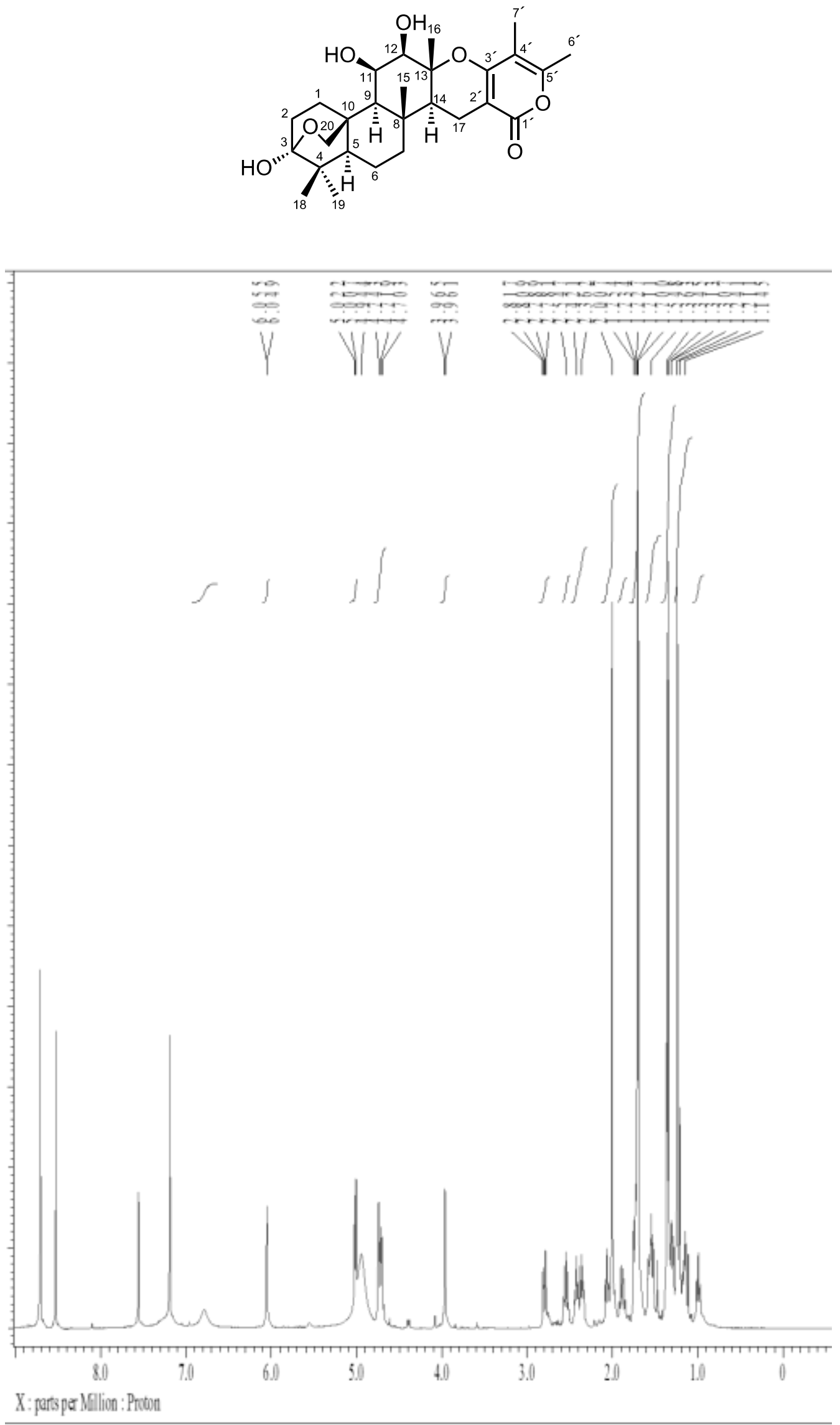
${ }^{13} \mathrm{C}$ NMR spectrum (150 MHz, pyridine- $\left.\mathrm{d}_{5}\right)$ of shearone $\mathrm{H}(\mathbf{8})$
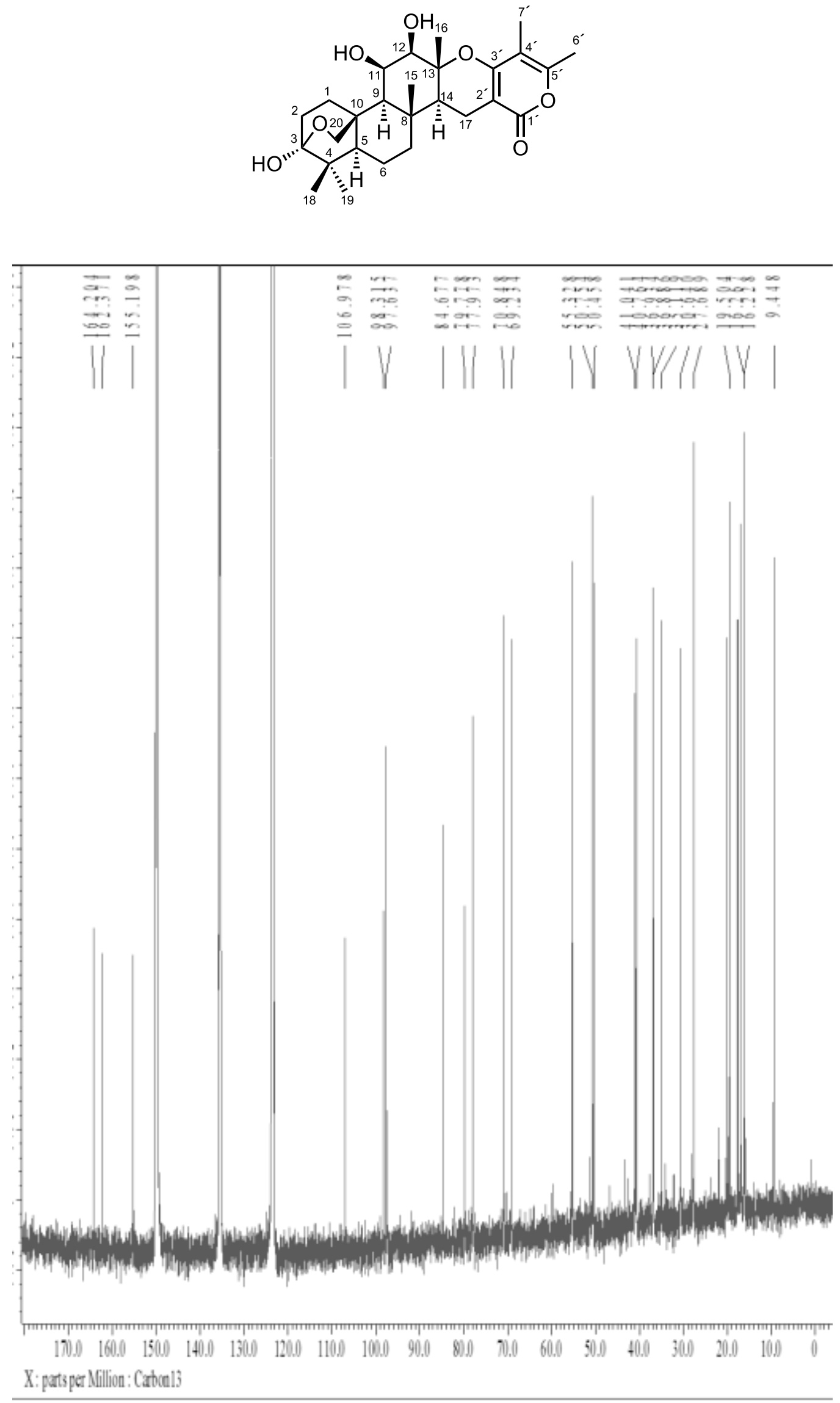
${ }^{1} \mathrm{H}-{ }^{1} \mathrm{H}$ COSY spectrum (pyridine- $\mathrm{d}_{5}$ ) of shearone $\mathrm{H}(\mathbf{8})$

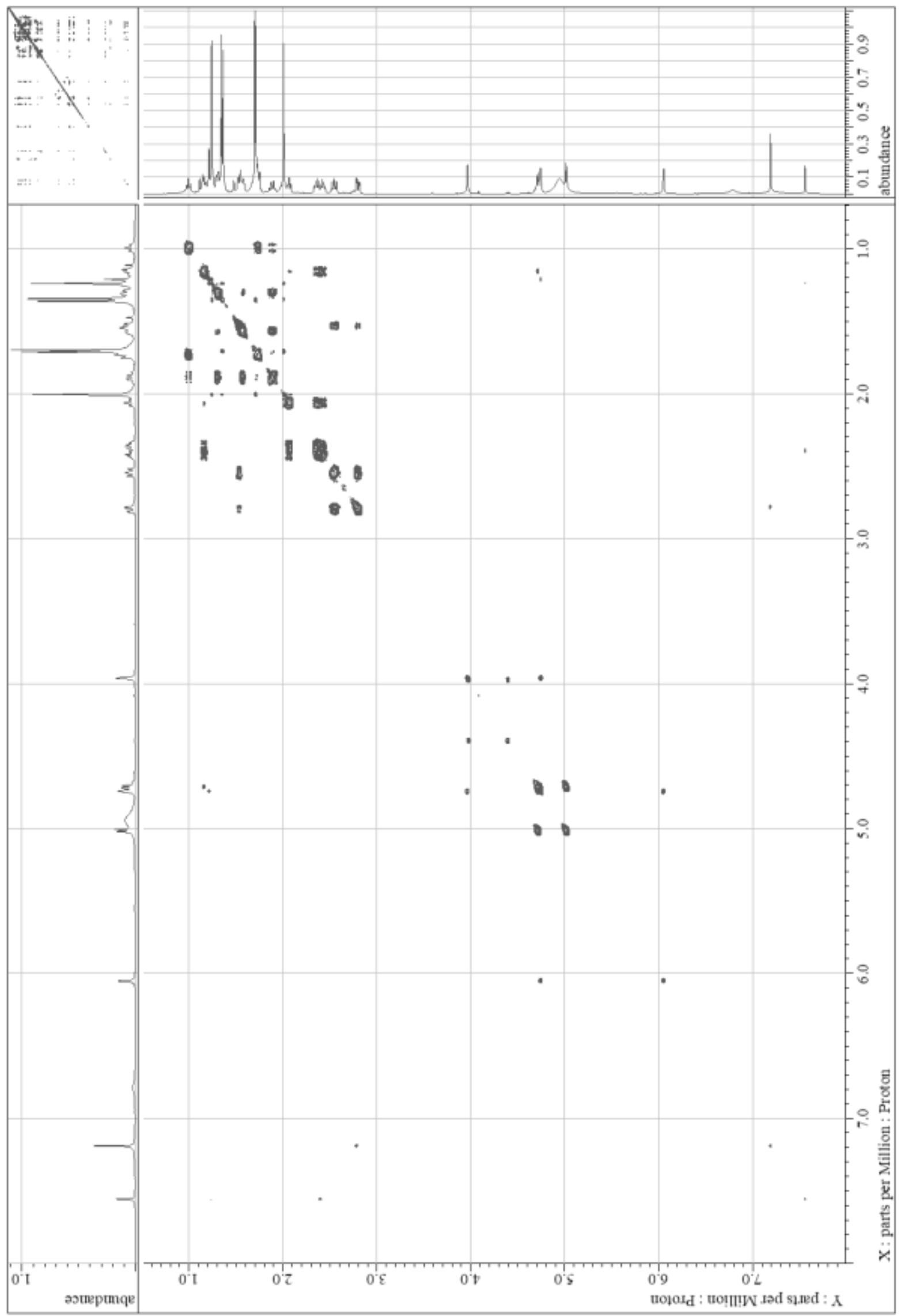


HMQC spectrum (pyridine- $\mathrm{d}_{5}$ ) of shearone H (8)

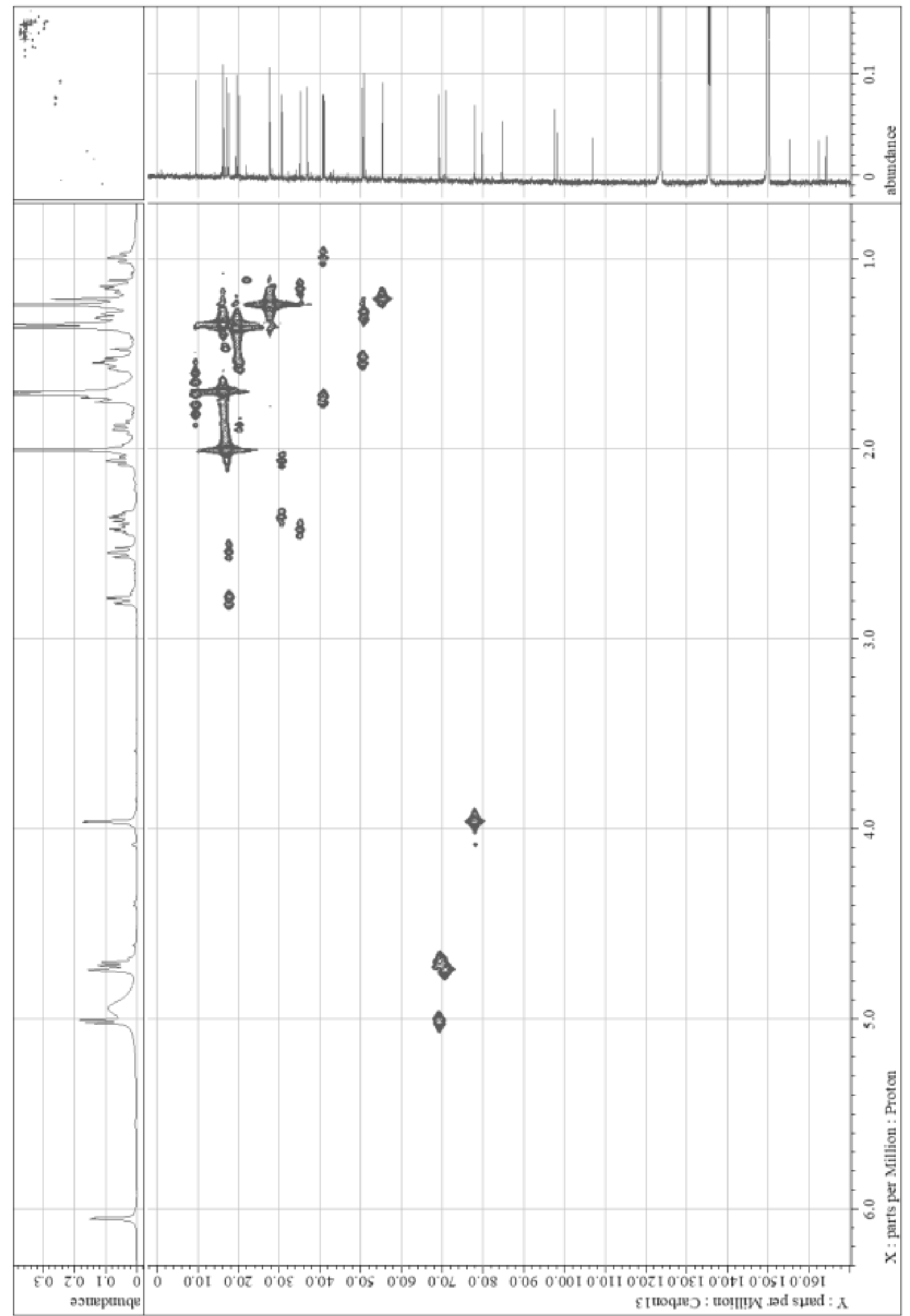


HMBC spectrum (pyridine- $\mathrm{d}_{5}$ ) of shearone $\mathrm{H}(\mathbf{8})$

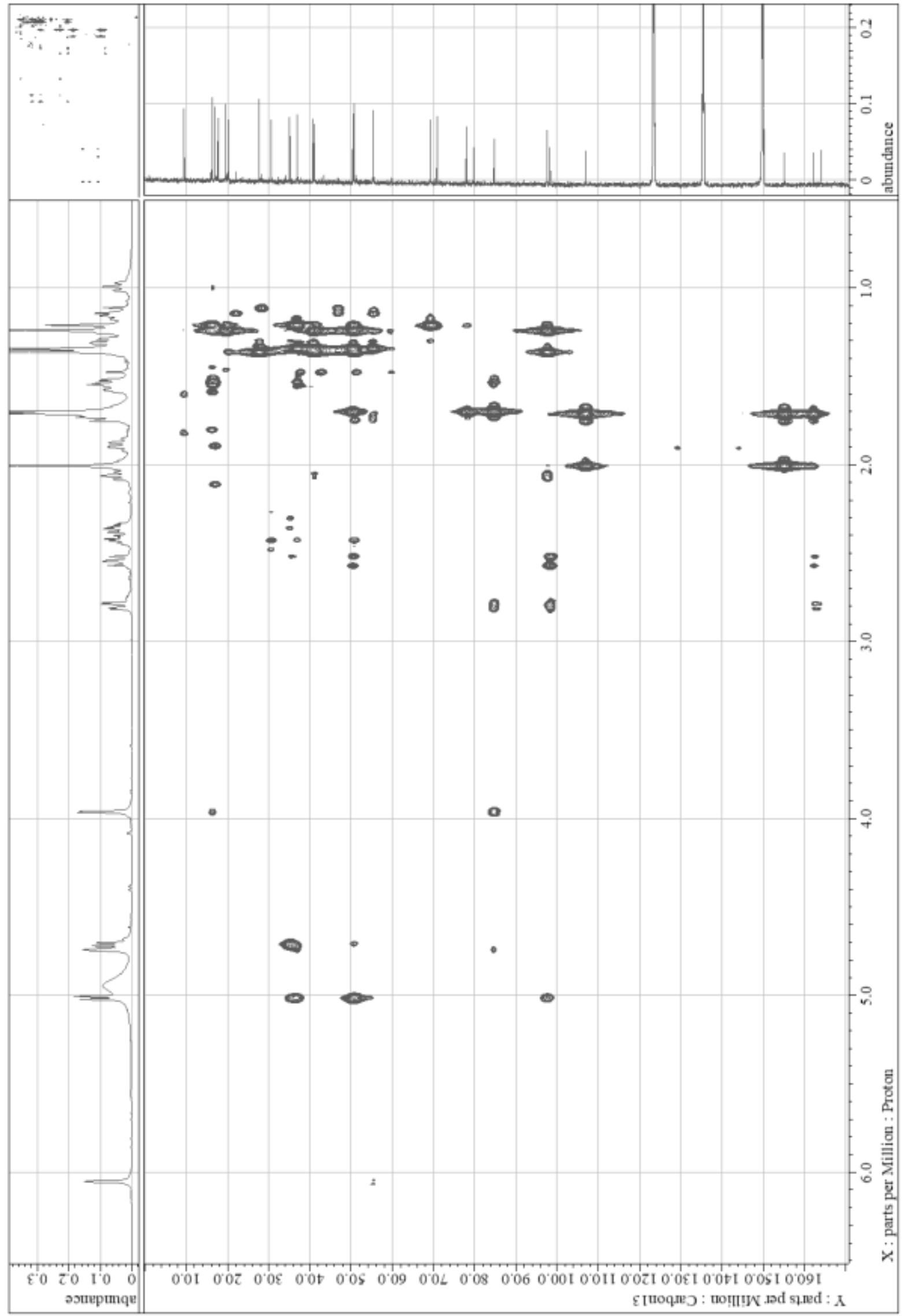


${ }^{1} \mathrm{H}$ NMR spectrum (600 MHz, pyridine- $\mathrm{d}_{5}$ ) of shearone I (9)
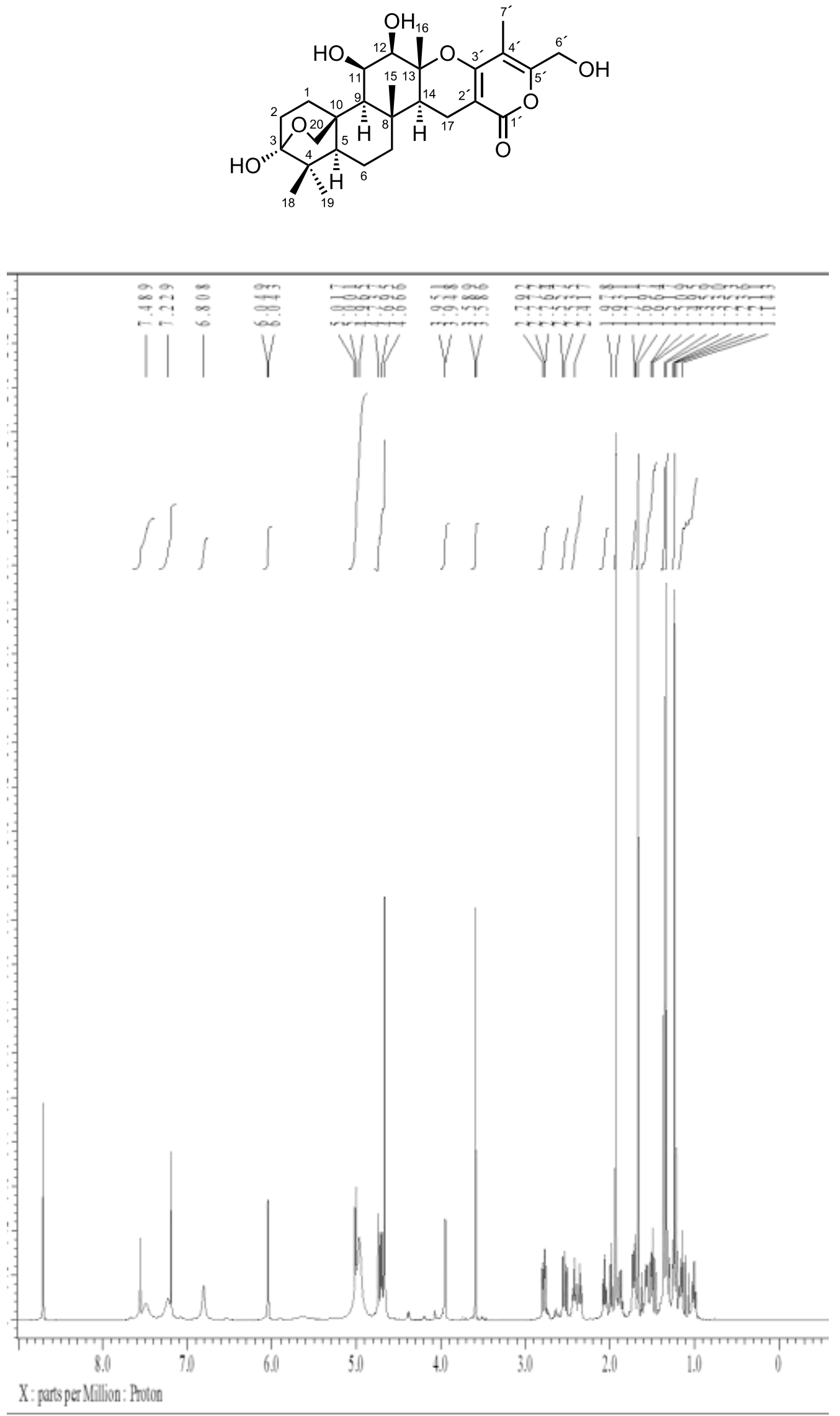
${ }^{13} \mathrm{C}$ NMR spectrum (150 MHz, pyridine- $\mathrm{d}_{5}$ ) of shearone I (9)

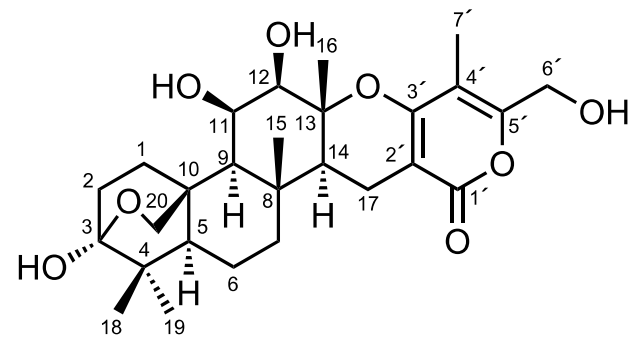

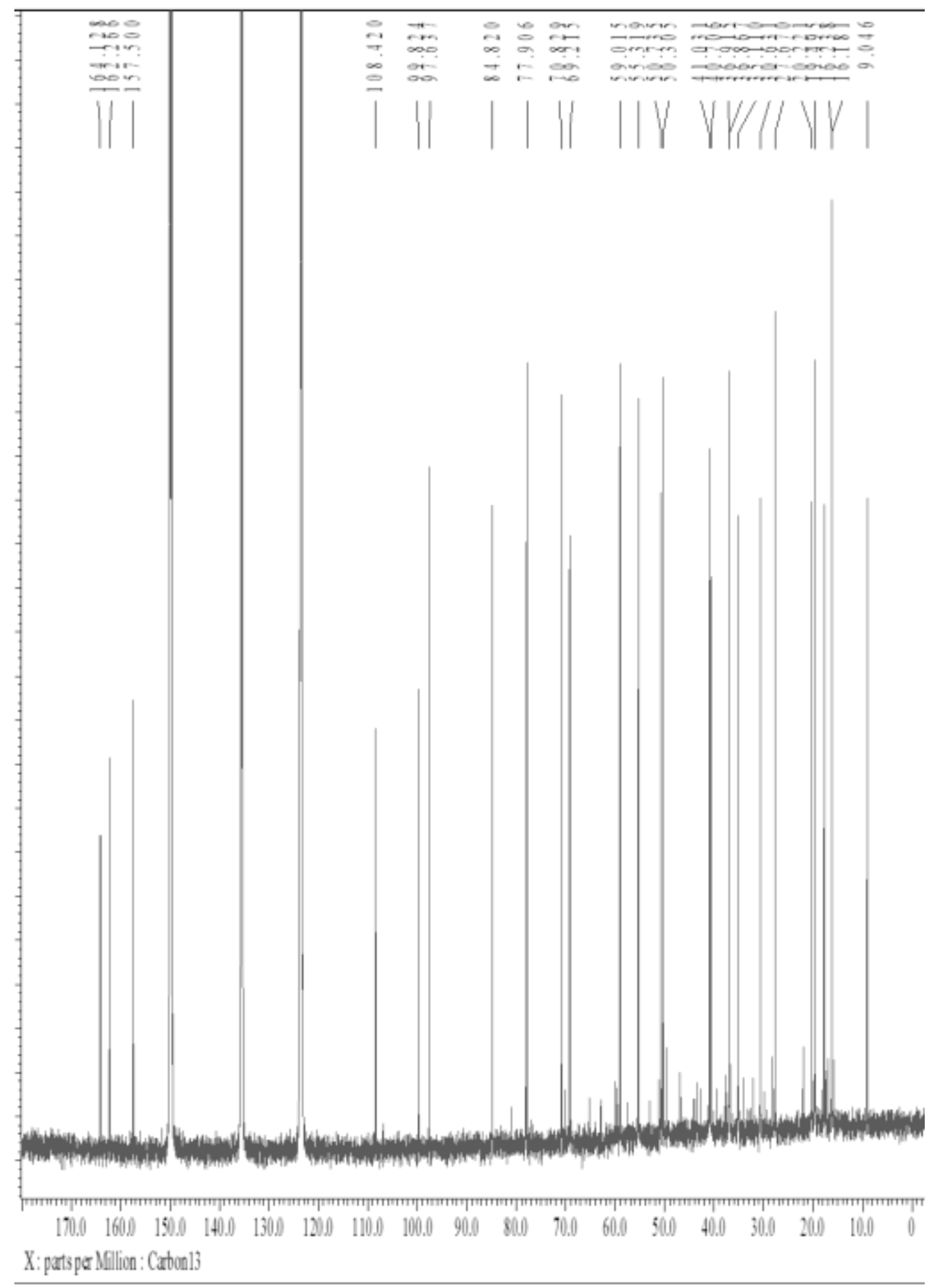


${ }^{1} \mathrm{H}-{ }^{1} \mathrm{H}$ COSY spectrum (pyridine- $\mathrm{d}_{5}$ ) of shearone I (9)

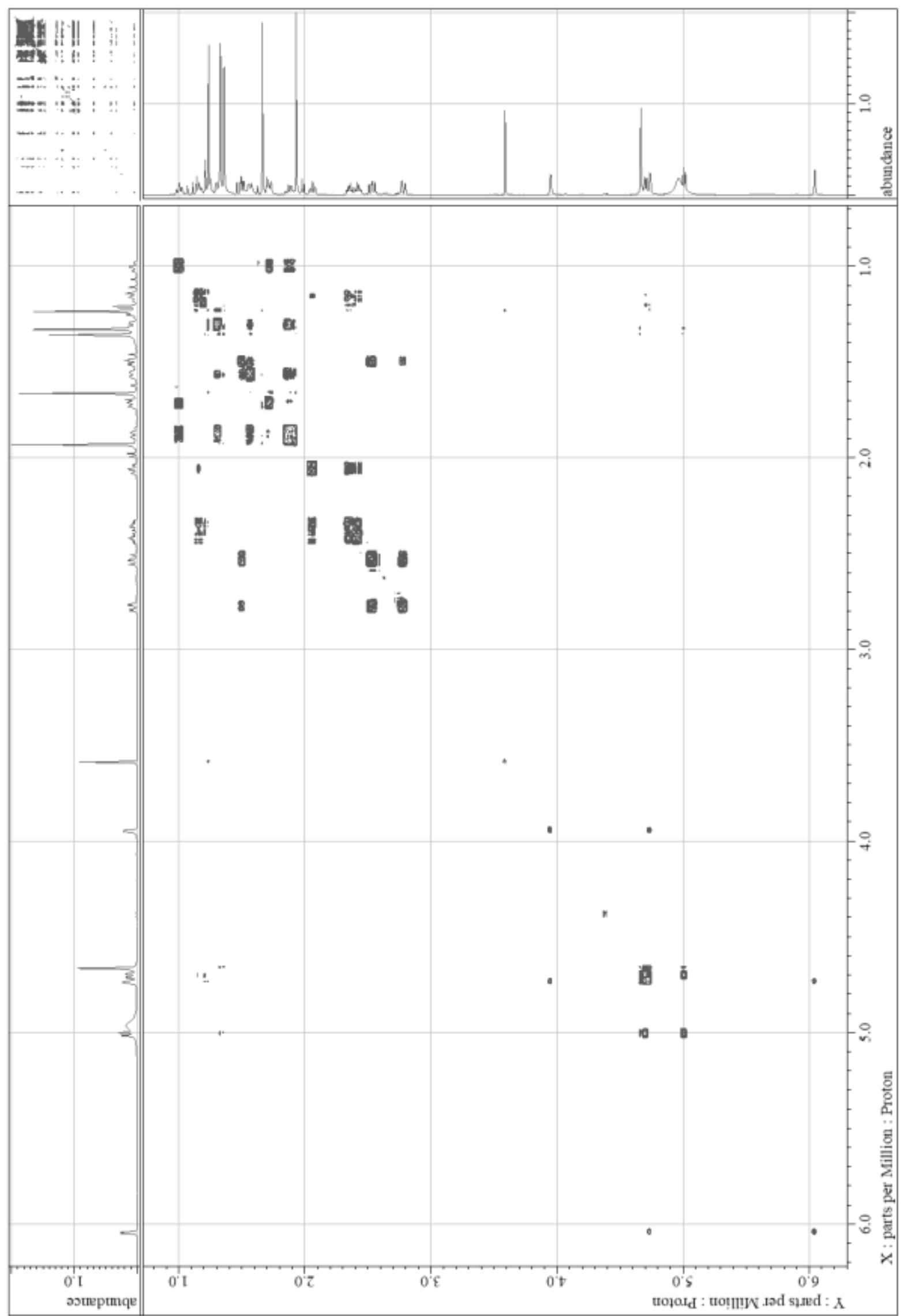


HMQC spectrum (pyridine- $\mathrm{d}_{5}$ ) of shearone I (9)

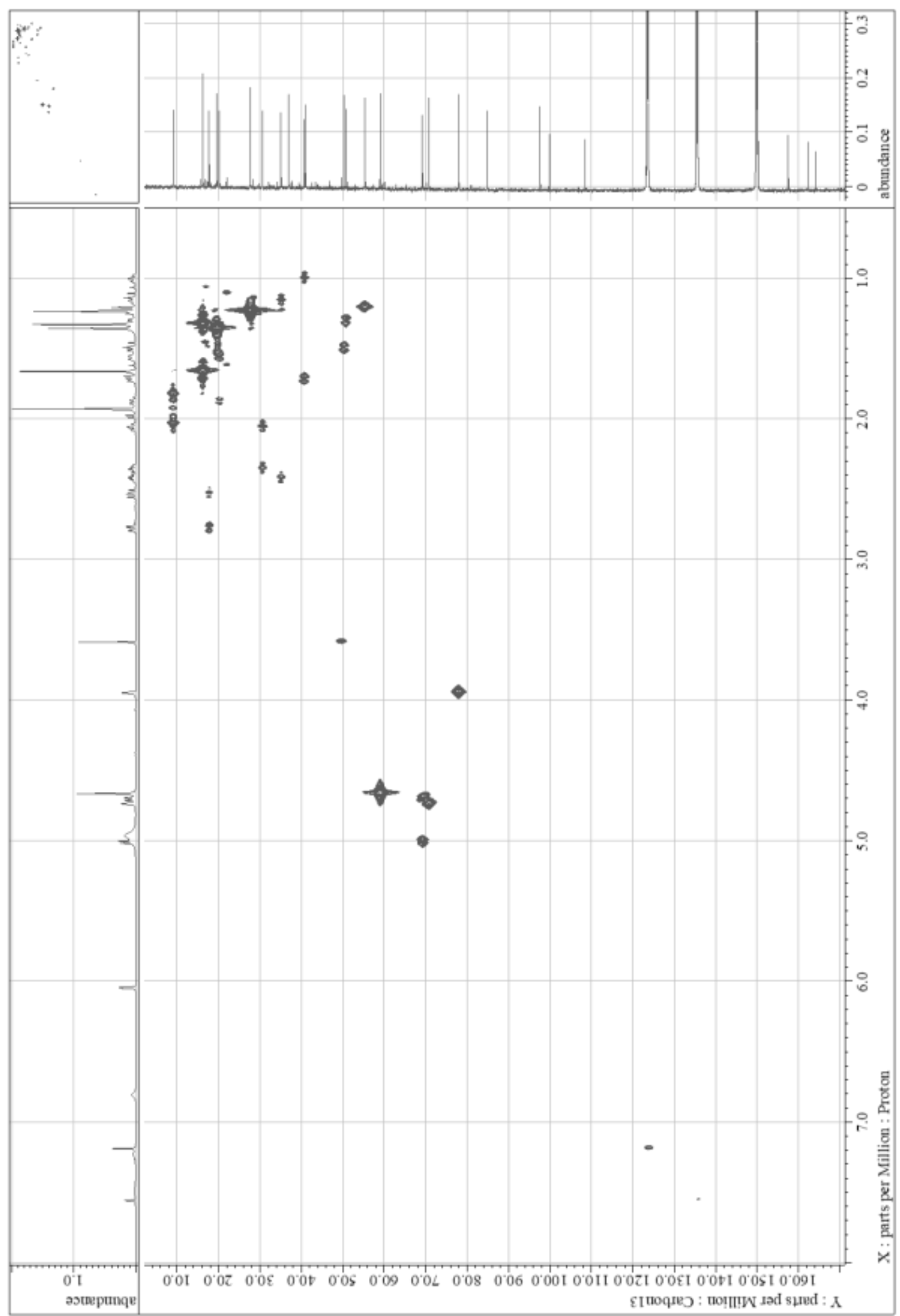


HMBC spectrum (pyridine- $\mathrm{d}_{5}$ ) of shearone I (9)

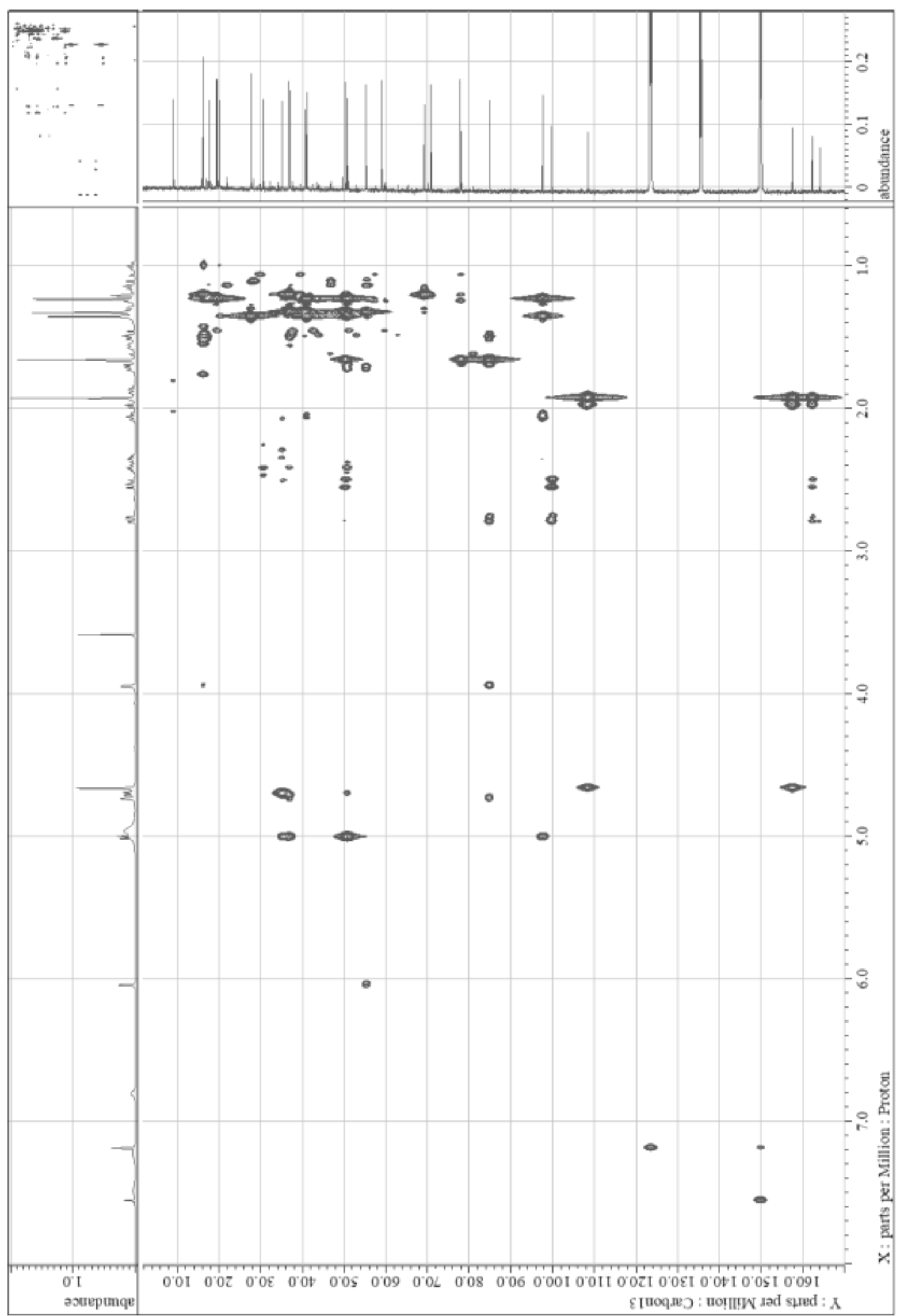




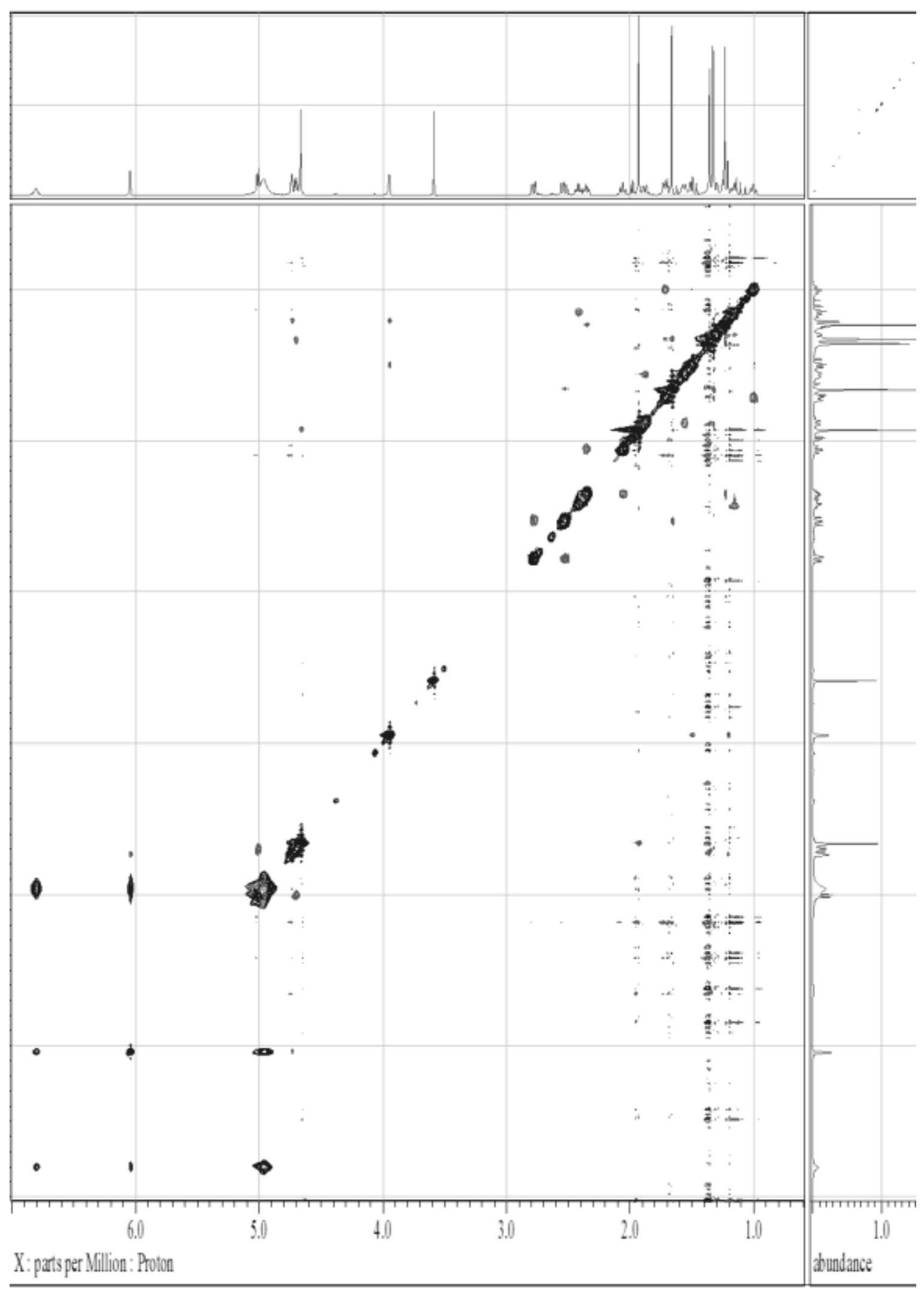


${ }^{1} \mathrm{H}$ NMR spectrum $\left(600 \mathrm{MHz}, \mathrm{CDCl}_{3}\right)$ of compound 1a
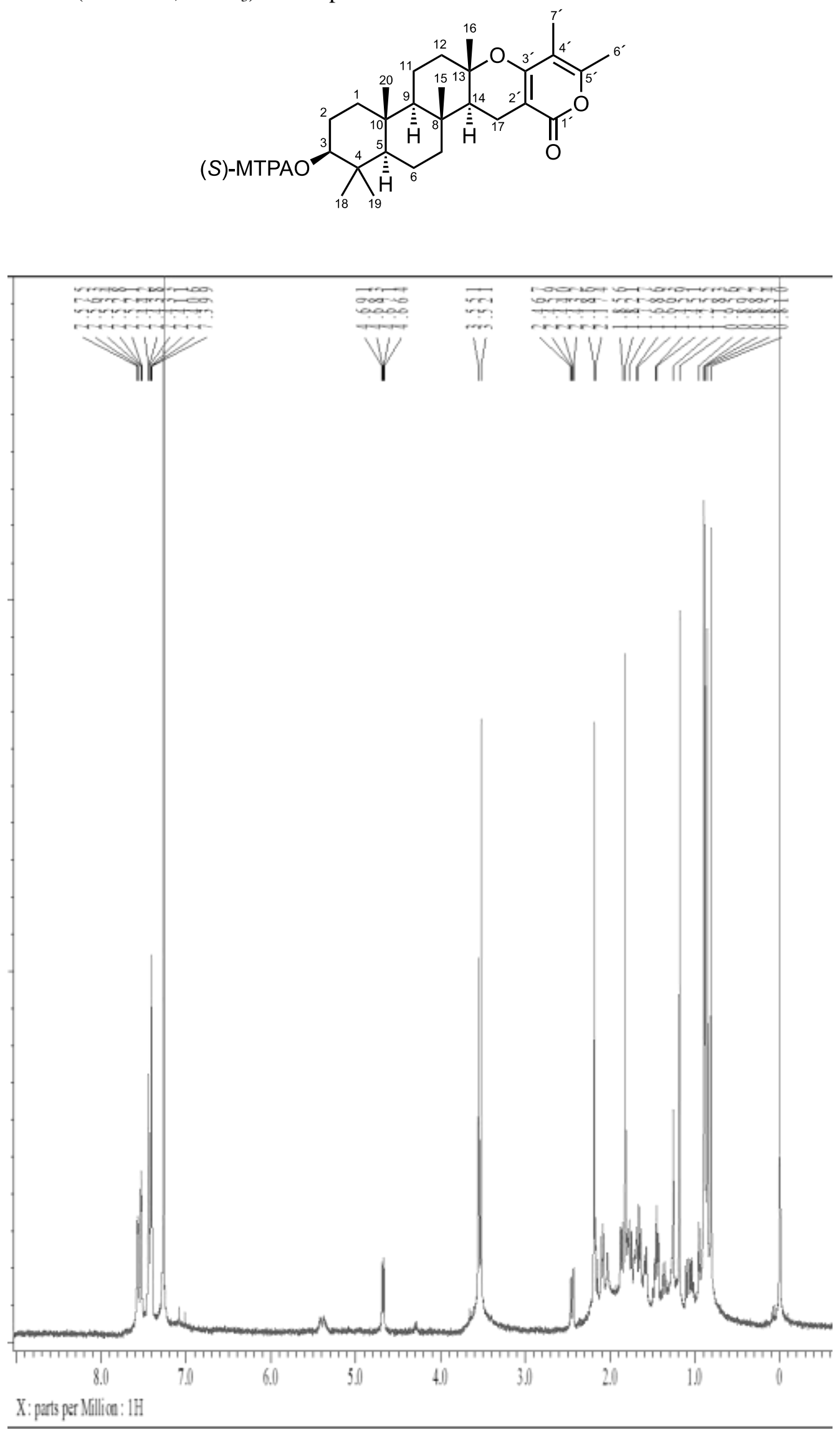
${ }^{1} \mathrm{H}-{ }^{1} \mathrm{H}$ COSY spectrum $\left(\mathrm{CDCl}_{3}\right)$ of compound $\mathbf{1 a}$

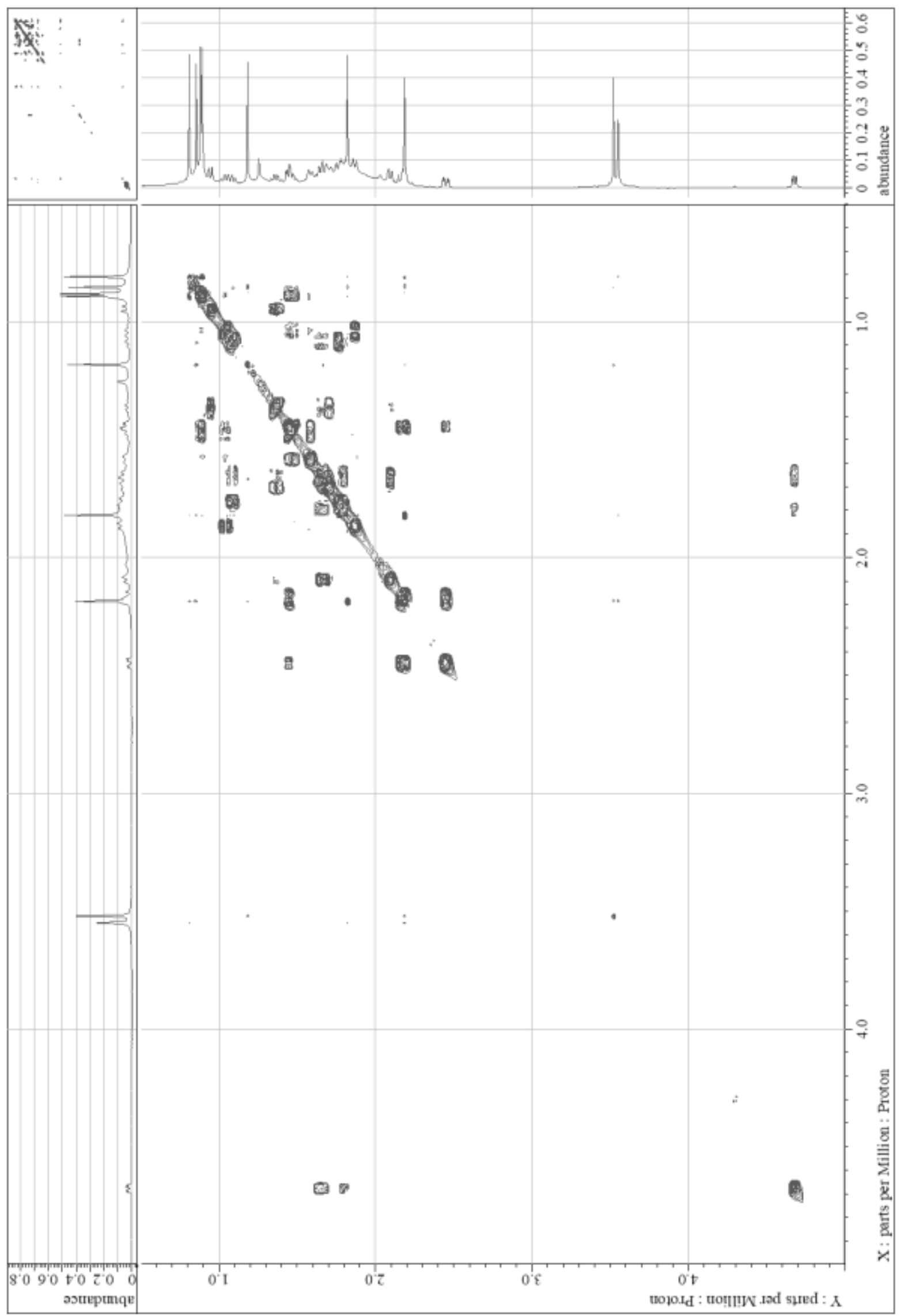


${ }^{1} \mathrm{H}$ NMR spectrum $\left(600 \mathrm{MHz}, \mathrm{CDCl}_{3}\right)$ of compound $\mathbf{1 b}$
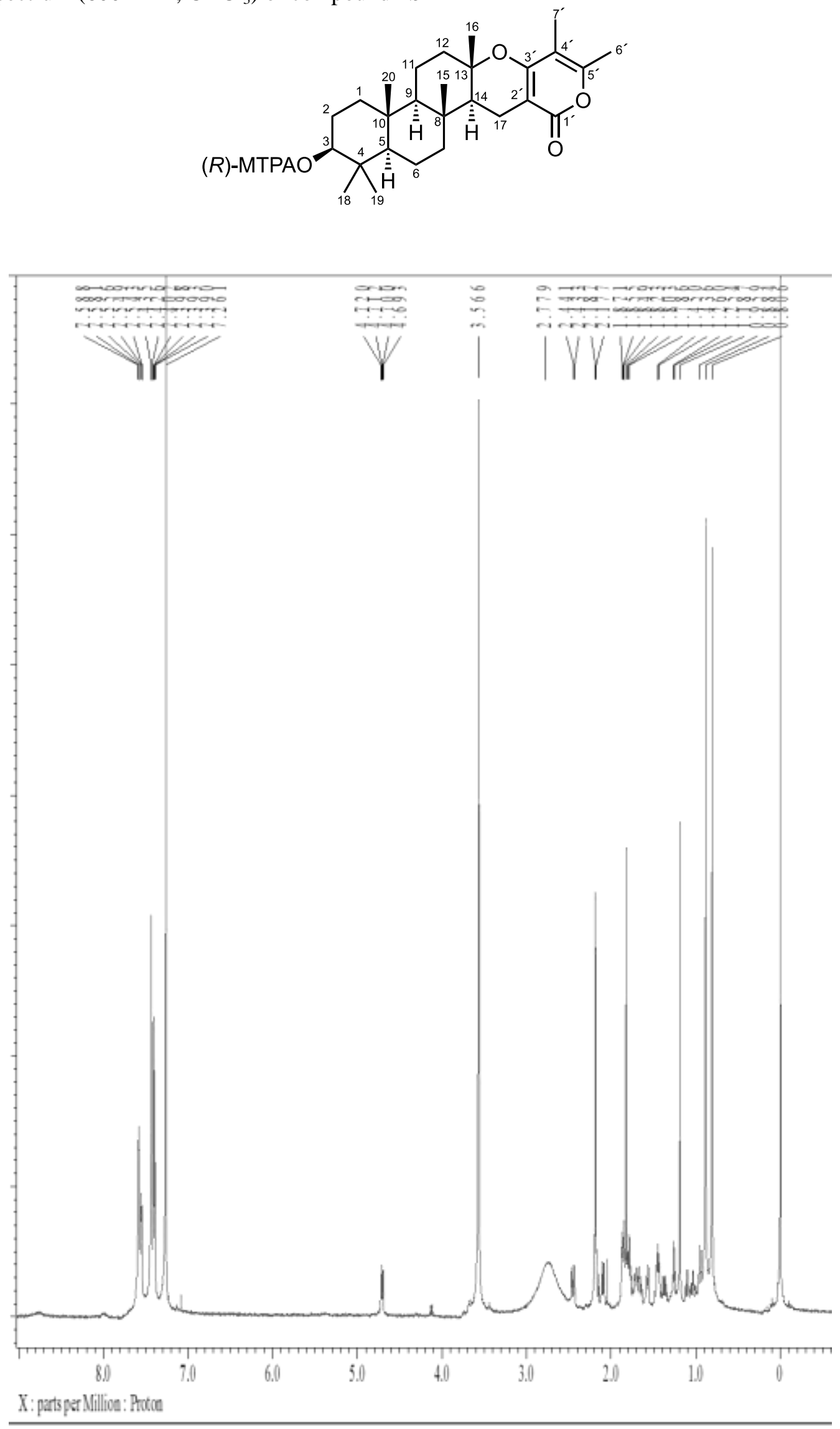
${ }^{1} \mathrm{H}-{ }^{1} \mathrm{H}$ COSY spectrum $\left(\mathrm{CDCl}_{3}\right)$ of compound

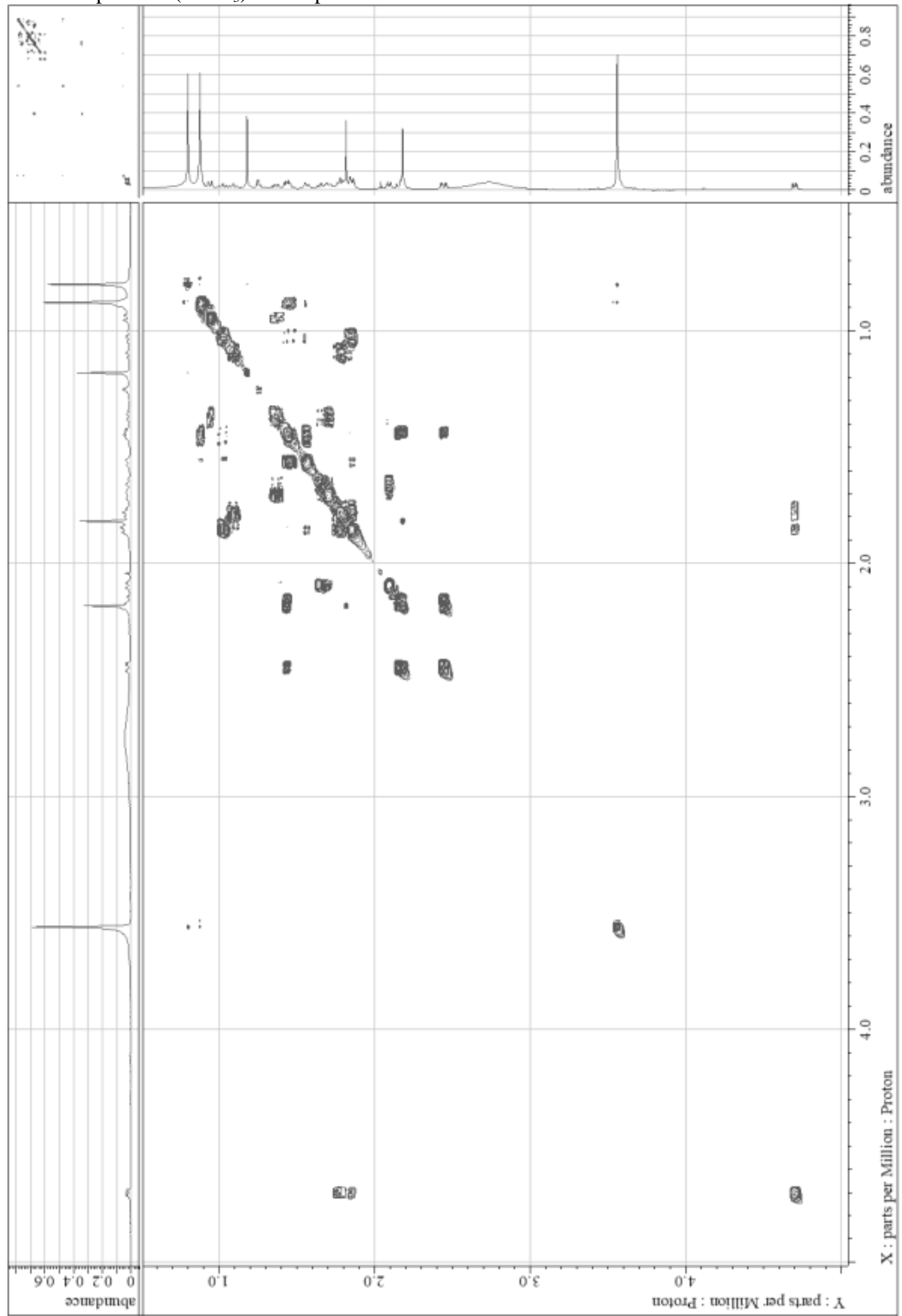

